This is the submitted version of the following article:

Pereyra C., Xie H., Lira-Cantu M.. Additive engineering for stable halide perovskite solar cells. Journal of Energy Chemistry, (2021). 60. : 599 - . 10.1016/j.jechem.2021.01.037,

which has been published in final form at

https://dx.doi.org/10.1016/j.jechem.2021.01.037 (c) https://dx.doi.org/10.1016/j.jechem.2021.01.037. This manuscript version is made available under the CC-BY-NC-ND 4.0 license http://creativecommons. org/licenses/by-nc-nd/4.0/ 
Review

\title{
Additive Engineering for Stable Halide Perovskite Solar Cells
}

\author{
Carlos Pereyra ${ }^{\mathrm{a}}$, Haibing Xie ${ }^{\mathrm{a},{ }^{*}}$ and Mónica Lira-Cantu ${ }^{\mathrm{a}, *}$
}

a Catalan Institute of Nanoscience and Nanotechnology (ICN2), CSIC and the Barcelona Institute of Science and Technology (BIST). Building ICN2, Campus UAB E08193, Bellaterra, Barcelona, Spain.

*Corresponding author.

E-mail address: haibing.xie@icn2.cat (Haibing Xie), monica.lira@icn2.cat (Mónica Lira-Cantu)

\begin{abstract}
Halide perovskite solar cells (PSCs) have already demonstrated power conversion efficiencies above $25 \%$, which makes them one of the most attractive photovoltaic technologies. However, one of the main bottlenecks towards their commercialization is their long-term stability, which should exceed the 20-year mark. Additive engineering is an effective pathway for the enhancement of device lifetime. Additives applied as organic or inorganic compounds, improve crystal grain growth enhancing power conversion efficiency. The interaction of their functional groups with the halide perovskite (HP) absorber, as well as with the transport layers, results in defect passivation and ion immobilization improving device performance and stability [1-4]. In this review, we briefly summarize the different types of additives recently applied in PSC to enhance not only efficiency but also long-term stability. We discuss the different mechanism behind additive engineering and the role of the functional groups of these additives for defect passivation. Special emphasis is given to their effect on the stability of PSCs under environmental conditions such as humidity, atmosphere, light irradiation
\end{abstract}


(UV, visible) or heat, taking into account the recently reported ISOS protocols [5]. We also discuss the relation between deep defect passivation, non-radiative recombination and device efficiency, as well as the possible relation between shallow defect passivation, ion immobilization and device operational stability. Finally, insights into the challenge and criteria for additive selection are provided for the further stability enhancement of PSCs.

Keywords: Additives; additive engineering; perovskite solar cells; defect passivation; shallow defect, deep defect; stability 


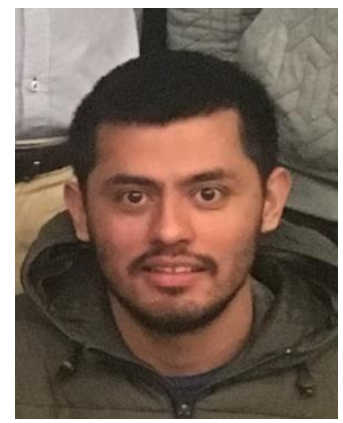

Carlos Pereyra received his B.Sc. in 2013 from the Department of Energy, at the Polytechnic University of Chiapas (Mexico). He is currently pursuing his Ph.D. studies at the Chemistry Department of the Autonoma University of Barcelona (Spain) and at the Nanostructured Materials for Photovoltaic Energy Group at the Catalan Institute of Nanoscience and Nanotechnology, ICN2 (Spain). His current research focuses on electronic devices based on halide perovskites, especially on the fabrication of highly efficient and stable carbon-based perovskite solar cells.

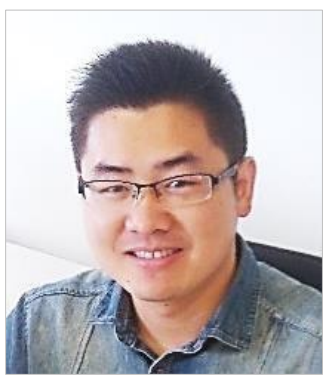

Haibing Xie received his Master degree in 2012 from the University of Science and Technology of China (USTC) and his Ph.D degree in 2016 from the University of Barcelona and the Catalonia Institute for Energy Research, IREC (Spain), majoring in Materials Science. He is expert on the study of $\mathrm{Cu}(\mathrm{In}, \mathrm{Ga}) \mathrm{Se}_{2}$ chalcopyrite solar cells and $\mathrm{CuZnSn}(\mathrm{S}, \mathrm{Se})_{2}$ kesterite solar cells. Since 2017, he has been working under a postdoctoral contract in the group of Prof. Monica Lira-Cantu at the Catalan Institute of Nanoscience and Nanotechnology (ICN2). His current work includes improving the long-term stability of perovskite solar cells and exploring emerging optoelectronic materials for photovoltaic applications. He has published more than 30 peer-reviewed high impact papers in photovoltaic field, with an h index of 16 with over 900 citations. 


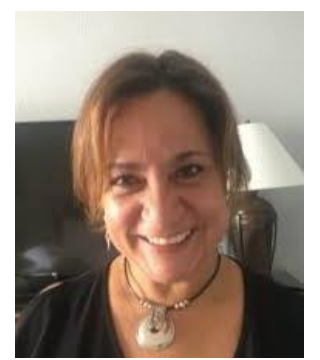

Prof. Monica Lira-Cantu obtained her PhD at the Materials Science

Institute of Barcelona, ICMAB and the Autonoma University of

Barcelona (Spain) in 1997. She is Group Leader of the Nanostructured Materials for Photovoltaic Energy Group at the Catalan Institute of Nanoscience and Nanotechnology, ICN2 in Barcelona (Spain). Her research interests are the synthesis and application of nanostructured materials for next-generation thin film solar cells: Dye sensitized Hybrid, Organic, All-oxide and Perovskite Solar Cells. She has more than 120 publications, among them more than 105 published papers, 9 patents, 10 book chapters and 1 edited book. She has an h index of 46 with more than 7848 citations.

\section{Introduction}

Halide perovskite solar cells (PSCs) have become a rapidly evolving photovoltaic technology attracting great interest due to the many advantages besides their impressive efficiency, among them are materials and optical tunability and versatility, striking optical properties or low temperature processability. In addition, their "soft" nature permits their fabrication by solution processing methods at low-cost and on flexible substrates. Metal halide perovskites (HPs) adopt the general chemical formula of $A B X_{3}$ and have unit cells composed of five atoms in a cubic structure ( $\alpha$ phase), where cation $B$ has six-nearest neighbour anions $X$ and cation $A$ has twelve (Fig. 1). Under ideal conditions, the stability of the crystal structure is highly dependent on its high symmetry cubic structure; the ionic radii of $A, B$, and $X$ should satisfy the requirement of a tolerance factor $t$ close to $1\left(t=\left(R_{A}+{ }^{-} R_{X}\right) /\left\{\sqrt{2}\left(R_{B}+R_{X}\right)\right\}\right.$, where $R_{A}, R_{B}$, 
and $R_{X}$ are the ionic radii of the corresponding ions). To satisfy $t=1$, the $A$ ion must be much larger than the $B$ ion [6-7].

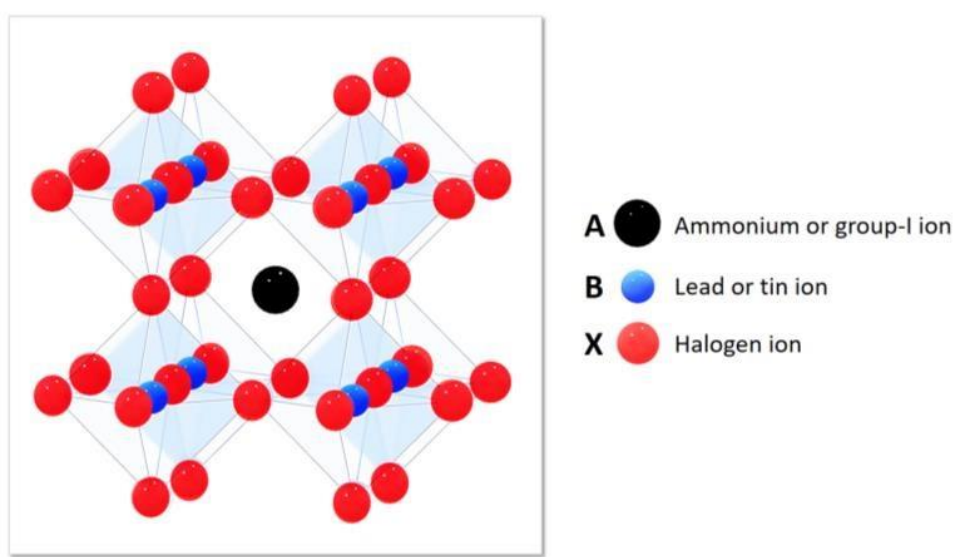

Fig. 1. Schematic representation of the halide perovskite (HP) crystalline structure $\mathrm{ABX}_{3}$.

Metal halide perovskites were first synthesized and reported in the 1970s [8-10]. These materials present a chemical formula $A B X_{3}$ where $\mathrm{A}^{+}=$methylammonium $\left(\mathrm{CH}_{3} \mathrm{NH}_{3}{ }^{+}\right.$ or $\left.\mathrm{MA}^{+}\right)$, formamidinium $\left(\mathrm{HC}\left(\mathrm{NH}_{2}\right)_{2}{ }^{+}\right.$or $\left.\mathrm{FA}^{+}\right)$, caesium $\left(\mathrm{Cs}^{+}\right)$, rubidium $\left(\mathrm{Rb}^{+}\right) ; \mathrm{B}^{2+}=$ lead $\left(\mathrm{Pb}^{2+}\right)$ or tin $\left(\mathrm{Sn}^{2+}\right)$; and $\mathrm{X}^{-}=$chlorine $\left(\mathrm{Cl}^{-}\right)$, bromine $\left(\mathrm{Br}^{-}\right)$, or iodine $\left(\mathrm{I}^{-}\right)$[7]. The first application of HPs as the absorber in a solar cell corresponds to Prof. Tsutomu Myasaka's group in 2009 [11]. They applied the methyl ammonium lead Iodide $\left(\mathrm{CH}_{3} \mathrm{NH}_{3} \mathrm{PbI}_{3}\right)$ as the absorber resulting in devices with power conversion efficiencies (PCEs) of 3.8\%. The HP was depicted as a pigment absorbed on a mesoporous $\mathrm{TiO}_{2}$ thin film surface in a device configuration based on the Dye Sensitized Solar Cell (DSSC). In the following 2 years, Prof. Nam-Gyu Park's group was able to increase the PCE up to $6.5 \%$ [12], but the stability of such devices was rather poor due to the dissolution of the perovskite by the liquid redox electrolyte. A breakthrough was achieved in 2012 with a contribution from the research groups of Prof. Park and Prof. 
Michael Gratzel [13] and, in parallel, to the groups of Prof. Henry Snaith and Prof. Myasaka [14] who, independently, reported the use of a solid-state hole transporter material, the 2,2',7,7'-tetrakis (N,N-di-p-methoxyphenylamine) -9,9'-spirobifluorene (spiro-OMeTAD) in replacement of the liquid electrolyte. As a result, an increase of the PCE above $9 \%$ was reported. After these pioneering studies, the efficiency of these PSCs has observed a rapid improvement that triggered an explosive research effort worldwide to improve PSC manufacturing with demonstrated rapid advances in optimizing device architectures and perovskite properties. Fig. 2 depicts the evolution reported on the PSC's efficiency in the last 11 years. Currently, the certified record PCE for a single-junction PSC has reached 25.2\% [15].

Among the most relevant works we can mention Heo et al. who reported the application of several polymeric hole selective contacts in PSCs applying the $\mathrm{CH}_{3} \mathrm{NH}_{3} \mathrm{Pbl}_{3}$ as the absorber, leading to a PCE of $12 \%$ [16]. Burschka et al. modified the deposition method of the perovskite layer using a two-step technique, increasing the PCE up to 14,14\%; [17] Liu et al. reported also a modification of the deposition method via physical vapour deposition, which resulted in a PCE of $15.4 \%$ [18]. With the aim of increasing uniformity and perovskite thin film density, solvent and composition engineering was carried out by Jeon et al. who reached $17.91 \%$ efficiency [19-20]. Yang et al. obtained a certified $20.11 \%$ PSC via intermolecular exchange in a $\mathrm{FAPbI}_{3}$-based PSCs [21] and Saliba et al. increased the PCE to $21.1 \%$ and $21.6 \%$ by using a triple and a quadruple cation perovskite system, respectively [22-23]. Other examples worth mentioning are those carried out by Yang et al. who reported a certified PCE of $22.1 \%$ using iodide management in a double cation 
perovskite system [24]. Jung et al. obtained a $22.67 \%$ efficiency using an alternative holetransport material, the Poly (3-hexylthiophene) (P3HT), which showed excellent optoelectronic properties [25]. Jiang et al. reported the use of an organic halide salt, the phenethylammonium iodide (PEAI), in mixed perovskite films for surface defect passivation with certified PCE of $23.32 \%$ [26]. The details of the device architectures for the last three examples with $23.7 \%, 24.2 \%$ and

25.2\% efficiency (Fig. 2) are still not available [15].

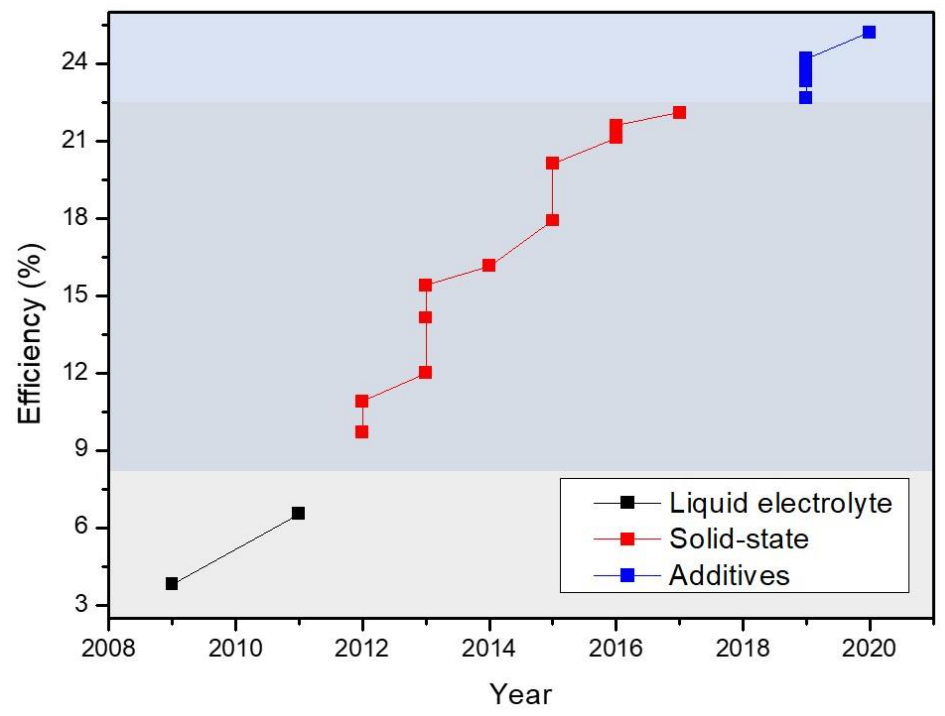

Fig. 2. Evolution of the power conversion efficiency of PSCs with time of selected lab-scale perovskite-based solar cells [3-26]. Liquid electrolytes were first employed following the DSSC technology (black), followed by solid state devices (red). The use of additives has recently allowed the highest efficiencies reported for the technology (blue).

Several issues associated with PSCs need to be addressed in order for the technology to become competitive. However, the critical hurdle of PSCs is their operational stability.

The ionic-electronic conductivity and the "soft material" nature of halide perovskites indicates a strong component for ion movement and ion migration. This is more pronounced under operational conditions (e.g., light irradiation, moisture, heat) and translates into device ion vacancy formation (charge trap formation), hysteresis, phase 
separation and device instability. Incredible gains in device stability have been achieved in recent years and in a relatively short period of time due to the employment of different strategies, among them is the interface/bulk engineering that primarily employs the use of additives. The inclusion of small amount of chemical additives in the perovskite precursor solution provides advantages in terms of attractive optical and electrical properties which influence the performance of the resulting device. Fig. 3 summarizes the efficiency and performance loss (in stability) of PSCs selected from the literature (for the years 2018-2020) with (w) and without (w/o) the application of additives within the perovskite absorber layer. The graphs are divided by the type of additive employed. In all cases, we observe a clear efficiency increase when additives are employed (Fig. 3a). This effect is attributed to the enhanced thin film properties and defect passivation effect of the additive on the HP thin film. In the case of performance loss (Fig. 3b), this is, the difference in percentage between the initial PCE and the PCE observed after stability analysis, we can also observe an improvement of the stability (or a reduced performance loss) after every stability analyses. The latter demonstrates the beneficial effect of additive engineering on the performance and lifetime of PSCs.
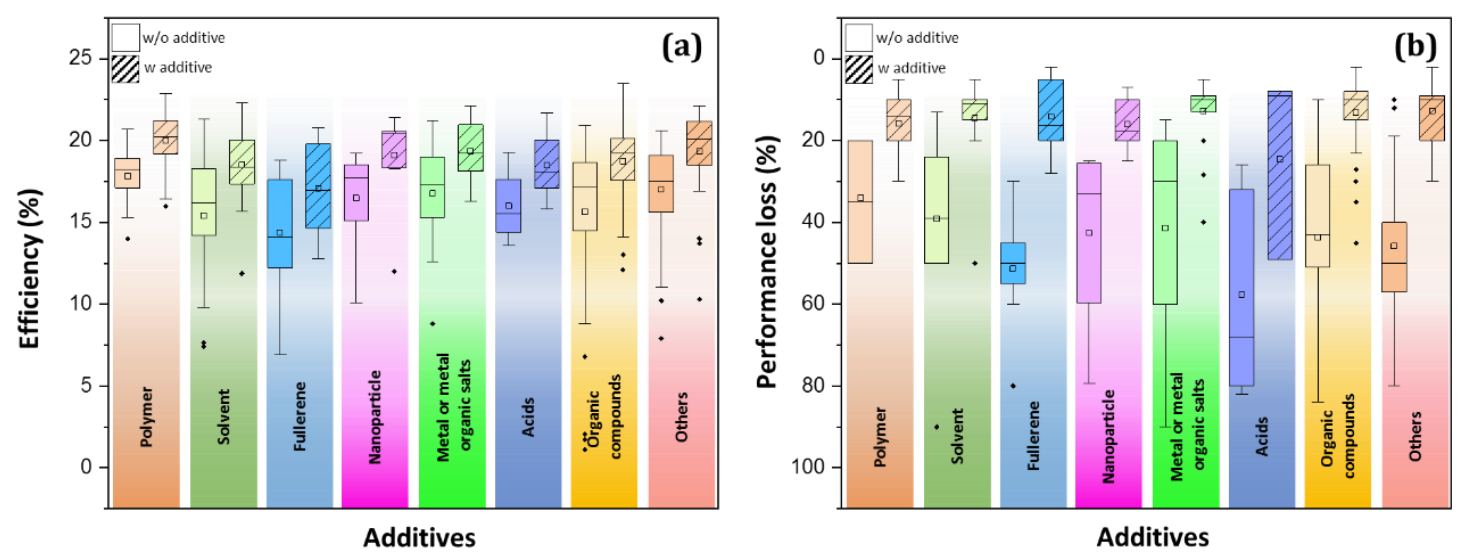

Fig. 3. Efficiency (a) and Performance loss after stability analysis (b) of PSCs with different types of additives (graphs based on data depicted in Table 1). 
Given the current rate of progress and continued improvements in PSCs, great efforts have been made through designing new device structures [14][27], interface engineering [28-30] and defect passivation [31], exploring new perovskite materials [20] [23] [32-34] and controlling the perovskite crystal growth [19][35-36]. The growth of the perovskite crystal plays an important role in optimizing the performance of PSC device.

We based this review on recent advances in additive engineering reported in the literature since 2018, with the aim to enhance PSCs stability. We include topics that range from physical material degradation to non-destructive phenomena that, nevertheless hamper efficient device operation. We will discuss the working mechanisms and important roles of additives in PSCs focusing on issues such as (see also Fig.5): a) Perovskite thin film processing, including the growth of the perovskite crystal, which is related to perovskite morphology, and plays an important role in optimizing device performance; b) Device performance: in order to achieve high device performance in PSCs, great efforts have been made to design new device structures, manipulate their surface by additive engineering and to explore new perovskite materials; c) Device lifetime: one of the most important criteria for PSCs is the ability to maintain stable power output under standard working conditions; d) Others: a section where we include additive's molecular configuration and size (e.g. chain length).

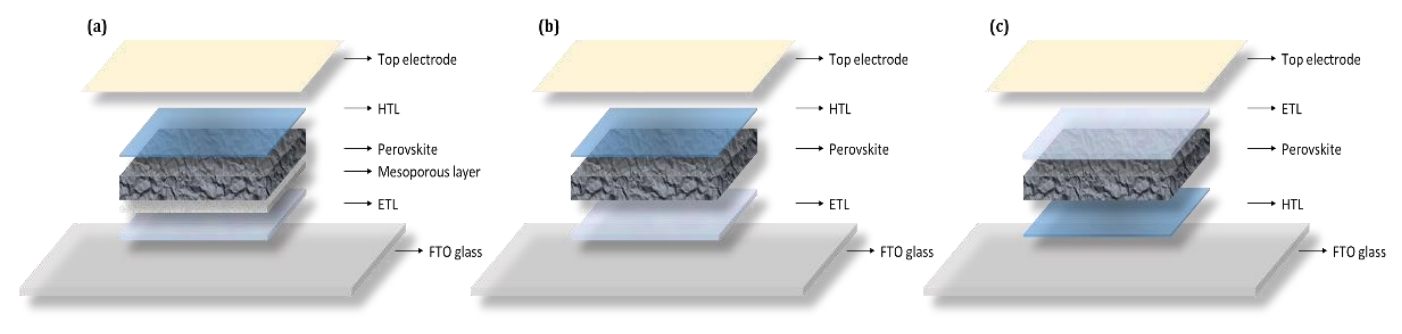

Fig. 4. Schematic diagram of three common perovskite solar cell architectures: mesoporous n-i-p (a), planar n-i-p (b), and planar $\mathrm{p}-\mathrm{i}-\mathrm{n}(\mathrm{c})$. 
For the latter, we divided this work in four sections starting with an overview of the different working mechanisms observed when additives (organic and inorganic) are employed in PSCs (Section 2). We include the most recent examples of organic additives depending on their functional group, chain length and molecular configuration and their effect in 2D perovskites. In Section 3 we elaborate on the effect of additives on perovskite grain size and their effect on grain boundaries and surface passivation. Section 4 encompass different examples where additives are employed to enhance PSC stability, here we include a brief discussion about the role of defects, and we finalize this work giving a general outlook of the future of additives in PSC future evolution.

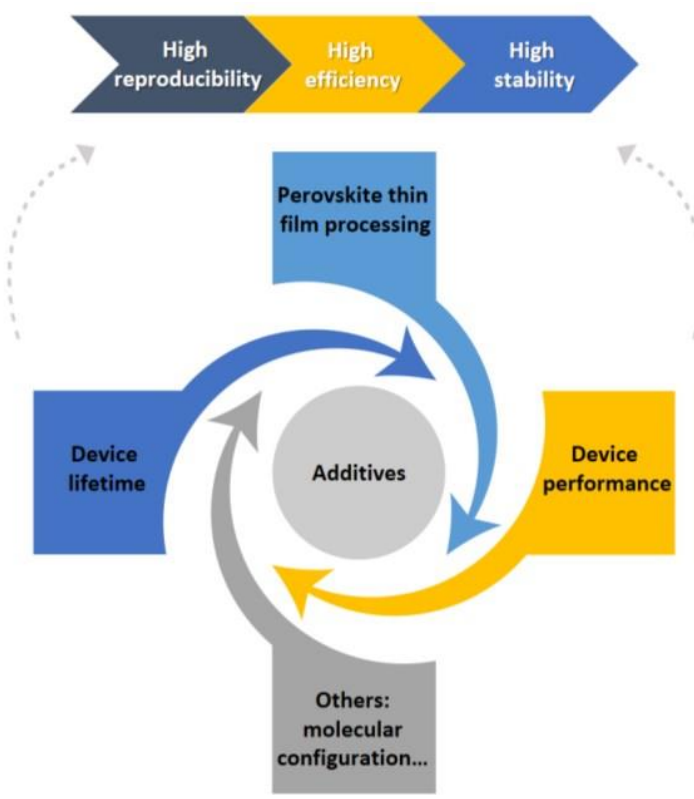

Fig. 5. The impact of additives in PSCs: Effect on device fabrication and reproducibility, device efficiency and device stability.

Table 1 includes the published research works on additive engineering for PSCs reported between 2019 and the middle part of 2020 . The table is organized by the type of additive and includes only those published works which report on any type of 
stability analysis. Stability test results and conditions are included in the corresponding columns. 
Table 1. PSCs employing additives to enhance device performance (PCE and Stability).

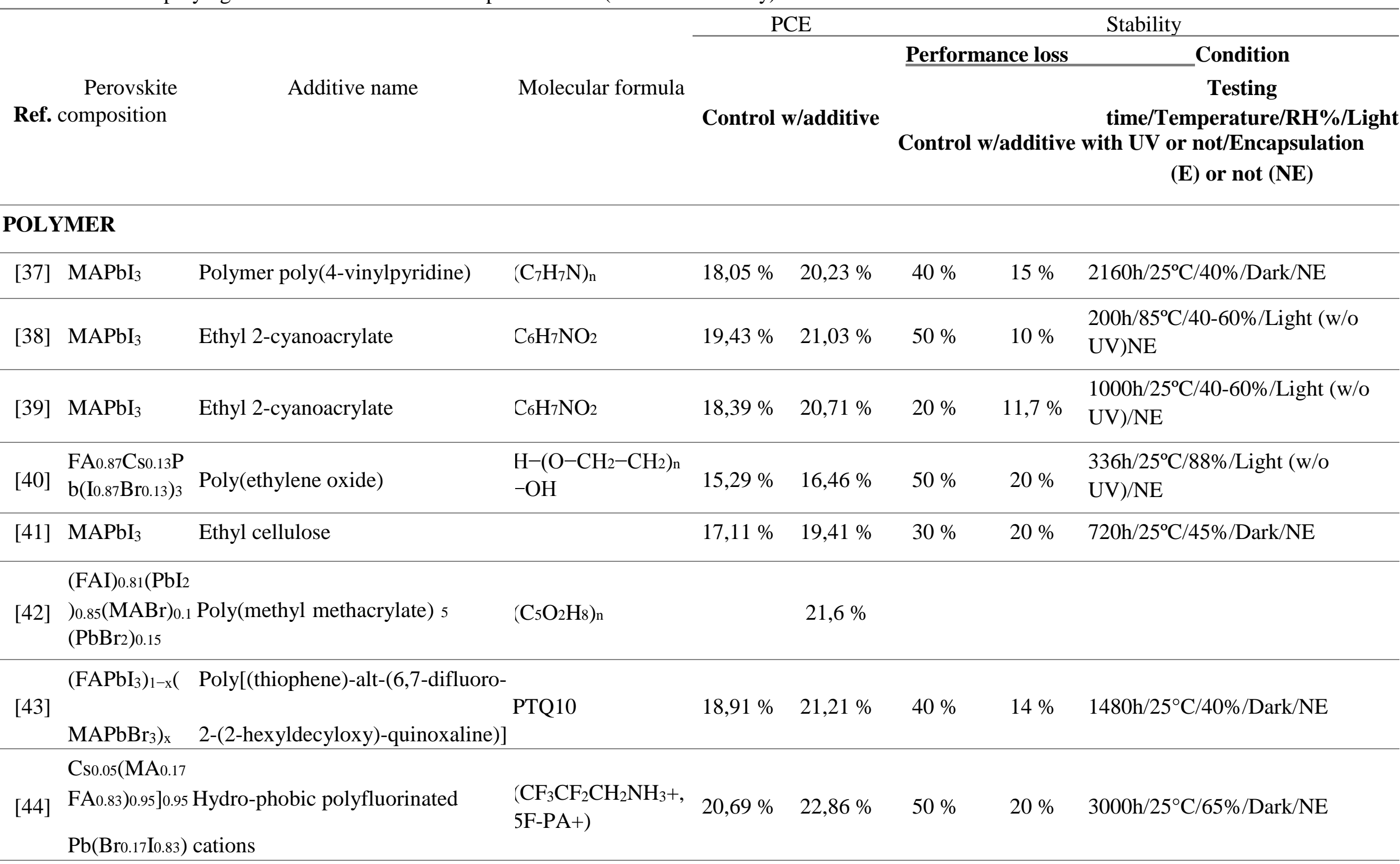




\begin{tabular}{|c|c|c|c|c|c|c|c|c|}
\hline [45] & $\begin{array}{l}\text { MAPbI } \\
(\mathrm{J} 71)\end{array}$ & $3 \quad$ Polymer Doping & $\left.{ }^{(} \mathrm{C}_{66} \mathrm{H}_{85} \mathrm{~F}_{2} \mathrm{~N}_{3} \mathrm{~S}_{6} \mathrm{Si}_{2}\right)_{\mathrm{n}} \quad 1$ & $17,43 \%$ & $19,19 \%$ & $20 \%$ & $10 \%$ & $336 \mathrm{~h} / 25^{\circ} \mathrm{C} / 45 \% / \mathrm{Dark} / \mathrm{NE}$ \\
\hline [46] & $\mathrm{MAPbI}_{3}$ & Trimethylolpropane triacrylate & $\mathrm{C}_{15} \mathrm{H}_{20} \mathrm{O}_{6}$ & $19,06 \%$ & $20,22 \%$ & & $25 \%$ & $\begin{array}{l}400 \mathrm{~h} / 25^{\circ} \mathrm{C} / 45 \% / \mathrm{Light}(\mathrm{w} / \mathrm{o} \\
\mathrm{UV}) / \mathrm{NE}\end{array}$ \\
\hline [47] & $\mathrm{MAPbI}_{3}$ & Polymer (PEG)-scaffold & $\begin{array}{l}\mathrm{H}-\left(\mathrm{O}-\mathrm{CH}_{2}-\mathrm{CH}_{2}\right)_{\mathrm{n}} \\
-\mathrm{OH}\end{array}$ & $14 \%$ & $16 \%$ & & $30 \%$ & $\begin{array}{l}300 \mathrm{~h} / 25^{\circ} \mathrm{C} / 70 \% / \mathrm{Light}(\mathrm{w} / \mathrm{o} \\
\mathrm{UV}) / \mathrm{NE}\end{array}$ \\
\hline [48] & $\begin{array}{l}\left(\mathrm{FAPbI}_{3}\right)_{0.85}( \\
\mathrm{MAPbBr} 3)_{0.15}\end{array}$ & Polyaniline & $\left(\mathrm{C}_{6} \mathrm{H}_{7} \mathrm{~N}\right)_{\mathrm{x}}$ & $16,96 \%$ & $19,09 \%$ & $20 \%$ & $14 \%$ & $1600 \mathrm{~h} / 25^{\circ} \mathrm{C} / 50 \% / \mathrm{Dark} / \mathrm{NE}$ \\
\hline [49] & $\begin{array}{c}\text { Cs } 0.07 \mathrm{Rb}_{0.03} \mathrm{~F} \\
\text { A0.765MA0.135 } \\
\text { PbI } 2.55 \mathrm{Br} 0.45\end{array}$ & Poly(methyl methacrylate) & $\left(\mathrm{C}_{5} \mathrm{O}_{2} \mathrm{H}_{8}\right)_{\mathrm{n}}$ & $18,50 \%$ & $20,86 \%$ & & & \\
\hline [50] & $\mathrm{MAPbI}_{3}$ & $\begin{array}{l}\text { Group of polarized ferroelectric } \\
\text { (polyinylidene fluoride- } \\
\text { trifluoroethylene polymer P(VDF- } \\
\text { TrFE)) }\end{array}$ & $\left(\mathrm{C}_{2} \mathrm{H}_{2} \mathrm{~F}_{2}\right) \mathrm{n}\left(\mathrm{C}_{2} \mathrm{HF}_{3}\right)_{\mathrm{m}} 1$ & $17,21 \%$ & $21,38 \%$ & $20 \%$ & $10 \%$ & $500 \mathrm{~h} / 25^{\circ} \mathrm{C} / 40 \% / \mathrm{Dark} / \mathrm{NE}$ \\
\hline$[51]$ & $\begin{array}{l}(\mathrm{Cs} \\
\quad 0.2 \mathrm{FA} 0.8) \mathrm{P} \\
\mathrm{b}(\mathrm{I} 0.95 \mathrm{Br} 0.05) 3\end{array}$ & $\begin{array}{l}\text { Poly[bis( } 4- \\
\text { phenyl })(2,4,6 \text { trimethylphenyl }) \text { amine }\end{array}$ & $e^{\left[\mathrm{C}_{6} \mathrm{H}_{4} \mathrm{~N}\left(\mathrm{C}_{6} \mathrm{H}_{2}\left(\mathrm{CH}_{3}\right)\right.\right.}$ & $18,64 \%$ & $20,05 \%$ & & $5 \%$ & $1440 \mathrm{~h} / 25^{\circ} \mathrm{C} / 40 \% / \mathrm{Dark} / \mathrm{NE}$ \\
\hline \multicolumn{9}{|c|}{ SOLVENT } \\
\hline$[52]$ & $\begin{array}{l}(\mathrm{FAPbI} \\
3)^{0.92(} \\
\mathrm{MAPbBr} 3)_{0.08}\end{array}$ & $\begin{array}{l}\text { Alkyl ammonium } \\
\text { bromide/chloroform }\end{array}$ & $\mathrm{CH}_{3} \mathrm{NH}_{3} \mathrm{Br} / \mathrm{CHCl}_{3}$ & $21,3 \%$ & $22,3 \%$ & $30 \%$ & $15 \%$ & $100 \mathrm{~h} / 25^{\circ} \mathrm{C} / 40 \% /$ Light (w/o UV)/E \\
\hline [53] & $\mathrm{MAPbI}_{3}$ & Ammonium benzenesulfonate & $\underline{\mathrm{C}}_{6} \mathrm{H}_{9} \mathrm{NO}_{3} \underline{\mathrm{S}}$ & $\underline{18,69 \%}$ & $20,62 \%$ & $20 \%$ & $15 \%$ & $1440 \mathrm{~h} / 25^{\circ} \mathrm{C} / 30 \% / \mathrm{Dark} / \mathrm{NE}$ \\
\hline [54] & $\mathrm{MAPbI}_{3}$ & Dimethylsulphoxide & $\left(\mathrm{CH}_{3}\right)_{2} \mathrm{SO}$ & $16,19 \%$ & $18,19 \%$ & & & \\
\hline
\end{tabular}




\begin{tabular}{|c|c|c|c|c|c|c|c|c|}
\hline [55] & $\mathrm{MAPbI}_{3}$ & Methanol & $\mathrm{CH}_{3} \mathrm{OH}$ & $16,53 \%$ & $19,51 \%$ & $50 \%$ & $15 \%$ & $720 \mathrm{~h} / 25^{\circ} \mathrm{C} / \mathrm{Dark} / \mathrm{NE}$ \\
\hline [56] & $\mathrm{MAPbI}_{3}$ & Tetraethyl orthosilicate & $\underline{\mathrm{SiC}_{8} \mathrm{H}_{20} \mathrm{O}_{4}}$ & $15,96 \%$ & $18,38 \%$ & $13 \%$ & $7 \%$ & $672 \mathrm{~h} / 25^{\circ} \mathrm{C} / 30 \% / \mathrm{Dark} / \mathrm{NE}$ \\
\hline [57] & $\begin{array}{l}\text { Cs0.05(MA0.17 } \\
\text { FA0.83)0.95 } \mathrm{Pb}( \\
0.83 \mathrm{Br} 0.17) 3\end{array}$ & $\begin{array}{l}\text { Dimethyl } \\
\text { sulfoxide/Chlorobenzene }\end{array}$ & $\left(\mathrm{CH}_{3}\right)_{2} \mathrm{SO} / \mathrm{C}_{6} \mathrm{H}_{5} \mathrm{Cl}$ & $16,6 \%$ & $18,4 \%$ & & & \\
\hline [58] & $\mathrm{MAPbI}_{3}$ & 2-Propanol & $\mathrm{C}_{3} \mathrm{H}_{8} \mathrm{O}$ & $16,02 \%$ & $19,70 \%$ & $50 \%$ & $15 \%$ & $960 \mathrm{~h} / 25^{\circ} \mathrm{C} / 40 \% / \mathrm{Dark} / \mathrm{NE}$ \\
\hline [59] & $\mathrm{MAPbI}_{3}$ & Water & $\mathrm{H}_{2} \mathrm{O}$ & $7,40 \%$ & $18 \%$ & & $10 \%$ & $960 \mathrm{~h} / 25^{\circ} \mathrm{C} / 40 \% / \mathrm{Dark} / \mathrm{NE}$ \\
\hline [60] & $\mathrm{MAPbI}_{3}$ & Water & $\mathrm{H}_{2} \mathrm{O}$ & $9,78 \%$ & $20,1 \%$ & & $10 \%$ & $720 \mathrm{~h} / 25^{\circ} \mathrm{C} / 40 \% / \mathrm{Dark} / \mathrm{NE}$ \\
\hline [61] & $\mathrm{MAPbI}_{3}$ & 2-Methylanisole & $\mathrm{CH}_{3} \mathrm{C}_{6} \mathrm{H}_{4} \mathrm{OCH}_{3}$ & $18,3 \%$ & $20 \%$ & $40 \%$ & $10 \%$ & $720 \mathrm{~h} / 25^{\circ} \mathrm{C} / 50 \% / \mathrm{Dark} / \mathrm{NE}$ \\
\hline$[62]$ & $\mathrm{a}-\mathrm{CsPbI}_{2} \mathrm{Br}$ & 2-Propanol & $\mathrm{C}_{3} \mathrm{H}_{8} \mathrm{O}$ & $12,65 \%$ & $16,07 \%$ & $30 \%$ & $5 \%$ & $1000 \mathrm{~h} / 25^{\circ} \mathrm{C} / 30 \% / \mathrm{Dark} / \mathrm{NE}$ \\
\hline [63] & $\mathrm{MAPbI}_{3}$ & Acetonitrile & $\mathrm{C}_{2} \mathrm{H}_{3} \mathrm{~N}$ & $15,04 \%$ & $17,81 \%$ & & & $\begin{array}{l}35 \mathrm{~h} / 25^{\circ} \mathrm{C} / 60 \% / \text { Light }(\mathrm{w} / \mathrm{o} \\
\mathrm{UV}) / \mathrm{NE}\end{array}$ \\
\hline [64] & $\mathrm{MAPbI}_{3}$ & Benzoquinone & $\mathrm{C}_{6} \mathrm{H}_{4}(=\mathrm{O})_{2}$ & $10,73 \%$ & $15,66 \%$ & & & $\begin{array}{l}1600 \mathrm{~h} / 25^{\circ} \mathrm{C} / 40 \% / \mathrm{Light}(\mathrm{w} / \mathrm{o} \\
\mathrm{UV}) / \mathrm{NE}\end{array}$ \\
\hline$[65]$ & $\mathrm{FAPbI}_{3}$ & Benzylamine & $\mathrm{C}_{7} \mathrm{H}_{9} \mathrm{~N}$ & $14,20 \%$ & $19,20 \%$ & $90 \%$ & $50 \%$ & $2880 \mathrm{~h} / 25^{\circ} \mathrm{C} / 50 \% /$ Dark/NE \\
\hline [66] & $\mathrm{MAPbI}_{3}$ & Dimethyl sulfide & $\mathrm{C}_{2} \mathrm{H}_{6} \mathrm{~S}$ & $16,46 \%$ & $17,56 \%$ & $50 \%$ & $14 \%$ & $1440 \mathrm{~h} / 25^{\circ} \mathrm{C} / 35 \% /$ Dark/NE \\
\hline [67] & $\mathrm{MAPbI}_{3}$ & 4-tert butylpyridine & $\mathrm{C}_{9} \mathrm{H}_{13} \mathrm{~N}$ & $16,20 \%$ & $17,30 \%$ & & & \\
\hline [68] & $\mathrm{MAPbI}_{3}$ & Methyl acetate & $\mathrm{C}_{3} \mathrm{H}_{6} \mathrm{O}_{2}$ & & $16,3 \%$ & & $20 \%$ & $360 \mathrm{~h} / 25^{\circ} \mathrm{C} / 60 \% / \mathrm{Dark} / \mathrm{NE}$ \\
\hline [69] & \multicolumn{2}{|c|}{$\begin{array}{l}\left.\mathrm{FA}_{0.83}\right)_{0.95} \mathrm{~Pb} \text { Pyridine } \\
\left(\mathrm{I}_{0.83} \mathrm{Br} 0.17\right)_{3}\end{array}$} & $\mathrm{C}_{5} \mathrm{H}_{5} \mathrm{~N}$ & $16,94 \%$ & $19,03 \%$ & & & \\
\hline
\end{tabular}




\begin{tabular}{|c|c|c|c|c|c|c|c|c|}
\hline [70] & $\mathrm{MAPbI}_{3}$ & 4-tert-butylpyridine & $\mathrm{C}_{9} \mathrm{H}_{13} \mathrm{~N}$ & $14,49 \%$ & $17,41 \%$ & $23,4 \%$ & $11 \%$ & $720 \mathrm{~h} / 25^{\circ} \mathrm{C} / 45 \% / \mathrm{Dark} / \mathrm{NE}$ \\
\hline [71] & $\mathrm{MAPbI}_{3}$ & Alkylamine & $\mathrm{R}-\mathrm{NH}_{2}$ & $18,30 \%$ & $21,50 \%$ & $50 \%$ & $10 \%$ & $1000 \mathrm{~h} / 25^{\circ} \mathrm{C} / 45 \% / \mathrm{Dark} / \mathrm{NE}$ \\
\hline [72] & FAI:MACl:M & 2,2,2-trifluoroethanol $\mathrm{ABr}$ & $\mathrm{C}_{2} \mathrm{H}_{3} \mathrm{~F}_{3} \mathrm{O}$ & $19,17 \%$ & $20,92 \%$ & $24 \%$ & $10 \%$ & $720 \mathrm{~h} / 25^{\circ} \mathrm{C} / 40 \% / \mathrm{Dark} / \mathrm{NE}$ \\
\hline [73] & $\mathrm{MAPbI}_{3}$ & Methyl acetate & $\mathrm{CH}_{3} \mathrm{COOCH}_{3}$ & & $16,3 \%$ & & $20 \%$ & $360 \mathrm{~h} / 60 \% / \mathrm{Dark} / \mathrm{NE}$ \\
\hline [74] & $\mathrm{CsPbI}_{3}$ & Ethylenediamine & $\mathrm{NH}_{2} \mathrm{CH}_{2} \mathrm{CH}_{2} \mathrm{NH}_{2}$ & $7,66 \%$ & $11,86 \%$ & & & $720 \mathrm{~h} / 25^{\circ} \mathrm{C} / 45 \% /$ Dark/NE \\
\hline [75] & CsFAMA & Alkylamine ligands & $\mathrm{R}-\mathrm{NH}_{2}$ & $20.5 \%$ & $22,3 \%$ & $39 \%$ & $10 \%$ & $\begin{array}{l}1020 \mathrm{~h} / 85^{\circ} \mathrm{C} / 45 \% / \text { Light (w/o } \\
\mathrm{UV}) / \mathrm{E}\end{array}$ \\
\hline \multicolumn{9}{|c|}{ FULLERENE } \\
\hline [76] & $\mathrm{MAPbI}_{3}$ & $\begin{array}{l}\text { Pyridine-functionalized fullerene } \\
\text { derivative }\end{array}$ & $\begin{array}{l}{[6,6]-(4-p y r i d i n y l)-} \\
C_{61} \text {-ethyl acid ethyl } \\
\text { ester (PyCEE) }\end{array}$ & $17,61 \%$ & $19,82 \%$ & $30 \%$ & $17 \%$ & $720 \mathrm{~h} / 25^{\circ} \mathrm{C} / 30 \% / \mathrm{Dark} / \mathrm{NE}$ \\
\hline [77] & $\mathrm{MAPbI}_{3}$ & Tetratetracontane (TTC) & $\mathrm{CH}_{3}\left(\mathrm{CH}_{2}\right)_{2} \mathrm{CH}_{3}$ & $17,34 \%$ & $20,05 \%$ & $40 \%$ & $23 \%$ & $\begin{array}{l}200 \mathrm{~h} / 25^{\circ} \mathrm{C} / 40 \% / \text { Light (w/o } \\
\mathrm{UV}) / \mathrm{NE}\end{array}$ \\
\hline [78] & $\mathrm{MAPbI}_{3}$ & $\begin{array}{l}\text { ([6,6]-phenyl-C } 61 \text {-butyric-acid } \\
\text { methyl ester) }\end{array}$ & $\mathrm{C}_{72} \mathrm{H}_{14} \mathrm{O}_{2}$ & $6,90 \%$ & $12.78 \%$ & & & \\
\hline \multicolumn{2}{|c|}{ [79] $\mathrm{MAPbI}_{3}$} & $\begin{array}{l}\text { Lithium-ion } \\
\text { containing[60]fullerenetri-fluoro } \\
\text { methanesulfonylimide salt }\end{array}$ & $\mathrm{Li}+@ \mathrm{C}_{60} \mathrm{TFSI}^{-}$ & $12,30 \%$ & $16,70 \%$ & & & $\begin{array}{l}1000 \mathrm{~h} / 30^{\circ} \mathrm{C} / 40 \% / \mathrm{Light}(\mathrm{w} / \mathrm{o} \\
\mathrm{UV}) / \mathrm{E}\end{array}$ \\
\hline$[80]$ & $\begin{array}{l}\mathrm{CH} \\
{ }_{3} \mathrm{NH}_{3} \mathrm{~Pb} 0.7 \\
{ }_{5} \mathrm{Snn}_{0.25} \mathrm{I}_{3}\end{array}$ & Fullerene & $\mathrm{C}_{60}$ & $12,5 \%$ & $13,7 \%$ & $60 \%$ & $20 \%$ & $168 \mathrm{~h} / 25^{\circ} \mathrm{C} / 50 \% / \mathrm{Dark} / \mathrm{NE}$ \\
\hline [81] & $\mathrm{MAPbI}_{3}$ & $\begin{array}{l}\text { Carboxylic-acid/fullerene } \\
\text { derivative }\end{array}$ & $\mathrm{R}-\mathrm{COOH} / \mathrm{C}_{60}$ & $11,75 \%$ & $13,97 \%$ & & & \\
\hline
\end{tabular}




\begin{tabular}{|c|c|c|c|c|c|c|c|}
\hline $\begin{array}{ll} & \mathrm{CH} \\
& { }_{3} \mathrm{NH}_{3} \mathrm{PbI}_{\mathrm{x}} \\
& \mathrm{Cl}_{3-\mathrm{x}}\end{array}$ & $\begin{array}{l}{[6,6] \text {-phenyl- } \mathrm{C}_{61} \text {-butyric styryl }} \\
\text { dendron ester }\end{array}$ & $\mathrm{C}_{72} \mathrm{H}_{14} \mathrm{O}_{2}$ & $12,23 \%$ & $17,21 \%$ & $50 \%$ & $15,4 \%$ & $720 \mathrm{~h} / 25^{\circ} \mathrm{C} / 40 \% / \mathrm{Dark} / \mathrm{NE}$ \\
\hline [83] $\mathrm{MAPbI}_{3}$ & $\begin{array}{l}\text { Phenyl- } \mathrm{C}_{61} \text {-butyric acid methyl } \\
\text { ester }\end{array}$ & $\mathrm{C}_{72} \mathrm{H}_{14} \mathrm{O}_{2}$ & & $14,9 \%$ & & & \\
\hline [84] $\mathrm{MAPbI}_{3}$ & $\begin{array}{l}\text { Phenyl-C61-butyric acid methyl } \\
\text { ester }\end{array}$ & $\mathrm{C}_{72} \mathrm{H}_{14} \mathrm{O}_{2}$ & & $14,4 \%$ & & & \\
\hline [85] $\mathrm{MAPbI}_{3}$ & $\begin{array}{l}\text { Phenyl- } \mathrm{C}_{61} \text {-butyric acid methyl } \\
\text { ester }\end{array}$ & $\mathrm{C}_{72} \mathrm{H}_{14} \mathrm{O}_{2}$ & $11,4 \%$ & $16 \%$ & & & \\
\hline $\begin{array}{l}\mathrm{FA} 0.85 \mathrm{MA} 0.15 \\
{[86] \mathrm{Pb}(\mathrm{I} 0.85 \mathrm{Br} 0.15)}\end{array}$ & $\begin{array}{l}\text { Fullerene derivative/bis - phenyl } \\
\mathrm{C}_{61} \text { _butyric acid methyl ester }\end{array}$ & $\begin{array}{l}-\left(\alpha_{-} \quad-\text { bis PCBM }\right) / \\
\mathrm{C}_{72} \mathrm{H}_{14} \mathrm{O}_{2}\end{array}$ & $18,8 \%$ & $20,8 \%$ & $50 \%$ & $4 \%$ & $600 \mathrm{~h} / 25^{\circ} \mathrm{C} / \mathrm{Light}(\mathrm{w} / \mathrm{o} \mathrm{UV}) / \mathrm{NE}$ \\
\hline [87] $\mathrm{MAPbI}_{3}$ & $\begin{array}{l}3,5- \\
\text { bis(perfluorooctyl)benzaldehyde } \\
\text { and fullerene }\end{array}$ & $\begin{array}{l}\left(\mathrm{CF}_{3}\right)_{2} \mathrm{C}_{6} \mathrm{H}_{3} \mathrm{CHO} / \mathrm{C}_{6} \\
0\end{array}$ & $15,67 \%$ & $18,11 \%$ & $50 \%$ & $17 \%$ & $720 \mathrm{~h} / 25^{\circ} \mathrm{C} / 60 \% /$ Dark/NE \\
\hline $\begin{array}{l}\text { MA0.17FA0.83 } \\
{[88] \mathrm{Pb}(\mathrm{I} 0.83 \mathrm{Br} 0.17)} \\
3\end{array}$ & $\begin{array}{l}\text { ITIC-Th (3,9-bis(2-methylene-(3- } \\
\text { (1,1-dicyanomethylene)indanone) } \\
\text { hexylthienyl) dithieno[2,3-d:2',3'd } \\
\text { indaceno[1,2-b:5,6-b'] dithiophene }\end{array}$ & $\begin{array}{l}\text {-5,5,11,11-tetrakis(5- } \\
\text { ']-s } \\
\text { e) }\end{array}$ & $18,07 \%$ & $19,20 \%$ & & $5 \%$ & $960 / 25^{\circ} \mathrm{C} / 45 \% / \mathrm{Dark} / \mathrm{NE}$ \\
\hline [89] $\mathrm{MAPbI}_{3-x} \mathrm{Cl}_{x}$ & $\begin{array}{l}\text { Phenyl- } \mathrm{C}_{61} \text {-butyric acid methyl } \\
\text { ester }\end{array}$ & ${ }_{72} \mathrm{H}_{14} \mathrm{O}_{2}$ & $13,5 \%$ & $15,7 \%$ & & $10 \%$ & $2 \mathrm{~h} / 80^{\circ} \mathrm{C} / 45 \% / \mathrm{Dark} / \mathrm{NE}$ \\
\hline [90] $\mathrm{CH}_{3} \mathrm{NH}_{3} \mathrm{PbI}_{3}$ & $\begin{array}{l}\text { hydrophilic }[6,6]-\text { phenyl- } \mathrm{C}_{61^{-}} \\
\text {butyric acid-(3,4,5-tris(2-(2-(2- } \\
\text { methoxyethoxy)ethoxy)ethoxy)ph } \\
\text { enyl)methanol ester }\end{array}$ & & $18,62 \%$ & $19,74 \%$ & $50 \%$ & $2 \%$ & $\begin{array}{l}1440 \mathrm{~h} / 25^{\circ} \mathrm{C} / 50 \% / \mathrm{Light}(\mathrm{w} / \mathrm{o} \\
\mathrm{UV}) / \mathrm{NE}\end{array}$ \\
\hline
\end{tabular}


Photo-crosslinked $[6,6]$ phenylC $61^{-}$

[91] $\mathrm{MAPbI}_{3}$

butyric oxetane dendron ester

C-PCBOD

$14,7 \% \quad 20,4 \% \quad 80 \%$

$28 \% 960 \mathrm{~h} / 25^{\circ} \mathrm{C} / 25 \% / \mathrm{Dark} / \mathrm{NE}$

\section{NANOPARTICLE}

Cs0.05(MA0.17

[92] FA0.83)0.95 $\mathrm{Pb}(\mathrm{I}$ Carbon NPs

C

$17,7 \% \quad 18,3 \%$ $0.83 \mathrm{Br} 0.17) 3$ (Cs0.05FA0.80

[93] $\mathrm{MA} 0.15) \mathrm{Pb}\left(\mathrm{I}_{0.8} \quad\right.$ Europium-doped titania

$\mathrm{Eu}-\mathrm{TiO}_{2}$

$19,22 \% \quad 21,40 \%$

$40 \%$

$25 \%$

$500 \mathrm{~h} / 25^{\circ} \mathrm{C} / 60 \% / \mathrm{Light}$ (w/o $5 \mathrm{Br} 0.15)_{3}$

[94] $\mathrm{MAPbI}_{3}$ Cesium, Lead and Bromine NPs $\quad \mathrm{CsPbBr}_{3}$

$18,51 \% \quad 20,46 \% \quad 26 \%$

$10 \% 500 \mathrm{~h} / 25^{\circ} \mathrm{C} / 30-40 \% /$ Dark/NE

[95] $\mathrm{MAPbI}_{3}$

Zinc oxide NPs

$\mathrm{ZnO}$

$13,40 \% \quad 18,34 \%$

[96] $\mathrm{MAPbI}_{3}$

Barium hydroxide hybridized boron-doped $\mathrm{ZnO}$

$\mathrm{B}: \mathrm{ZnO}$

$17,63 \% \quad 20,53 \% \quad 25 \%$

$20 \% \quad 2400 \mathrm{~h} / 25^{\circ} \mathrm{C} / \mathrm{Dark} / \mathrm{NE}$

[97] ${ }_{3} \mathrm{NH}_{3} \mathrm{PbI}_{3}-\mathrm{CH}_{3}$ Metal-Organic Framework ${ }_{\mathrm{x}} \mathrm{Cl}_{\mathrm{x}}$ Nanocrystals

\begin{tabular}{c}
\hline [98] $\mathrm{MAPbI}_{3}$ \\
\hline $\mathrm{Cs} 0.05(\mathrm{MA} 0.1$ \\
[99] $\mathrm{FA} 0.85)_{0.95} \mathrm{~Pb}($ \\
$0.85 \mathrm{Br} 0.15)_{3}$ \\
\hline $\mathrm{FA} 0.85 \mathrm{MA} 0.1$
\end{tabular}

[100] $\mathrm{Pb}(\mathrm{I} 0.85 \mathrm{Br} 0.15)$

Carbon nanodots

$10,10 \% \quad 12 \%$

Car

Cobalt(II) oxide NPs

$15,11 \% \quad 19,50 \%$

$7 \% \quad 500 \mathrm{~h} / 25^{\circ} \mathrm{C} / 40 \% / \mathrm{Dark} / \mathrm{NE}$

$\mathrm{CoO}$

$18,75 \%$

$20,72 \%$

$79,39 \%$

$17,84 \%$

$720 \mathrm{~h} / 25^{\circ} \mathrm{C} / 50 \% /$ Dark/NE

Cesium, Lead and Bromine NCs $\mathrm{CsPbBr}_{3}$

$17,95 \% \quad 20,56 \%$

$1440 \mathrm{~h} / 25^{\circ} \mathrm{C} / 45 \% /$ Dark/NE

\section{METAL OR METAL ORGANIC SALTS}

[101] $\mathrm{Cs}_{\mathrm{x}} \mathrm{FA}_{1-\mathrm{x}} \mathrm{PbI}_{3} \mathrm{GaAA}_{3}$

Gallium(III)

$14 \%$

$17 \%$

$30 \%$

$10 \% 800 \mathrm{~h} / 25^{\circ} \mathrm{C} / 50 \% /$ Dark/NE 


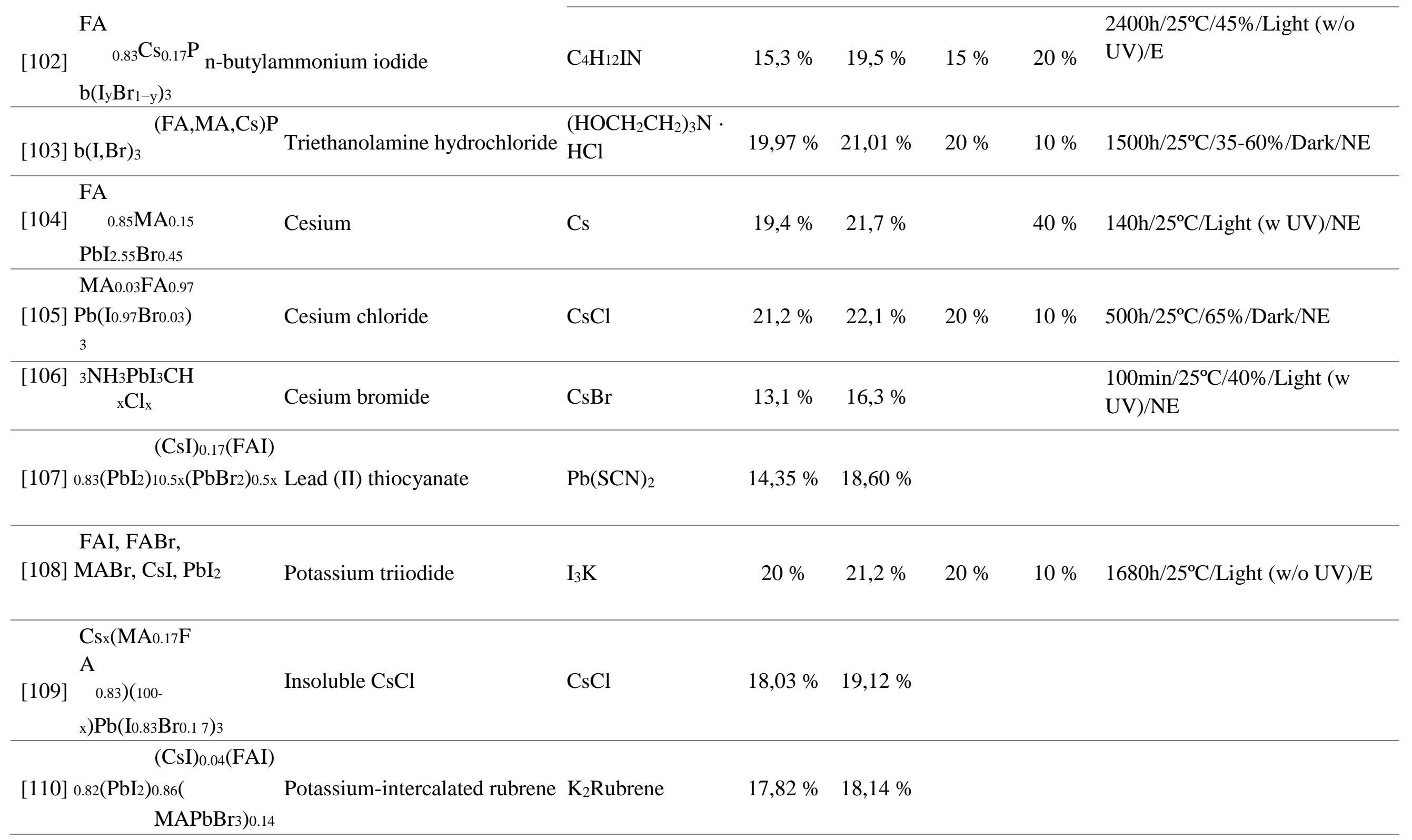




\begin{tabular}{|c|c|c|c|c|c|c|c|}
\hline$[111] \mathrm{MAPbI}_{3}$ & Calcium iodide & $\mathrm{CaI}_{2}$ & $16,7 \%$ & \multicolumn{2}{|l|}{19,25} & $7 \%$ & $\begin{array}{l}300 \mathrm{~h} / 25^{\circ} \mathrm{C} / 40 \% / \text { Light } \\
\mathrm{UV} / \mathrm{NE}\end{array}$ \\
\hline [112] $\mathrm{MAPbI}_{3}$ & n-Butylammonium iodide & $\mathrm{C}_{16} \mathrm{H}_{36} \mathrm{IN}$ & 17,75 & $\% \quad 19,56 \%$ & $30 \%$ & $5 \%$ & $100 \mathrm{~h} / 95^{\circ} \mathrm{C} / \mathrm{Dark} / \mathrm{NE}$ \\
\hline [113] $\mathrm{MAPbI}_{3}$ & Zinc Chloride & $\mathrm{ZnCl}_{2}$ & 16,49 & $18,2 \%$ & $56 \%$ & $7 \%$ & $720 \mathrm{~h} / 25^{\circ} \mathrm{C} / 30 \% / \mathrm{Dark} / \mathrm{NE}$ \\
\hline [114] $\mathrm{MAPbI}_{3}$ & Aluminium acetylacetonate & $\mathrm{Al}\left(\mathrm{C}_{5} \mathrm{H}_{7} \mathrm{O}_{2}\right)_{3}$ & $17,1 \%$ & $19,1 \%$ & & & \\
\hline $\begin{array}{r}\mathrm{Csx}(\mathrm{MA} 0.17 \mathrm{~F} \\
[115] \mathrm{A} 0.83)(100 \mathrm{x}) \mathrm{Pb}( \\
\mathrm{I} 0.83 \mathrm{Br} 0.17) 3\end{array}$ & $\begin{array}{l}\text { Cesium as additive into triple } \\
\text { perovskite }\end{array}$ & Cs & $17,42 \%$ & $20,96 \%$ & $60 \%$ & $10 \%$ & $250 \mathrm{~h} / 25^{\circ} \mathrm{C} / 40 \% / \mathrm{Dark} / \mathrm{NE}$ \\
\hline$[116] \mathrm{MAPbI}_{3}$ & Potassium & $\mathrm{K}$ & $19,21 \%$ & $20,56 \%$ & & & $1000 \mathrm{~h} / 25^{\circ} \mathrm{C} / 10 \% / \mathrm{NE}$ \\
\hline \begin{tabular}{cl}
\multicolumn{2}{|c}{$\mathrm{FA}$} \\
{$[117] \quad{ }_{0.8 \mathrm{Cs} 0.2 \mathrm{~Pb}(}$} \\
$\left.\mathrm{I}_{1-\mathrm{x} B r}\right)_{3}$
\end{tabular} & Lead (II) thiocyanate & $\mathrm{Pb}(\mathrm{SCN})_{2}$ & $14,20 \%$ & $17,18 \%$ & & & \\
\hline [118] $\mathrm{MAPbI}_{\mathrm{x}} \mathrm{Cl}_{3-\mathrm{x}}$ & Indium (III) chloride & $\mathrm{InCl}_{3}$ & $12,61 \%$ & $17,55 \%$ & & & $350 \mathrm{~h} / 25^{\circ} \mathrm{C} / 40 \% / \mathrm{Dark} / \mathrm{NE}$ \\
\hline [119] $\mathrm{MAPbI}_{3}$ & Hydrogen iodide & $\mathrm{HI}$ & $14,30 \%$ & $17,60 \%$ & & & \\
\hline$[120] \mathrm{MAPbI}_{3}$ & $\begin{array}{l}\text { 1,1,1-trifluoro-ethyl ammonium } \\
\text { iodide }\end{array}$ & $\mathrm{CF}_{3} \mathrm{CH}_{2} \mathrm{I}$ & $15,60 \%$ & $18 \%$ & & & \\
\hline $\begin{array}{cc}\text { [121] } & (\mathrm{FAPbI} \\
& 3)_{x}(\mathrm{M} \\
\mathrm{APbBr} 3) 1-x\end{array}$ & Theophylline & $\mathrm{C}_{7} \mathrm{H}_{8} \mathrm{~N}_{4} \mathrm{O}_{2}$ & $19,34 \%$ & $21,32 \%$ & $80 \%$ & $10 \%$ & $500 \mathrm{~h} / 40^{\circ} \mathrm{C} / 40 \% /$ Light (w/o UV)/E \\
\hline [122] $\mathrm{MAPbI}_{3}$ & Lead (II) thiocyanate & $\mathrm{Pb}(\mathrm{SCN})_{2}$ & $16,41 \%$ & $18,15 \%$ & & & \\
\hline $\begin{array}{c}\left(\mathrm{FAPbI}_{3}\right)_{0.85} \\
{[123]\left(\mathrm{MAPbBr}_{3}\right)_{0.1} \mathrm{I}} \\
{ }_{5}\end{array}$ & Lead (II) iodide & $\mathrm{PbI}_{2}$ & $17,7 \%$ & $19 \%$ & & & \\
\hline
\end{tabular}


$\left(\mathrm{FAPbI}_{3}\right)_{0.85}$

[124] $\left(\mathrm{MAPbBr}_{3}\right)_{0.1}$ Lead (II) iodide

$\mathrm{PbI}_{2}$

$18,12 \%$

5

Cs0.06FA0.79M

[125] $\mathrm{A}_{0.15} \mathrm{~Pb}\left(\mathrm{I}_{0.85} \mathrm{~B}\right.$ Potassium Iodide

KI

$17,3 \% \quad 21,5 \% \quad 30 \%$

$20 \%$

$350 \mathrm{~h} / 25^{\circ} \mathrm{C} / 45 \% /$ Light (w UV)/NE

r0.15)3

(FAPbI

[126]

$\left.{ }_{3}\right)_{0.85}($ Potassium Iodide

KI

$20,55 \%$

MAPbBr3) 0.15

(FAPbI

[127]

3) ${ }_{0.85}($ Potassium Iodide

KI

$19,10 \% \quad 19,26 \%$

$\mathrm{MAPbBr} 3)_{0.15}$

$\mathrm{BA} x(\mathrm{FA} 0.83 \mathrm{Cs}$

[128] 0.17) ${ }_{1-\mathrm{xPb}}(\mathrm{I} 0.6 \mathrm{~B}$ (iso-butylammonium iodide) and

formammi-dinium iodide

iBAI and FAI

$21,7 \%$

$13 \%$

$912 \mathrm{~h} / 25^{\circ} \mathrm{C} / 20-75 \% / \mathrm{Dark} / \mathrm{NE}$

$\mathrm{r} 0.4)_{3}$

[129] $0.85 \mathrm{MA} 0.1 \mathrm{C}$ FA

$\mathrm{S} 0.05 \mathrm{PbI} 2.7 \mathrm{Br} 0.3$ Potassium Iodide

KI

$17,99 \% \quad 18,20 \%$

(Cs0.05FA0.54

[130] MA0.41) $\mathrm{Pb}(\mathrm{I} 0.9$ Sodium Fluoride

$\mathrm{NaF}$

$19,68 \% \quad 21,92 \%$

$20 \%$

$5 \%$

$1000 \mathrm{~h} / 25^{\circ} \mathrm{C} / 45 \% /$ Light (w/o 8Bro.02)3

(FA,MA,Cs)P

$[131] \mathrm{b}(\mathrm{I}, \mathrm{Br})_{3}(\mathrm{Cl})$ Europium(III) oxide

$\mathrm{Eu}_{2} \mathrm{O}_{3}$

$20,9 \%$

$9 \%$

$500 \mathrm{~h} / 25^{\circ} \mathrm{C} / 45 \% / \mathrm{Light}$ (w/o

(CsFAMA) $\mathrm{Pb}$

[132]

$(\mathrm{IBr})_{3}$

Rubidium iodide

$\mathrm{RbI}$

$21,8 \%$

$5 \% \quad 500 \mathrm{~h} / 85^{\circ} \mathrm{C} / \mathrm{Light}(\mathrm{w} / \mathrm{o} \mathrm{UV}) / \mathrm{NE}$ 


\begin{tabular}{|c|c|c|c|c|c|c|c|}
\hline [133] $\mathrm{MAPbI}_{3}$ & Magnesium iodide & $\mathrm{MgI}_{2}$ & & $17,8 \%$ & & $10 \%$ & $600 \mathrm{~h} / 25^{\circ} \mathrm{C} / 40 \% / \mathrm{Dark} / \mathrm{NE}$ \\
\hline$[134] \mathrm{MAPbI}_{3}$ & Nickel(II) chloride & $\mathrm{NiCl}_{2}$ & $17,25 \%$ & $20,6 \%$ & & & \\
\hline$[135] \mathrm{MAPbI}_{3}$ & $\begin{array}{l}\text { Butylphosphonic acid 4ammonium } \\
\text { chloride }\end{array}$ & $\mathrm{C}_{4} \mathrm{H}_{13} \mathrm{ClNO}_{3} \mathrm{P}$ & $8,8 \%$ & $16,55 \%$ & $60 \%$ & $20 \%$ & $360 \mathrm{~h} / 25^{\circ} \mathrm{C} / 55 \% / \mathrm{Dark} / \mathrm{NE}$ \\
\hline$[136] \mathrm{MAPbI}_{3}$ & Monoammonium zinc porphyrin & $\mathrm{ZnP}$ & $17,8 \%$ & $19,4 \%$ & & $10 \%$ & $1000 \mathrm{~h} / 85^{\circ} \mathrm{C} / 45 \% / \mathrm{NE}$ \\
\hline [137] ${ }_{1}^{\mathrm{n}-1 \mathrm{Pbn} \mathrm{I}_{3 \mathrm{n}+}}$ & Zinc phthalocyanine & $\mathrm{C}_{32} \mathrm{H}_{16} \mathrm{~N}_{8} \mathrm{Zn}$ & $19 \%$ & $20,3 \%$ & $90 \%$ & $10 \%$ & $1000 \mathrm{~h} / 85^{\circ} \mathrm{C} / 45 \% / \mathrm{Dark} / \mathrm{NE}$ \\
\hline$[138] \mathrm{MAPbI}_{3-x} \mathrm{Cl}_{x}$ & $\mathrm{HPbI}_{3}$ & $\mathrm{HPbI}_{3}$ & $15,36 \%$ & $18,59 \%$ & $39,6 \%$ & $28,4 \%$ & $1008 \mathrm{~h} / 25^{\circ} \mathrm{C} / 30 \% / \mathrm{Dark} / \mathrm{NE}$ \\
\hline$[139] \begin{array}{l}\text { (FAPbI } \\
\text { APbBr3 })_{1-x}(\mathrm{M}\end{array}$ & $\begin{array}{l}\text { organic ammoniums } \\
\text { (nbutylammonium (BA), } \\
\text { octylammonium (OCA), and } \\
\text { oleylammonium (OLA)) }\end{array}$ & $\begin{array}{l}\mathrm{C}_{4} \mathrm{H}_{12} \mathrm{IN}, \mathrm{C}_{8} \mathrm{H}_{20} \mathrm{IN} \\
\text { and } \mathrm{C}_{18} \mathrm{H}_{38} \mathrm{IN}\end{array}$ & $13,13 \%$ & $16,58 \%$ & $50 \%$ & $10 \%$ & $4000 \mathrm{~h} / 25^{\circ} \mathrm{C} / 30 \% /$ Dark $/ \mathrm{NE}$ \\
\hline \multicolumn{8}{|l|}{ ACIDS } \\
\hline$[140] \mathrm{MAPbI}_{3}$ & $\begin{array}{l}\gamma \text {-Aminobutyric acid and Hydriodic } \\
\text { acid }\end{array}$ & $\begin{array}{l}\mathrm{CNH}_{2}\left(\mathrm{CH}_{2}\right)_{3} \mathrm{COOH} \\
\text { and } \mathrm{HI}\end{array}$ & $16,34 \%$ & $17,35 \%$ & $32 \%$ & $9 \%$ & $312 \mathrm{~h} / 25^{\circ} \mathrm{C} / 75 \% / \mathrm{Dark} / \mathrm{NE}$ \\
\hline$[141] \mathrm{MAPbI}_{3}$ & Terephthalic acid & $\mathrm{C}_{8} \mathrm{H}_{6} \mathrm{O}_{4}$ & $15,53 \%$ & $18,51 \%$ & $80 \%$ & $49 \%$ & $35 \mathrm{~h} / 25^{\circ} \mathrm{C} / 30 \% / \mathrm{Dark} / \mathrm{NE}$ \\
\hline $\begin{array}{r}(\mathrm{FAI})_{0.81}\left(\mathrm{PbI}_{2}\right. \\
[142])_{0.85}(\mathrm{MABr})_{0.1} \\
\text { bromo } 1\end{array}$ & $\begin{array}{l}\text { Lewis base } \mathrm{BrPh}-\mathrm{ThR} \text { and Lewis } \\
\text { acid bis-PCBM }\left(\mathrm{N}-\left(45\left(\mathrm{PbBr}_{2}\right)_{0.15}\right.\right. \\
\text { phenyl)thiourea) }\end{array}$ & & $19,30 \%$ & $21,70 \%$ & $68 \%$ & $8 \%$ & $\begin{array}{l}3600 \mathrm{~h} / 25^{\circ} \mathrm{C} / 20 \% / \text { Light (w/o } \\
\mathrm{UV}) / \mathrm{NE}\end{array}$ \\
\hline$\left[\begin{array}{c}\mathrm{FA} \\
{[143]{ }_{\mathrm{bI}_{3}}{ }_{0.85} \mathrm{Cs}_{0.15} \mathrm{P}}\end{array}\right.$ & Phosphoric acid & $\mathrm{H}_{3} \mathrm{PO}_{4}$ & $15,20 \%$ & $17,70 \%$ & & & \\
\hline
\end{tabular}




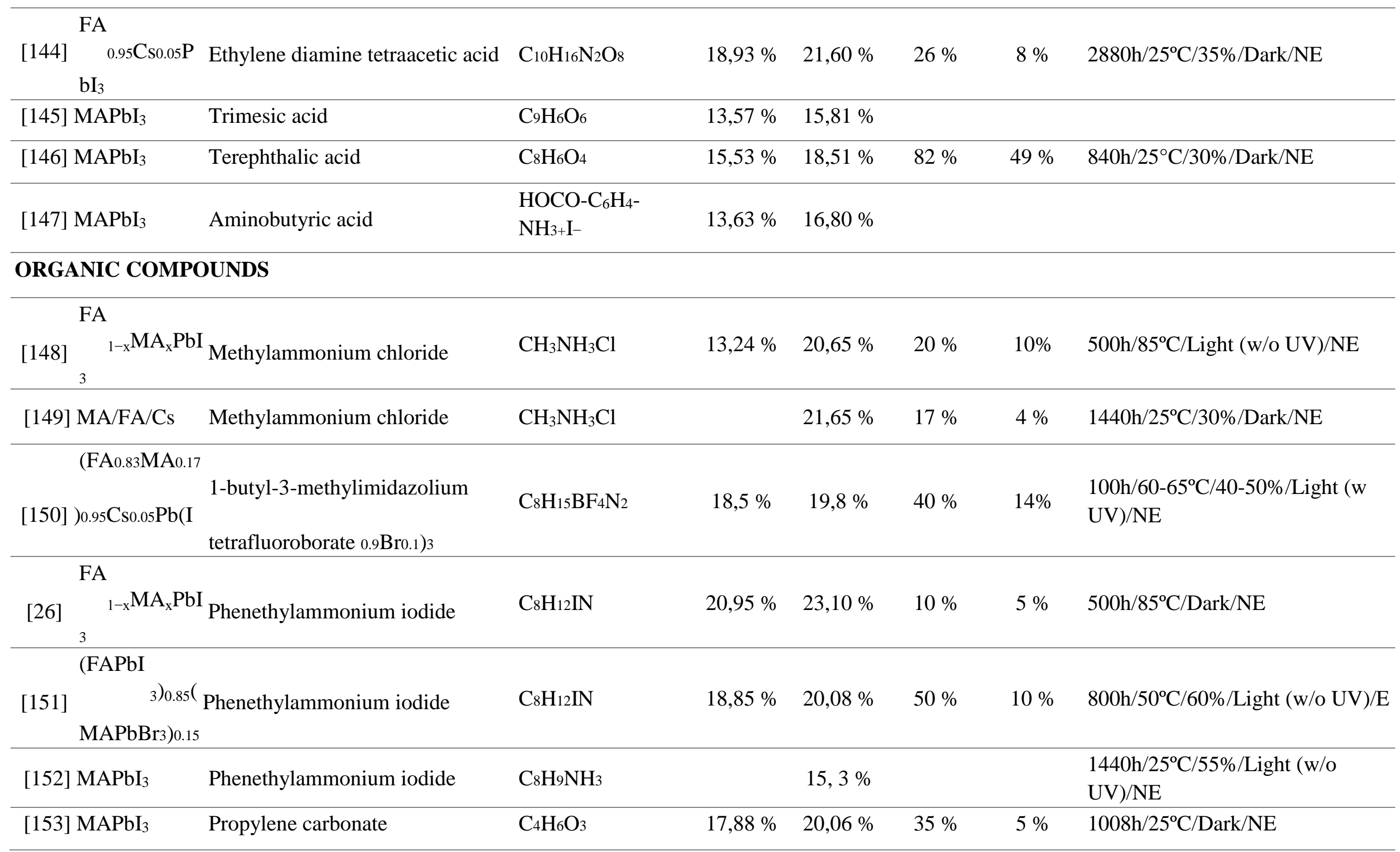




\begin{tabular}{|c|c|c|c|c|c|c|c|}
\hline [154] $\mathrm{MAPbI}_{3}$ & Urea & $\mathrm{CH}_{4} \mathrm{~N}_{2} \mathrm{O}$ & $17,34 \%$ & $18,55 \%$ & $43 \%$ & $35 \%$ & $648 \mathrm{~h} / 25^{\circ} \mathrm{C} / \mathrm{Dark} / \mathrm{NE}$ \\
\hline \begin{tabular}{cc}
\multicolumn{2}{c}{ FA } \\
{$[155]$} & $0.83 \mathrm{MA} 0.17$ \\
& $\mathrm{PbI} 2.51 \mathrm{Br} 0.49$
\end{tabular} & $\begin{array}{l}\text { 2-(6-bromo-1,3-dioxo- } \\
\text { 1Hbenzo[de]isoquinolin- } \\
\text { 2(3H)yl)ethan-1-ammonium } \\
\text { iodide (2- } \\
\text { NAM) }\end{array}$ & 2-NAM & $18,6 \%$ & $20,0 \%$ & $51 \%$ & $35 \%$ & $\begin{array}{l}144 \mathrm{~h} / 25^{\circ} \mathrm{C} / 60 \% / \mathrm{Light}(\mathrm{w} / \mathrm{o} \\
\mathrm{UV}) / \mathrm{NE}\end{array}$ \\
\hline [156] $\mathrm{MAPbI}_{3}$ & $\begin{array}{l}\text { Methylammonium acetate and } \\
\text { thio-semicarbazide }\end{array}$ & $\begin{array}{l}\mathrm{CH}_{3} \mathrm{NH}_{2} \cdot \\
\mathrm{CH}_{3} \mathrm{COOH} \text { and } \\
\mathrm{CH}_{5} \mathrm{~N}_{3} \mathrm{~S}\end{array}$ & & $19,19 \%$ & & $10 \%$ & $\begin{array}{l}1000 \mathrm{~h} / 25^{\circ} \mathrm{C} / 25 \% / \text { Light (w/o } \\
\mathrm{UV}) / \mathrm{NE}\end{array}$ \\
\hline \begin{tabular}{cc}
\multicolumn{2}{c}{$(\mathrm{FAPbI}$} \\
{$[157]$} & $3)^{0.87(}($ \\
& $\mathrm{MAPbBr} 3)_{0.13}$
\end{tabular} & $\begin{array}{l}\text { Formamidinium chloride and } \\
\text { 1adamantylamine hydrochloride }\end{array}$ & $\begin{array}{l}\mathrm{HN}=\mathrm{CHNH}_{2} \cdot \mathrm{HCl} \\
\cdot \text { and } \mathrm{C}_{10} \mathrm{H}_{17} \mathrm{~N} \cdot \\
\mathrm{HCl}\end{array}$ & $19,43 \%$ & $21,2 \%$ & $33 \%$ & $12 \%$ & $700 \mathrm{~h} / 25^{\circ} \mathrm{C} / 40 \% / \mathrm{Dark} / \mathrm{NE}$ \\
\hline$[158] \mathrm{FAI} \cdot \mathrm{PbI}_{3}$ & $\begin{array}{l}\text { Methylammonium chloride and } \\
\text { N-methyl-2-pyrrolidone }\end{array}$ & $\begin{array}{l}\mathrm{CH}_{3} \mathrm{NH}_{3} \mathrm{Cl} \text { and } \\
\mathrm{C}_{5} \mathrm{H}_{9} \mathrm{NO}\end{array}$ & $15,68 \%$ & $19,38 \%$ & & $10 \%$ & $5520 \mathrm{~h} / 25^{\circ} \mathrm{C} / 20 \% / \mathrm{Dark} / \mathrm{NE}$ \\
\hline [159] $\mathrm{MAPbI}_{3}$ & Trimethylammonium chloride & $\left(\mathrm{CH}_{3}\right)_{3} \mathrm{~N} \cdot \mathrm{HCl}$ & $18,67 \%$ & $20,36 \%$ & $20 \%$ & $10 \%$ & $600 \mathrm{~h} / 25^{\circ} \mathrm{C} / 70 \% / \mathrm{Dark} / \mathrm{E}$ \\
\hline $\begin{array}{r}\mathrm{Cs} 0.05(\mathrm{FA} 0.83 \\
\left.\left.[160] \mathrm{MA}_{0.17}\right)_{0.95}\right]_{0.9} \\
\mathrm{~Pb}\left(\mathrm{I}_{0.83} \mathrm{Br} 0.17\right)\end{array}$ & t-Butylammonium iodide & $\mathrm{C}_{4} \mathrm{H}_{12} \mathrm{IN}$ & $18,67 \%$ & $20,62 \%$ & $37 \%$ & $20 \%$ & $\begin{array}{l}1174 \mathrm{~h} / 45-50^{\circ} \mathrm{C} / 45-55 \% / \text { Light } \\
\text { (w/o UV)/NE }\end{array}$ \\
\hline [161] MAPbI 3 & Pyrrole & $\mathrm{C}_{4} \mathrm{H}_{5} \mathrm{~N}$ & $18,58 \%$ & $20,07 \%$ & $26 \%$ & $10 \%$ & $768 \mathrm{~h} / 25^{\circ} \mathrm{C} / 30 \% / \mathrm{Dark} / \mathrm{NE}$ \\
\hline $\begin{array}{l}\mathrm{FA}^{2} \\
{[162]{ }^{0.88} \mathrm{Cs} 0.12 \mathrm{P}} \\
\mathrm{bI}_{3}\end{array}$ & 2,2'-Bipyridine & $\mathrm{C}_{10} \mathrm{H}_{8} \mathrm{~N}_{2}$ & $17,58 \%$ & $19,02 \%$ & $43 \%$ & $23 \%$ & $192 \mathrm{~h} / 85^{\circ} \mathrm{C} /$ Dark $/ \mathrm{NE}$ \\
\hline$[163] \mathrm{CH}_{3} \mathrm{NH}_{3} \mathrm{PbI}_{3}$ & $\begin{array}{l}\text { Methylammonium chloride and } \\
\text { methylammonium acetate }\end{array}$ & $\begin{array}{l}\mathrm{CH}_{3} \mathrm{NH}_{3} \mathrm{Cl} \text { and } \\
\mathrm{CH}_{3} \mathrm{NH}_{2} .\end{array}$ & $15,6 \%$ & $19,64 \%$ & $20 \%$ & $10 \%$ & $\begin{array}{l}120 \mathrm{~h} / 25^{\circ} \mathrm{C} / 15 \% / \mathrm{Light}(\mathrm{w} / \mathrm{o} \\
\mathrm{UV}) / \mathrm{NE}\end{array}$ \\
\hline $\begin{array}{r}\text { Cs0.05FA0.81M } \\
{[164] \mathrm{A}_{0.14} \mathrm{PbI}_{2.55} \mathrm{Br}}\end{array}$ & Formamidine acetate & $\begin{array}{l}\mathrm{CHHN}=\mathrm{CHNHCOC} \\
2 \cdot \\
\mathrm{CH}_{3} \mathrm{COOH}\end{array}$ & H $20,77 \%$ & $21,81 \%$ & $50 \%$ & $5 \%$ & $300 \mathrm{~h} / 25^{\circ} \mathrm{C} / 60 \% / \mathrm{Dark} / \mathrm{NE}$ \\
\hline
\end{tabular}




\begin{tabular}{|c|c|c|c|c|c|c|c|}
\hline \multicolumn{2}{|c|}{ [165] $\mathrm{CH}_{3} \mathrm{NH}_{3} \mathrm{PbI}_{3}$ 2-Pyridylthiourea } & $\mathrm{C}_{6} \mathrm{H}_{7} \mathrm{~N}_{3} \mathrm{~S}$ & $15,5 \%$ & $18,2 \%$ & $12 \%$ & $8 \%$ & $720 \mathrm{~h} / 25^{\circ} \mathrm{C} / 55 \% / \mathrm{Dark} / \mathrm{NE}$ \\
\hline$[166] \mathrm{MAPbI}_{3}$ & $\begin{array}{l}\text { n-octyltrimethylammonium } \\
\text { bromide }\end{array}$ & $\mathrm{C}_{11} \mathrm{H}_{26} \mathrm{BrN}$ & $15,80 \%$ & $18,32 \%$ & $26 \%$ & $8 \%$ & $720 \mathrm{~h} / 70^{\circ} \mathrm{C} / 40 \% /$ Dark/NE \\
\hline [167] $\mathrm{MAPbI}_{3}$ & Formamidine acetate salt & $\begin{array}{l}\mathrm{HN}=\mathrm{CHNH}_{2} \\
\mathrm{CH}_{3} \mathrm{COOH}\end{array}$ & $12,13 \%$ & $18,90 \%$ & & $10 \%$ & $1920 \mathrm{~h} / 25^{\circ} \mathrm{C} / 40 \% /$ Dark/NE \\
\hline$[168] \mathrm{MAPbI}_{3}$ & Methylammonium chloride & $\mathrm{CH}_{3} \mathrm{NH}_{3} \mathrm{Cl}$ & $17,15 \%$ & $19,71 \%$ & & & \\
\hline [169] $\mathrm{MAPbI}_{3}$ & $\begin{array}{l}\text { Hydroxyl and carbonyl functiona } \\
\text { groups }\end{array}$ & $-\mathrm{OH}$ and $\mathrm{C}=\mathrm{O}$ & $15,67 \%$ & $18,24 \%$ & $84 \%$ & $27 \%$ & $48 \mathrm{~h} / 25^{\circ} \mathrm{C} / 80 \% /$ Dark $/ \mathrm{NE}$ \\
\hline $\begin{array}{rr} & (\mathrm{FAPbI} \\
{[170]} & 3 \\
& \mathrm{CsPbBr} 3\end{array}$ & Melaminium iodide & $\mathrm{C}_{3} \mathrm{H}_{7} \mathrm{~N}_{6}{ }^{+} \bullet \mathrm{I}^{-} \bullet \mathrm{H}_{2} \mathrm{O}$ & $15,86 \%$ & $17,32 \%$ & $31 \%$ & $15 \%$ & $96 \mathrm{~h} / 25^{\circ} \mathrm{C} / 65 \% / \mathrm{Dark} / \mathrm{NE}$ \\
\hline $\begin{array}{r}\mathrm{Cs}_{0.05}(\mathrm{M} \\
\left.[171] \mathrm{FA}_{0.83}\right)_{0.9} \\
0.83 \mathrm{Br} 0.17\end{array}$ & Potassium thiocyanate & $\mathrm{KSCN}$ & $17,83 \%$ & $19,23 \%$ & $40 \%$ & $10 \%$ & $\begin{array}{l}240 \mathrm{~h} / 25^{\circ} \mathrm{C} / 40 \% / \text { Light (w/o } \\
\mathrm{UV}) / \mathrm{NE}\end{array}$ \\
\hline [172] $\mathrm{MAPbI}_{3}$ & 3,4-dihydroxybenzhydrazide & $\mathrm{C}_{7} \mathrm{H}_{8} \mathrm{~N}_{2} \mathrm{O}_{3}$ & $14,47 \%$ & $17,58 \%$ & $30 \%$ & $15 \%$ & $840 \mathrm{~h} / 25^{\circ} \mathrm{C} / \mathrm{Dark} / \mathrm{NE}$ \\
\hline [173] $\mathrm{MAPbI}_{3}$ & Phenothiazine & $\mathrm{C}_{12} \mathrm{H}_{9} \mathrm{NS}$ & $14,38 \%$ & $15,50 \%$ & & & $168 \mathrm{~h} / 25^{\circ} \mathrm{C} / 50 \% / \mathrm{Dark} / \mathrm{NE}$ \\
\hline [174] $\mathrm{MAPbI}_{3}$ & Potassium thiocyanate & $\mathrm{KSCN}$ & $19,30 \%$ & $19,62 \%$ & & & \\
\hline [175] $\mathrm{MAPbI}_{3}$ & Methylammonium thiocyanate & $\mathrm{C}_{2} \mathrm{H}_{6} \mathrm{~N}_{2} \mathrm{~S}$ & $2,04 \%$ & $18,22 \%$ & $60 \%$ & $10 \%$ & $1000 \mathrm{~h} / 25^{\circ} \mathrm{C} / 25 \% / \mathrm{Dark} / \mathrm{NE}$ \\
\hline$[176] \mathrm{FAPbI}_{3}$ & Methylammonium chloride & $\mathrm{CH}_{3} \mathrm{NH}_{3} \mathrm{Cl}$ & & $23,48 \%$ & & $10 \%$ & $\begin{array}{l}1200 \mathrm{~h} / 40^{\circ} \mathrm{C} / 25 \% / \mathrm{Light}(\mathrm{w} / \mathrm{o} \\
\mathrm{UV}) / \mathrm{NE}\end{array}$ \\
\hline$[177] \mathrm{MAPbI}_{3}$ & Rhodanine & $\mathrm{C}_{3} \mathrm{H}_{3} \mathrm{NOS}_{2}$ & $12,1 \%$ & $20,3 \%$ & $70 \%$ & $15 \%$ & $\begin{array}{l}65 \mathrm{~h} / 25^{\circ} \mathrm{C} / 60 \% / \text { Light (w/o } \\
\mathrm{UV}) / \mathrm{NE}\end{array}$ \\
\hline
\end{tabular}




\begin{tabular}{|c|c|c|c|c|c|c|c|}
\hline$[178] \mathrm{MAPbI}_{3}$ & Methylamine & $\mathrm{CH}_{3} \mathrm{NH}_{2}$ & $16,92 \%$ & $18,82 \%$ & & & $3120 \mathrm{~h} / 25^{\circ} \mathrm{C} / 35 \% /$ Dark/NE \\
\hline [179] $\mathrm{MAPbI}_{3}$ & Copper(I) bromide & $\mathrm{CuBr}$ & $13,7 \%$ & $15,2 \%$ & & & \\
\hline [180] CsFAMA & n-Octyl-ammonium sulfate & $\mathrm{C}_{16} \mathrm{H}_{40} \mathrm{~N}_{2} \mathrm{O}_{4} \mathrm{~S}$ & $19,16 \%$ & $21,1 \%$ & $15,8 \%$ & $3,2 \%$ & $1200 \mathrm{~h} / 65^{\circ} \mathrm{C} / 45 \% /$ Light (w UV)/E \\
\hline $\begin{array}{ll}{[181]} & 0.17 \mathrm{FA} 0.83 \mathrm{P} \mathrm{Cs} \\
\mathrm{b}(\mathrm{I} 0.90 \mathrm{Br} 0.10) 3\end{array}$ & $\begin{array}{l}\text { 1-butyl-1-methylpiperidinium } \\
\text { tetrafluoroborate }\end{array}$ & $\left([\mathrm{BMP}]^{+}[\mathrm{BF} 4]^{-}\right)$ & $17,6 \%$ & $20,1 \%$ & $50 \%$ & $5 \%$ & $\begin{array}{l}1200 \mathrm{~h} / 85^{\circ} \mathrm{C} / 40 \% / \text { Light (w/o } \\
\mathrm{UV}) / \mathrm{NE}\end{array}$ \\
\hline [182] $\mathrm{MAPbI}_{3-\mathrm{x}} \mathrm{Cl}_{\mathrm{x}} \mathrm{I}$ & Methylammonium chloride & $\mathrm{CH}_{3} \mathrm{NH}_{3} \mathrm{Cl}$ & $8,80 \%$ & $15,41 \%$ & & & \\
\hline$[183] \mathrm{FAPbI}_{3}$ & Phenylethylammonium iodide & $\mathrm{C}_{8} \mathrm{H}_{12} \mathrm{IN}$ & & $17,17 \%$ & $50 \%$ & $10 \%$ & $384 \mathrm{~h} / 25^{\circ} \mathrm{C} / 40 \% / \mathrm{Dark} / \mathrm{NE}$ \\
\hline$[184] \mathrm{CsPbI}_{3}$ & Methylammonium iodide & $\mathrm{CH}_{3} \mathrm{NH}_{2} \cdot \mathrm{HI}$ & $6,80 \%$ & $12,10 \%$ & $40 \%$ & $7 \%$ & $720 \mathrm{~h} / 25^{\circ} \mathrm{C} / 60 \% / \mathrm{Dark} / \mathrm{NE}$ \\
\hline$[185] \mathrm{FA}_{0.98} \mathrm{Cs}_{0.02} \mathrm{P}_{\Gamma}$ & $\mathrm{N}$-methyl-2-pyrrolidone $\mathrm{bI}_{3}$ & $\mathrm{C}_{5} \mathrm{H}_{9} \mathrm{NO}$ & & $20,19 \%$ & & & \\
\hline [186] $\mathrm{MAPbI}_{3}$ & Thiourea and ethyl acetate (EA) & $\begin{array}{l}\mathrm{CH}_{4} \mathrm{~N}_{2} \mathrm{~S} \text { and } \\
\mathrm{C}_{4} \mathrm{H}_{8} \mathrm{O}_{2}\end{array}$ & $13,22 \%$ & $17,57 \%$ & $80 \%$ & $15 \%$ & $1200 \mathrm{~h} / 25^{\circ} \mathrm{C} / 50 \% / \mathrm{Dark} / \mathrm{NE}$ \\
\hline [187] $\mathrm{MAPbI}_{3}$ & $\begin{array}{l}\text { Sodium dodecyl benzene } \\
\text { sulfonate }\end{array}$ & $\begin{array}{l}\mathrm{CH}_{3}\left(\mathrm{CH}_{2}\right)_{11} \mathrm{C}_{6} \mathrm{H}_{4} \mathrm{~S} \\
\mathrm{O}_{3} \mathrm{Na}\end{array}$ & $16,26 \%$ & $20,15 \%$ & $20 \%$ & $10 \%$ & $1008 \mathrm{~h} / 25^{\circ} \mathrm{C} / \mathrm{Dark} / \mathrm{NE}$ \\
\hline 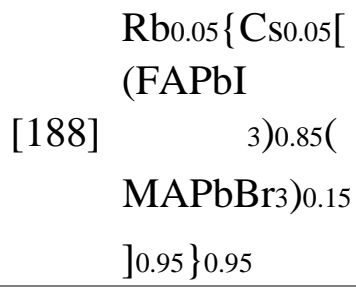 & Thiourea & $\mathrm{CH}_{4} \mathrm{~N}_{2} \mathrm{~S}$ & $17,68 \%$ & $20,92 \%$ & $40 \%$ & $5 \%$ & $100 \mathrm{~h} / 65^{\circ} \mathrm{C} / 30 \% /$ Dark/NE \\
\hline$[189] \mathrm{MAPbI}_{3}$ & Thiourea & $\mathrm{CH}_{4} \mathrm{~N}_{2} \mathrm{~S}$ & $18,08 \%$ & $19,57 \%$ & $63 \%$ & $2 \%$ & $\begin{array}{l}1440 \mathrm{~h} / 25^{\circ} \mathrm{C} / 20 \% / \mathrm{Light}(\mathrm{w} / \mathrm{o} \\
\mathrm{UV}) / \mathrm{NE}\end{array}$ \\
\hline [190] $\mathrm{MAPbI}_{3}$ & Methylammonium chloride & $\mathrm{CH}_{3} \mathrm{NH}_{3} \mathrm{Cl}$ & $15,5 \%$ & $18,2 \%$ & & $30 \%$ & $40 \mathrm{~h} / 85^{\circ} \mathrm{C} / 65 \% / \mathrm{NE}$ \\
\hline
\end{tabular}




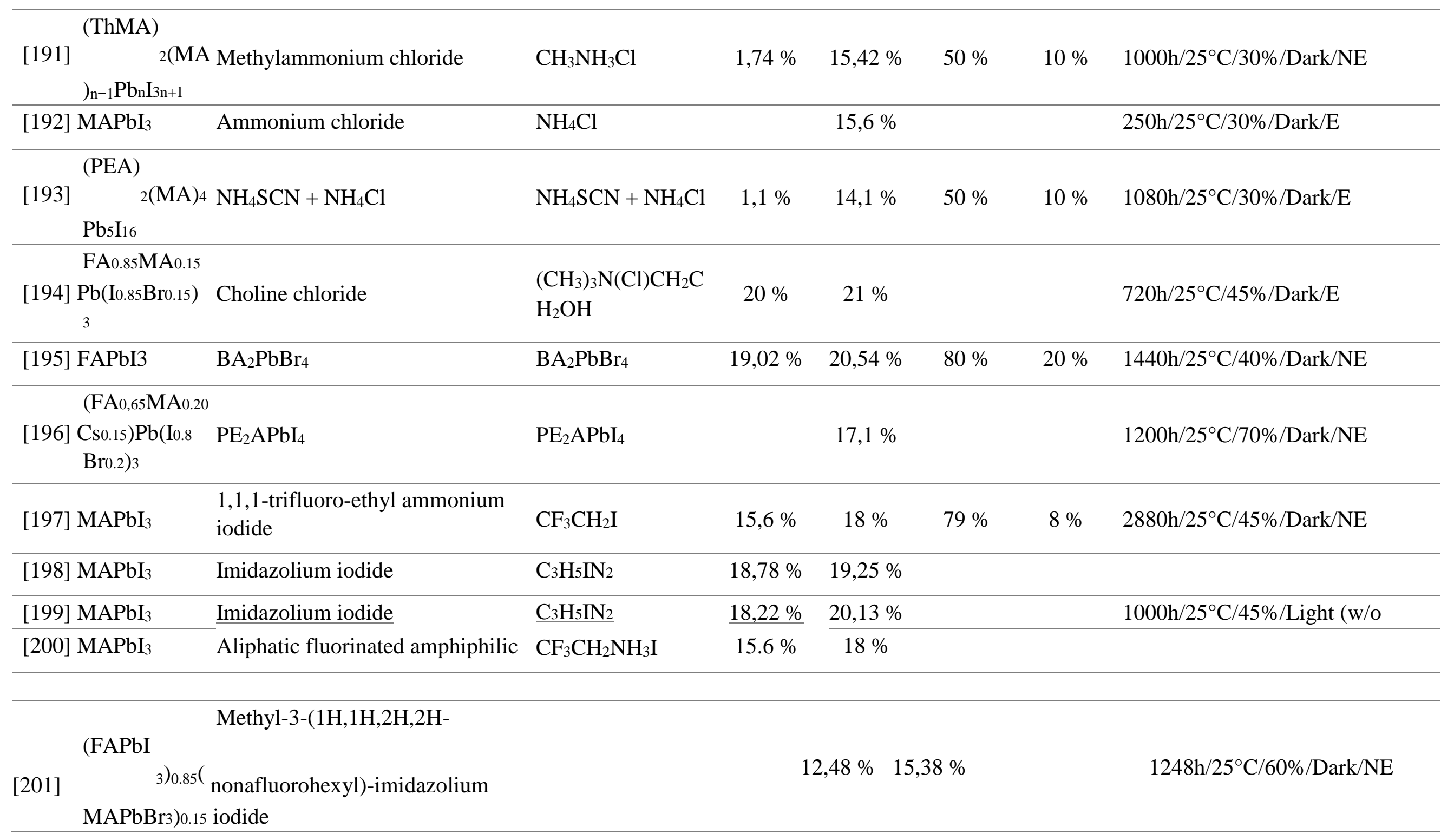


$\mathrm{Cs}_{0.05}\left(\mathrm{MA}_{0.15}\right.$ Methyl-3-(1H,1H,2H,2H-

[202] $\left.\mathrm{FA}_{0.85}\right)_{0.95} \mathrm{~Pb}$ (I nonafluorohexyl)-imidazolium $\left.{ }_{0.85} \mathrm{Br}_{0.15}\right)_{3} \quad$ iodide $\left[\begin{array}{ll}\text { 1-methyl-3-(1H,1H,2H,2Hnonafluorohexyl) } & \\ \text { imidazolium Iodide with }-\mathrm{CH}_{2}-\mathrm{CH}=\mathrm{CH}_{2}\end{array}\right.$

$\begin{array}{lllll}17,92 \% & 19,14 \% \quad 65 \% \quad 45 \% & \begin{array}{l}460 \mathrm{~h} / 25^{\circ} \mathrm{C} / 45 \% / \mathrm{Light}(\mathrm{w} / \mathrm{o} \\ \mathrm{UV}) / \mathrm{NE}\end{array}\end{array}$

[204] $\mathrm{MAPbI}_{3}$ 1-ethylamine hydrobromide-3methylimidazolium hexafluorophosphate

$10,08 \% \quad 13,01 \% \quad 48 \% \quad 6 \% \quad 840 \mathrm{~h} / 25^{\circ} \mathrm{C} / 20 \% / \mathrm{Dark} / \mathrm{NE}$

Salt 1-(4-ethenylbenzyl)-

[205] $\mathrm{MAPbI}_{3} \quad 3(3,3,4,4,5,5,6,6,7,7,8,8,8$ tridecafluorooctylimida-

zolium iodide

$19,21 \% \quad 19,51 \% \quad 51 \% \quad 17 \% \quad$\begin{tabular}{l}
$700 \mathrm{~h} / 60^{\circ} \mathrm{C} / 45 \% / \mathrm{Light}$ \\
\hline
\end{tabular}

\begin{tabular}{|c|c|c|c|c|c|c|c|}
\hline [206] $\mathrm{MAPbI}_{3}$ & Lead salt of pyridine-2carboxylate & $\mathrm{PbPyA}_{2}$ & $18,86 \%$ & $19,96 \%$ & $76,4 \%$ & $20 \%$ & $480 \mathrm{~h} / 90^{\circ} \mathrm{C} / 60 \% / \mathrm{Dark} / \mathrm{NE}$ \\
\hline [207] $\mathrm{MAPbI}_{3}$ & Methylammonium formate & $\mathrm{C}_{2} \mathrm{H}_{7} \mathrm{NO}_{2}$ & $19,1 \%$ & $19,5 \%$ & & & \\
\hline
\end{tabular}

\section{OTHERS}

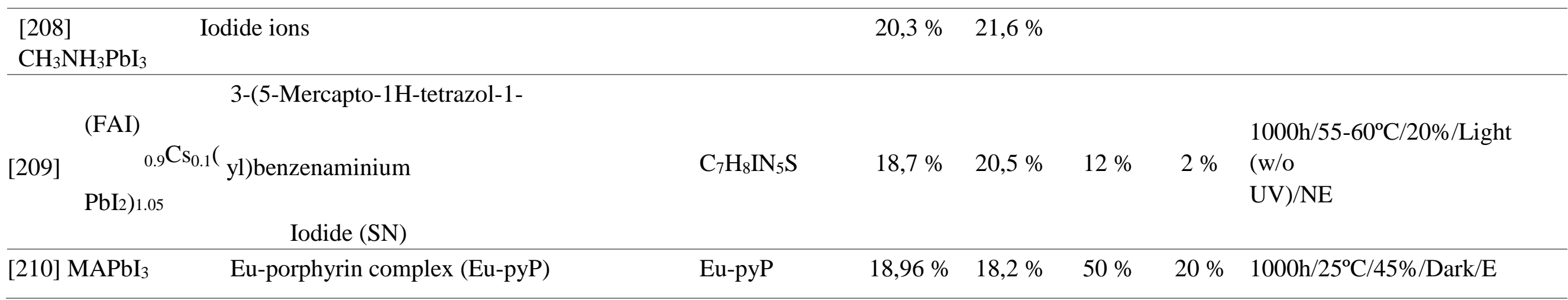


1-alkyl-4-amino-1,2,4-triazolium"

(termed as RATZ; R represents

[211] $\mathrm{MAPbI}_{3}$

alkyl chain, and ATZ represents 4amino-1,2,4-

$16,13 \% \quad 20,03 \% \quad 30 \% \quad 20 \% \quad 3200 \mathrm{~h} / 25^{\circ} \mathrm{C} / 40 \% / \mathrm{Dark} / \mathrm{NE}$ triazolium

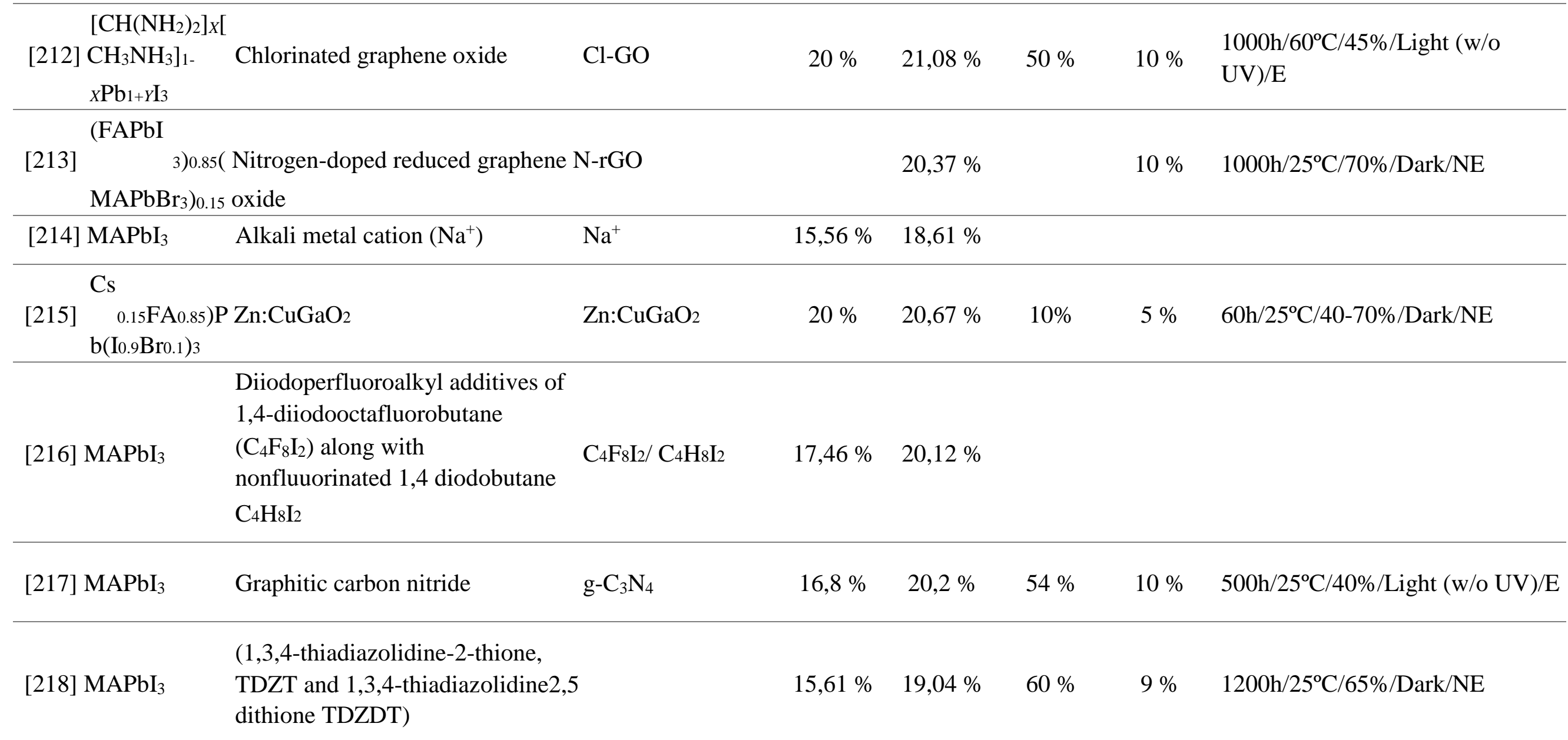




\begin{tabular}{|c|c|c|c|c|c|c|}
\hline [219] $\mathrm{MAPbI}_{3}$ & $\begin{array}{l}\text { Lithium } \\
\text { bis(trifluoromethanesulfonyl)imid } \\
\text { e (LiTFSI) and 4-tertbutylpyridine } \\
\text { (tBP) }\end{array}$ & $11,02 \%$ & $18,17 \%$ & $50 \%$ & $10 \%$ & $960 \mathrm{~h} / 25^{\circ} \mathrm{C} / 30 \% / \mathrm{Dark} / \mathrm{NE}$ \\
\hline$[220] \mathrm{MAPbI}_{3}$ & $\begin{array}{l}\text { 6,6,12,12-tetrakis(4-hexylphenyl) } \\
\text { indacenobis(dithieno[3,2-b;2',3'd]thiophene) } \\
\text { end-capped by 3- } \quad(1,1- \\
\text { dicyanomethylene)-5/6fluoro-1-indanone } \\
\text { terminal groups }\end{array}$ & $19,60 \%$ & $21,70 \%$ & $80 \%$ & $30 \%$ & $1440 \mathrm{~h} / 25^{\circ} \mathrm{C} / 40 \% /$ Dark/NE \\
\hline [221] $\mathrm{MAPbI}_{3}$ & $\mathrm{CsPbBrCl}_{2}$ QDs & $20,60 \%$ & $21,50 \%$ & $60 \%$ & $20 \%$ & $500 \mathrm{~h} / 25^{\circ} \mathrm{C} / 50 \% / \mathrm{Light}(\mathrm{w} / \mathrm{o} \mathrm{UV}) / \mathrm{E}$ \\
\hline [222] $\mathrm{CsPbI}_{2} \mathrm{Br}$ & Europium-Doped & $10,21 \%$ & $13,71 \%$ & & $7 \%$ & $\begin{array}{l}370 \mathrm{~h} / 25^{\circ} \mathrm{C} / 40 \% / \mathrm{Light}(\mathrm{w} / \mathrm{o} \\
\mathrm{UV}) / \mathrm{NE}\end{array}$ \\
\hline [223] $\mathrm{MAPbI}_{3}$ & 1,3,7-trimethylxanthine & $17,59 \%$ & $20,25 \%$ & $40 \%$ & $14 \%$ & $1300 \mathrm{~h} / 85^{\circ} \mathrm{C} / \mathrm{Light}$ (w/o UV)/NE \\
\hline $\begin{array}{l}\text { [224] }{ }_{3} \mathrm{NH}_{3} \mathrm{PbI}_{3} \mathrm{CH} \\
{ }_{x} \mathrm{Cl}_{\mathrm{x}}\end{array}$ & $\mathrm{ICH}_{2}\left(\mathrm{CH}_{2}\right)_{6} \mathrm{CH}_{2} \mathrm{I}$ & $7,90 \%$ & $10,30 \%$ & & & \\
\hline
\end{tabular}


(phenyl-C61-butyric acid methyl

ester) (PCBM), (3,9-bis(2methylene-

(3-(1,1dicyanomethylene)-

indanone) )5,5,11,11-tetrakis(4-

hexylphenyl)dithieno[2,3-d:2',3'-d']-

[225] $\mathrm{MAPbI}_{3}$

sindaceno[1,2-b:5,6-

$17,52 \% \quad 19,28 \% \quad 50 \% \quad 13 \% \quad 960 \mathrm{~h} / 25^{\circ} \mathrm{C} / 50 \% / \mathrm{Dark} / \mathrm{NE}$

b']dithiophene) (ITIC), 7,7'-[4,4Bis(2-ethylhexyl)-

4H-silolo[3,2b:4,5-b']dithiophene- 2,6diyl]bis[6-

fluoro-4-(5'-hexyl-[2,2'bithiophen]-5-yl)benzo[c]

$[1,2,5]$ thiadiazole $])\left(\operatorname{pDTS}\left(\mathrm{FBTTh}_{2}\right)_{2}\right.$

Cs0.05FA0.81M

[226] $\mathrm{A}_{0.14} \mathrm{PbI}_{2.55} \mathrm{Br} \mathrm{D}-4$-tert-butylphenylalanine

$\mathrm{C}_{13} \mathrm{H}_{19} \mathrm{NO}_{2}$

$19,10 \% \quad 21,40 \%$

0.45

\begin{tabular}{|c|c|c|c|c|c|c|c|}
\hline [227] $\mathrm{MAPbI}_{3}$ & 1H,1H-perfluorooctylamine & $\mathrm{C}_{8} \mathrm{H}_{4} \mathrm{~F}_{15} \mathrm{~N}$ & $16,48 \%$ & $21,31 \%$ & $50 \%$ & $5 \%$ & $2500 \mathrm{~h} / 25^{\circ} \mathrm{C} / 75 \% / \mathrm{Dark} / \mathrm{NE}$ \\
\hline [228] $\mathrm{MAPbI}_{3}$ & Methimazole & $\mathrm{C}_{4} \mathrm{H}_{6} \mathrm{~N}_{2} \mathrm{~S}$ & $17,48 \%$ & $19,57 \%$ & $50 \%$ & $20 \%$ & $\begin{array}{l}700 \mathrm{~h} / 25^{\circ} \mathrm{C} / 45 \% / \mathrm{Light}(\mathrm{w} / \mathrm{o} \\
\mathrm{UV}) / \mathrm{NE}\end{array}$ \\
\hline [229] $\mathrm{MAPbI}_{3}$ & $\begin{array}{l}\text { Nonfullerene small molecule } \\
\text { (IT4F) }\end{array}$ & & $15,59 \%$ & $18,35 \%$ & $59,8 \%$ & $20,2 \%$ & $792 \mathrm{~h} / 15^{\circ} \mathrm{C} / 10 \% / \mathrm{Dark} / \mathrm{NE}$ \\
\hline $\begin{array}{r}\text { Cso.05FA } \\
{[230] \mathrm{A}_{0.14} \mathrm{PbBr}} \\
2.55\end{array}$ & 3-alkylthiophene & $\mathrm{C}_{10} \mathrm{H}_{16} \mathrm{~S}$ & $18,08 \%$ & $19,89 \%$ & $50 \%$ & $20 \%$ & $700 \mathrm{~h} / 25^{\circ} \mathrm{C} / 40 \% /$ Dark/NE \\
\hline [231] $\mathrm{CsPbI}_{2} \mathrm{Br}$ & Carbide-metal oxide (C-MOX) & $(\mathrm{C}-\mathrm{MOX})$ & & $14 \%$ & & $10 \%$ & $1000 \mathrm{~h} / 45^{\circ} \mathrm{C} / 45 \% /$ Dark/E \\
\hline
\end{tabular}




\begin{tabular}{|c|c|c|c|c|c|c|c|}
\hline [232] $\mathrm{MAPbI}_{3}$ & 2-Pyridylthiourea & $\mathrm{C}_{6} \mathrm{H}_{7} \mathrm{~N}_{3} \mathrm{~S}$ & $15,5 \%$ & $18,2 \%$ & $60 \%$ & $8 \%$ & $720 \mathrm{~h} / 25^{\circ} \mathrm{C} / 55 \% /$ Dark/NE \\
\hline$[233] \mathrm{MAPbI}_{3}$ & 1,3,4-thiadiazolidine-2,5-dithione & $\mathrm{C}_{2} \mathrm{H}_{2} \mathrm{~N}_{2} \mathrm{~S}_{3}$ & $15,61 \%$ & $19,04 \%$ & $25,4 \%$ & $9,8 \%$ & $1200 \mathrm{~h} / 25^{\circ} \mathrm{C} / 65 \% / \mathrm{Dark} / \mathrm{NE}$ \\
\hline [234] $\mathrm{MAPbI}_{3}$ & N,N-dibutylaminophenyl & & $18,19 \%$ & $20,09 \%$ & & $14 \%$ & $720 \mathrm{~h} / 25^{\circ} \mathrm{C} / 30 \% /$ Dark/NE \\
\hline$[235] \mathrm{MAPbI}_{3}$ & DRSBDT-2OT and mixed HTM & & $17,13 \%$ & $21,31 \%$ & $43,7 \%$ & $15,9 \%$ & $768 \mathrm{~h} / 25^{\circ} \mathrm{C} / 35 \% / \mathrm{Dark} / \mathrm{NE}$ \\
\hline $\begin{array}{ll}\text { [236] } & \text { FAI/MAI/M } \\
& \mathrm{ACl} / \mathrm{MABr}\end{array}$ & $\begin{array}{l}\text { 6,6,12,12-tetrakis }(4 \\
\text { hexylphenyl)indacenobis(dithieno [ } \\
\text { b;2',3'-d]thiophene) end- capp } \\
\text { (1,1-dicyanomethylene)-5/6-fluoro- } \\
\text { indanone }\end{array}$ & $\begin{array}{l}{[3,2-} \\
\text { ped by } 3- \\
-1-\end{array}$ & $17,9 \%$ & $19,8 \%$ & & & $1440 \mathrm{~h} / 25^{\circ} \mathrm{C} / 45 \% / \mathrm{Dark} / \mathrm{NE}$ \\
\hline [237] $\mathrm{MAPbI}_{3}$ & Guanidine thiocyanate & $\mathrm{C}_{2} \mathrm{H}_{6} \mathrm{~N}_{4} \mathrm{~S}$ & $15,24 \%$ & $16,92 \%$ & & & \\
\hline$[238] \mathrm{A}_{2} \mathrm{PbI}_{4}$ & Pentafluorophenylethylammoniu & FEA m & $20 \%$ & $22,1 \%$ & $57 \%$ & $10 \%$ & $\begin{array}{l}1000 \mathrm{~h} / 25^{\circ} \mathrm{C} / 40 \% / \mathrm{Light}(\mathrm{w} / \mathrm{o} \\
\mathrm{UV}) / \mathrm{NE}\end{array}$ \\
\hline 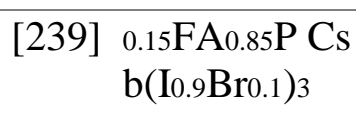 & Lead(II) chloride & $\mathrm{PbCl}_{2}$ & $20,03 \%$ & $21,30 \%$ & $19 \%$ & $5 \%$ & $8760 \mathrm{~h} / 25^{\circ} \mathrm{C} / 40 \% / \mathrm{Dark} / \mathrm{NE}$ \\
\hline
\end{tabular}




\section{Working mechanism of additives in PSCs}

Different inorganic additives can be applied in PSC to passivate defects and enhance device performance. Some examples include the use of potassium Iodide (KI), redox shuttles like the pair $\mathrm{Eu}^{+3} / \mathrm{Eu}^{+2}$, the use of graphene and doped graphene or among others. In general, additives form strong ion bonds with uncoordinated $\mathrm{Pb}^{2+}$ and hydrogen bonds are created between the additive and MA, FA and halide ions to enhance the $\mathrm{Pb}-\mathrm{I}$ bonding and MA-I bonding. In this way, MA, iodine vacancies and other deep defects can be reduced and passivated. At the same time non-radiative recombination and ion migration can be suppressed. The final result is the enhancement of the PCE and the increase of the stability of the final PSCs.

\subsection{Inorganic additives}

PSCs with inorganic additives have attracted great interest recently due of their prominent photoelectric properties and thermal stability for stable, highly efficient

PSCs. Stability improvements have been reported through the incorporation of partial Cs ion in the FA-site leading to the contraction of the cubo-octahedral volume of the perovskite. The partial replacement of the Cs cation by the FA cation results in suppressed charge recombination and was attributed to the reduced trap density being close to the maximum of the valence band, resulting in an increase of the shunt resistance and a decrease in the saturation current [240]. Furthermore, it has been found that the segregation of cations and halides during the growth of mixed halide lead perovskite films is influenced by the formation of two competing phases: an MA-I-rich solvated phase and FA-Br-rich hexagonal phase. The roles of addition of $\mathrm{Cs}^{+}$and $\mathrm{Rb}^{+}$, 
individually and collectively, it is of vital importance on the crystallization of perovskite thin films. The use of these components enables the uniform distribution of halides, preventing the formation of isolated halide- and cation-rich phases. However, the optimal addition of $\mathrm{Cs}^{+}$and $\mathrm{Rb}^{+}$into the perovskite precursor results in well-defined mixed-halide mixed cation perovskite crystals that correlate with excellent device performance. This improved performance is attributed to the synergistic effect of $\mathrm{Cs}^{+}$ and $\mathrm{Rb}^{+}$in suppressing inherent halide segregation by promoting the unique formation of the desired 3C phase (also referred to as $\alpha$ ) during antisolvent dripping [241]. Son et al. (Fig. 6a) demonstrated that adding a small amount of potassium iodide (KI) in HPs is a universal approach toward hysteresis-free PSCs.[129] In 2018, Mojtaba Abdi-Jalebi et al. introduced the same KI additive to triple-cation PSCs. The excess halides filled these vacancies, thereby passivating the non-radiative recombination pathways and leading to high luminescence efficiencies. They discovered that the device power conversion efficiency (PCE) increases from $17.3 \%(x=0)$ to $21.5 \%(x=0.1)$ upon passivation, with the elimination of hysteresis in the latter case consistent with the inhibition of ion migration. This is also consistent with a rapid increase in stabilized efficiency to a value of $21.3 \%$, compared to a slower increase to just $17.2 \%$ for the control. (Fig. 6b) [125]. 
(a)

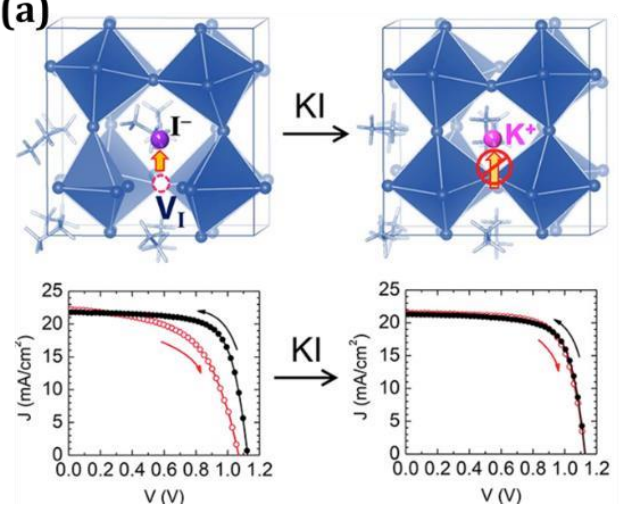

(b)
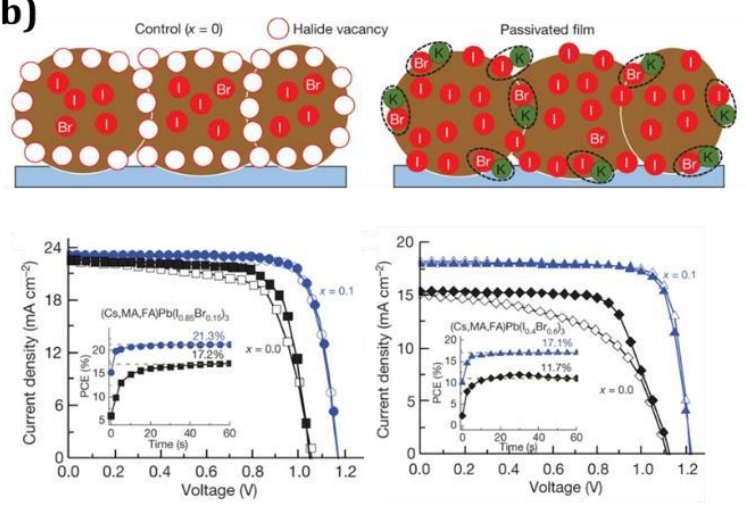

Fig. 6. (a) Eliminating hysteresis by KI additives. KI eliminates the hysteresis by preventing the formation of Frenkel defect. Reproduced with permission. Copyright 2018, American Chemical Society [129]. (b) schematic of a crosssection of a film showing halide-vacancy management in cases of excess halides, in which the surplus halide is immobilized through complexing with potassium into benign compounds at the grain boundaries and surfaces. $\mathrm{J}-\mathrm{V}$ curves in forward (open symbols) and reverse (closed symbols) mode of the best-performing solar cells with (Cs,MA,FA) $\mathrm{Pb}\left(\mathrm{I}_{0.85} \mathrm{Br}_{0.15}\right)_{3}$ and $(\mathrm{Cs}, \mathrm{MA}, \mathrm{FA}) \mathrm{Pb}\left(\mathrm{I}_{0.4} \mathrm{Br}_{0.6}\right)_{3}$ absorbers without $(x=0)$ and with $(x=0.1)$ passivation. Reproduced with permission. Copyright 2018, Springer Nature [125].

The fabrication of PSC through solution processing methods results in the generation of $\mathrm{Pb}^{0}$ and iodine $\mathrm{I}^{0}$ defects. This indicates, for example, that $\mathrm{Pb}$ is unsaturated and thus, iodine deficiencies may also be present in the perovskite lattice of the reference sample. These defects serve as not only recombination centers to deteriorate device efficiency but also degradation initiators to hamper device lifetimes. Moreover, it has been shown that the formed $I_{2}$ could further accelerate the decomposition of the HPs. The application of additives could effectively suppress the formation of metallic $\mathrm{Pb}$ via either direct electron donation to unsaturated $\mathrm{Pb}$ or immobilization of iodine. To avoid the formation and accumulation of these defects, the incorporation of europium ion pair $\mathrm{Eu}^{3+}-\mathrm{Eu}^{2+}$ has been employed to act as "redox shuttle" that selectively oxidized $\mathrm{Pb}^{0}$ and reduces $\mathrm{I}^{0}$ defects simultaneously in a cyclic transition. As a result, the final PSCs showed exceptional stability improvement and high PCE (Fig. 7a) [131]. 
The application of wide-bandgap lead oxysalt layers reduces defect density on the perovskite surfaces by passivating under coordinated surface lead centers, which are defect-nucleating sites. The group Huang used lead oxysalt to increase the carrier recombination lifetime and to boost the efficiency of the solar cells. Its use also improved the water resistance of perovskite films by forming strong chemical bonds. Therefore, the top layer of lead sulfate on the perovskite surface efficiently suppresses ion migration, possibly due to the tightly bonded lead sulfate layer which immobilizes surface defects. [180] The devices stabilized by the lead oxysalt exhibited an efficiency of $21.1 \%$ and maintain $96.8 \%$ of their initial efficiency after operation at maximum power point under simulated air mass (AM) $1.5 \mathrm{G}$ irradiation for 1200 hours at $65^{\circ} \mathrm{C}$ (Fig. 2b).

(a)
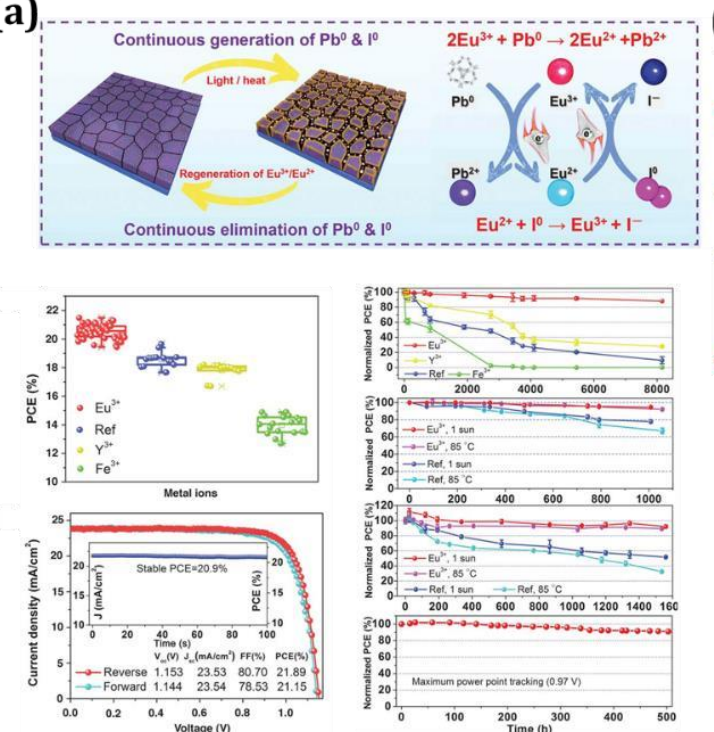

(b)

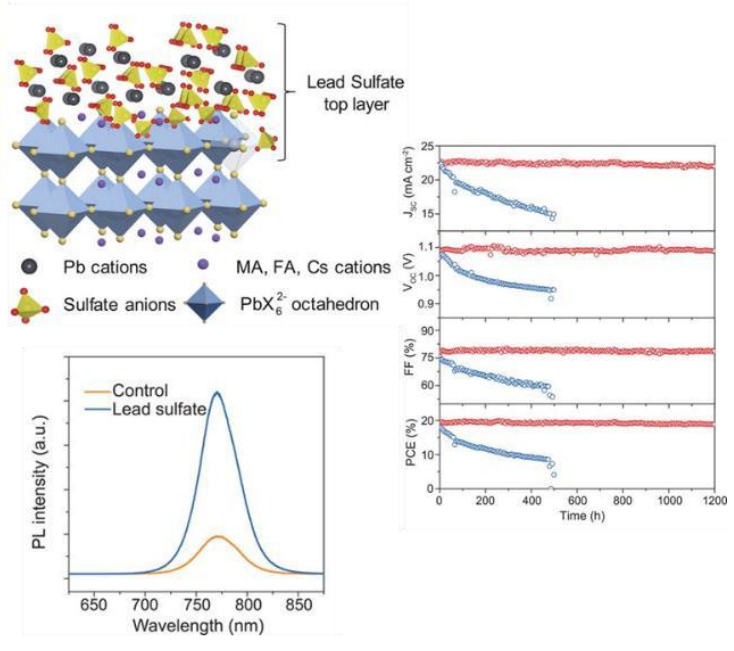

Fig. 7. (a) Proposed mechanism diagram of cyclically elimination of $\mathrm{Pb}^{0}$ and $\mathrm{I}^{0}$ defects and regeneration of $\mathrm{Eu}^{3+} \mathrm{Eu}^{2+}$ metal ion pair. Long-term stability and original performance evolution of PSCs. Reproduced with permission. Copyright 2019, Science [131]. (b) schematic illustration of protection of perovskites through in situ formation of a lead sulfate top layer on the perovskite surface. Time-resolved PL of the perovskite films with and without lead sulfate layers. Stability test of encapsulated solar cell devices based on control (blue) and sulfate-treated (red) CsFAMA perovskite active layers. Reproduced with permission. Copyright 2019, Science [180]. 
Due to the weak bonding nature in HPs, the soft crystal lattice is easily decomposed, usually starting at the surface, and leads to great difficulties in forming stable heterostructures on perovskite surfaces. The formation of strong chemical bonds on the surface of soft perovskite films can greatly prevent perovskite loss, thus reducing damage to organic charge transport semiconductors. Wang et al. used a perovskite film with a surface-rich $\mathrm{Pb}$ and a chlorinated graphene oxide (Cl-GO) layer, where strong $\mathrm{Pb}-\mathrm{Cl}$ and $\mathrm{Pb}-\mathrm{O}$ bonds are formed to join the two layers. A certified stabilized $\mathrm{PCE}$ of 18.7\% was achieved based on Cl-GO modified devices for longer than 1000 hours (Fig. 8a) [212]. In addition, the control of the reaction rate and formation of extremely dense, textured, smooth and large grains of the perovskite layer, is crucial to ensure highly efficient PSCs. Mali et al. (Fig. 8b) developed a new simple dual-retarded reaction processing (DRP) method to synthesize a high-quality mixed-cation perovskite thin film via intermediate phase and incorporation of nitrogen-doped reduced graphene oxide (N-rGO). This DRP process allows the fabrication of PSCs with a maximum conversion efficiency higher than $20.3 \%$ [213].

(a)

(a) $)_{\text {PDO IOCONHOS }}$
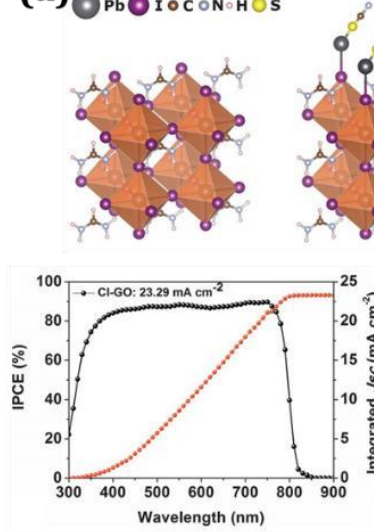
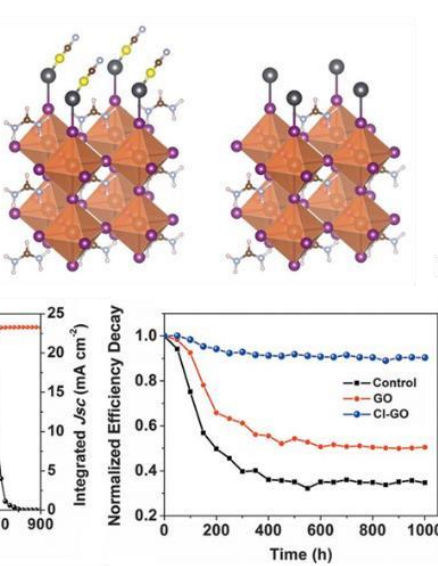

(b)
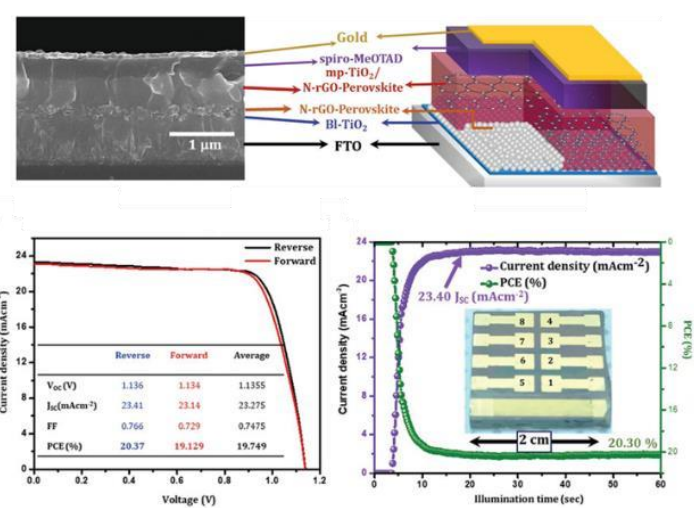
Fig. 8. (a) Schematic representation of the pristine perovskite layer conversion through the treatment with $\mathrm{Pb}(\mathrm{SCN})_{2}$, and the $\mathrm{Pb}$ surface-rich perovskite layer. IPCE spectrum and integrated $\mathrm{J}_{\mathrm{sc}}$ of the PSC applying the perovskite/ClGO interface. Operational stability of the control cell and the cell with GO and Cl-GO. Reproduced with permission. Copyright 2019, Science [212]. (b) cross sectional FESEM image and schematic representation of a complete perovskite solar cell fabricated by DRP method, where a textured and compact perovskite with N-rGO capping layer fully covers the mesoporous $\mathrm{mp}-\mathrm{TiO}_{2}$ layer infiltrated with perovskite. $\mathrm{J}-\mathrm{V}$ curves for the best cell using the DRP method recorded in reverse and forward scanning directions. Steady-state photocurrent stability of SRP-based device under constant illumination and respective efficiency of champion cell recorded at the maximum power point. Reproduced with permission. Copyright 2019, WILEY-VCH Verlag GmbH \& Co. KGaA, Weinheim [213].

\subsection{Organic additives}

The application of organic additives has a long tradition in the development of highly efficient and highly stable PSCs. Organic additives can be selected depending on their properties which are directly related to their functional group(s), molecular structure or chain length. In this section, we present the most recent works reported on the development of stable PSC applying organic additives, including a section on additives for $2 \mathrm{D}$ perovskites.

\subsubsection{Functional groups}

The introduction of additives (organic molecules or ligands) in the HP absorber, was initially proposed with the aim of increasing device efficiency. Different molecules have been employed to passivate defects reducing the non-radiative recombination loss

and increase device efficiency. A recent review by Choy, et al., enlists the use of different molecules in PSCs and categorizes them depending on the type of ligand. Most organic additives introduce functional groups such as carboxylic or ammonium. Being the monoammonium or diammonium groups the most utilized [242-247]. The type of bond between the additive and the PSC material dictates not only the optoelectronic 
properties of materials but also the intrinsic and extrinsic stability of devices. For example, additives with functional groups $\mathrm{S}=\mathrm{O}$ or $\mathrm{P}=\mathrm{O}$ or $\mathrm{C}=\mathrm{O}$ can control the halide perovskite thin film crystallization and passivate uncoordinated $\mathrm{Pb}^{2+}$ defects by the creation Metal-O bonds. Hydroxyl $(-\mathrm{OH})$ and carboxyl $(-\mathrm{COOH})$ groups can act as Lewis bases passivating uncoordinated $\mathrm{Pb}$. Especially, under illumination, the hydrogen bonding energy between organic cations and $\mathrm{Pb}_{2} \mathrm{I}$ framework can be weakened and the organic cations become easier to migrate, which, without an organic additive, would accelerate the decomposition of the halide perovskite [248]. Recently, the inhibition of ion migration, due to the type and binding strength of the additive applied, was linked to the long-term stability of PSCs. For example, Bark, et al., introduced anchoring alkyl amine ligands (AAL) with different chain lengths in the perovskite layer. Defect passivation and ion immobilization was effective due to the filling of the amine group into the A-site vacancies of the perovskite. In this case, the amount of efficiency (and $\mathrm{V}_{\mathrm{oc}}$ ) increase, as well as the stability improvement, is related to the length of the organic molecule. The activation energy, Ea, of the pristine halide perovskite was $243 \mathrm{meV}$, in comparison with the $422 \mathrm{meV}$ observed with the AAL additive, a clear indication of ion immobilization [249]. As a consequence, the PSC showed no loss in efficiency after $1000 \mathrm{~h}$ under continuous irradiation of 1 sun. Li et al., introduced rubrene in the perovskite layer. The supramolecular cation- $\square$ interaction (a kind of noncovalent force) between the aromatic rubrene and the organic cations of the halide perovskite ensured ion immobilization. The energy of the cation $-\pi$ interaction have been found to be as strong as $1.5 \mathrm{eV}(1500 \mathrm{meV})$, which is enough to immobilize the organic cations in HP 
[248]. The chemical bonding modulation of the HP was also studied by tuning the bond strength of additives. The introduction of small amounts of alkali halide $(\mathrm{NaX})$ at the FAI-terminated surfaces, was reported to stabilize the local structure via increase bonding with $\mathrm{Pb}$, and via hydrogen bonds with FA ions. This was observed for Fluoride which forms a stronger bond in comparison with other halides such as I, $\mathrm{Br}$ or $\mathrm{Cl}$ [130]. The PSC retain $90 \%$ of the initial efficiency after $1000 \mathrm{~h}$ under continuous light irradiation. The chemical shift trend varies considerably depending on the functional group participating in the hydrogen bonding [244][250]. Quantum dots have also been employed to enhance PSC efficiency and stability. For example, PbS [251], PbSe [252], SnS [253] or CdSe [254]. In quantum dot sensitized solar cells with tuneable band gap, several organic molecules with different end-groups $\left(-\mathrm{CH}_{3},-\mathrm{NH}_{2},-\mathrm{COOH}\right)$ showed that the nature of the end-group did not significantly affect the uptake of CdS quantum dots on $\mathrm{TiO}_{2}$, nor the final optical properties of the device. The power conversion efficiencies in devices made with phosphonic acids were up to $\sim 3$ times higher compared to those without any anchoring agent, possibly due to the PA monolayers acting as recombination barriers or passivating defects at the $\mathrm{TiO}_{2}$ surface [255]. The latter indicates that binding of functional groups in the HP is a complicated process that involves not only the chemical environment and the materials themselves, but also, the type of the molecule including chain type and length, as well as bonding strength. All of these characteristics of the functional group affect the final properties of the HP thin films and the interfaces with the transport layers of the device. In the case of long-term stability, the activation energy for ion migration is highly dependent on chemical bonding and crystal structure of the materials [256]. Therefore, structural engineering 
of perovskite crystals can be used to modulate the strength and geometry of the chemical bonds and thus enhance the activation energies to modulate and control ion migration. However, the mechanisms behind binding modes in perovskite-additive interactions and the correlation between defect passivation, non-radiative recombination and device stability remain poorly understood.

Li et al. reported a one-step solution-processing strategy using phosphonic acid ammonium additives that results in efficient PSCs with enhanced stability. The introduction of molecularly engineered alkylphosphonic acid $\omega$-ammonium cations as crosslinking agents facilitates the growth of perovskite crystals in the mesoporous network and creates smooth coating layers, enhancing the material's photovoltaic performance from $8.8 \%$ to $16.7 \%$ as well as its resistance to moisture (Fig. 9a) [135]. Interestingly, multifunctional molecules have also been used as templates to direct nucleation or crystal growth. Dongqin $\mathrm{Bi}$ et al. demonstrated a concept of multifunctional molecular modulation of stable PSCs. The designed bifunctional molecular modulator SN links the mercapto-tetrazolium (S) and phenylammonium (N) moieties, which passivate the surface defects. As a result, molecular modulation simultaneously enhances the perovskite grain size and crystallinity and reduces the level of defects acting as centers for no-radiative charge carrier recombination (Fig. 9b) [209]. 

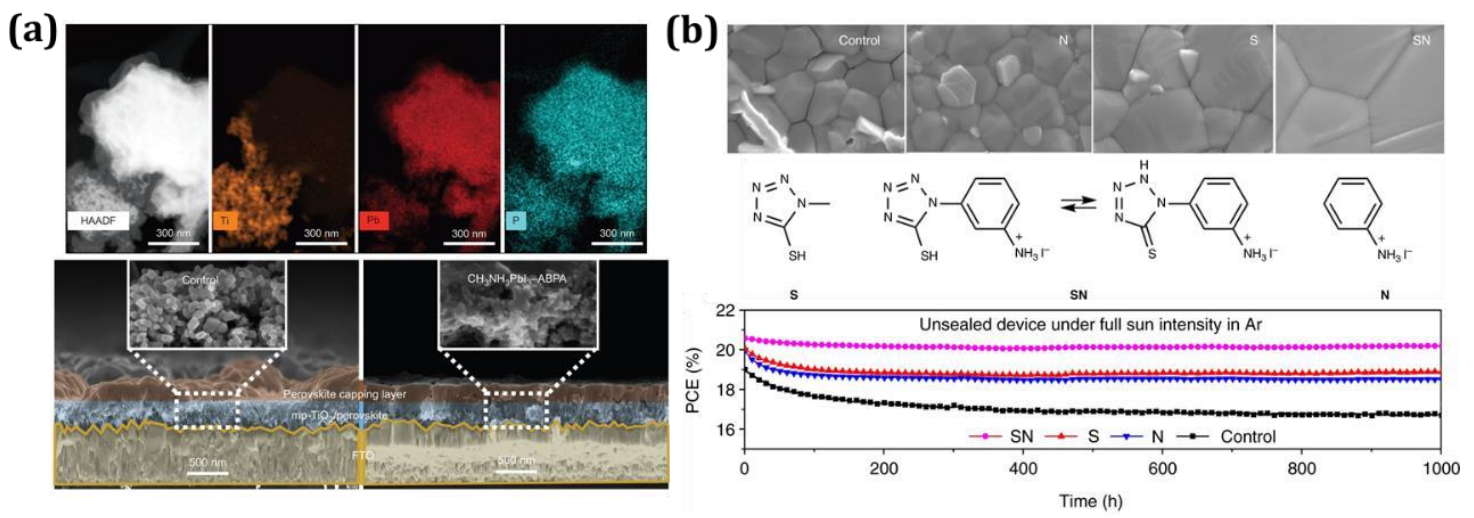

Fig. 9. (a) From left to right, HAADF and EDS mapping (in STEM mode) of the Ti, $\mathrm{Pb}$ and $\mathrm{P}$ components of the 4ABPA-anchored perovskite grains with the $\mathrm{mp}-\mathrm{TiO}_{2}$ scaffold. Cross-sectional SEM images of pristine and 4ABPAanchored $\left(\mathrm{CH}_{3} \mathrm{NH}_{3} \mathrm{PbI}_{3}-\mathrm{ABPA}\right)$ perovskite films deposited on $\mathrm{TiO}_{2} / \mathrm{FTO}$ substrates. Reproduced with permission. Copyright 2015, NATURE CHEMISTRY [135]. (b) plane-view (top) SEM images of the pristine (control) and modulator-containing (N, S, and SN) perovskite films deposited on the mesoporous- $\mathrm{TiO}_{2} /$ compact- $^{-}$ $\mathrm{TiO}_{2} / \mathrm{FTO}$. Structure of N, S, and SN modulators employed in the study, with the corresponding tautomeric forms of SN.

Evolution of the PCE over time measured by maximum power point tracking of unsealed PSCs of aperture area of $0.16 \mathrm{~cm}^{2}$ under light soaking with full solar intensity at temperature between 55 and $60{ }^{\circ} \mathrm{C}$. Cell was kept under an Ar atmosphere. Reproduced with permission. Copyright 2018, NATURE COMMUNICATIONS [209].

Zhang et al. (Fig. 10a) employed two amino acids, 4-aminobenzoic acid (GABA) and 4-aminobutyric acid (PABA), with similar molecular size and closed chain length to study the molecular rigidity of the organic coupling agents affecting the quality of perovskite films. The cells with PABA as coupling agent improved the quality of perovskite films by reducing the defects and enhancing the crystalline, thus leaded to a significant improvement of the photocurrent and efficiency of the solar cells. The PCE of PABA-treated cell was increased from $13.6 \%$ up to $16.8 \%$, mainly due to the enhancement of the short-circuit current density $\left(\mathrm{J}_{\mathrm{sc}}\right)$ from 19.12 to $22.00 \mathrm{~mA}$. [147] It has been shown that polymers with functional groups can interact with the perovskite to passivate defects. Jun Peng et al. reported double-side passivated perovskite cells by inserting ultrathin poly(methyl methacrylate) PMMA films at both the perovskite/ETL and perovskite/HTL interfaces, finding strong evidence that the excellent passivation 
provided by PMMA films is associated with the Lewis-base nature of the oxygen atoms in the carbonyl $(\mathrm{C}=\mathrm{O})$ groups of PMMA, where donor electrons can reduce the charge state of $\mathrm{Pb} 2+$ defect ions at the perovskite/ETL and perovskite/HTL interfaces, effectively reducing nonradiative recombination. The passivation properties of PMMA allowed open circuit voltages up to $1.22 \mathrm{~V}$, achieving a high PCE of $20.8 \%$ with negligible hysteresis for champion passivated cells (Fig. 10b) [49].

(a)<smiles>NCCCC(=O)O</smiles>

4-Aminobutyric Acid

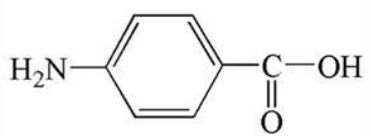

4-Aminobenzoic Acid

(b)

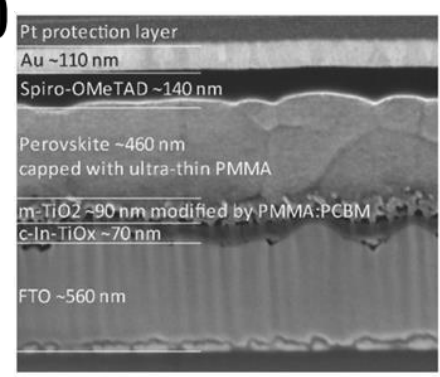

(a)
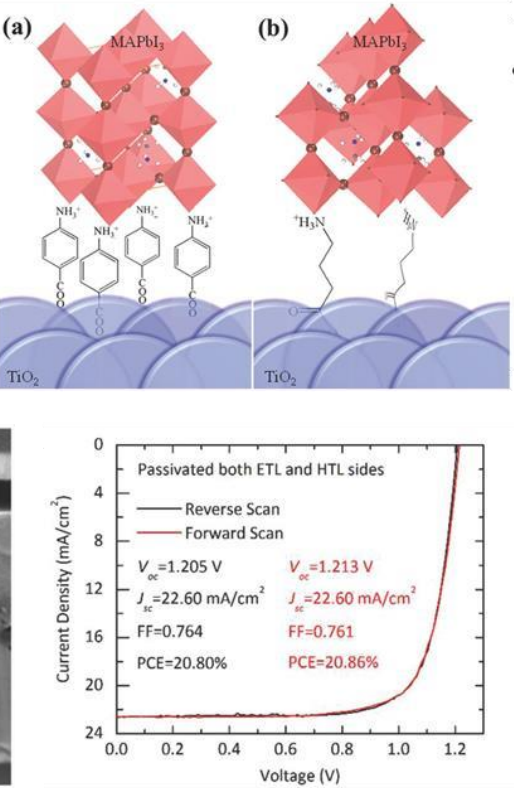

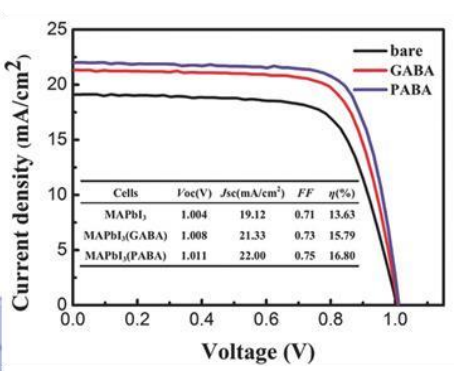

Voltage (V)

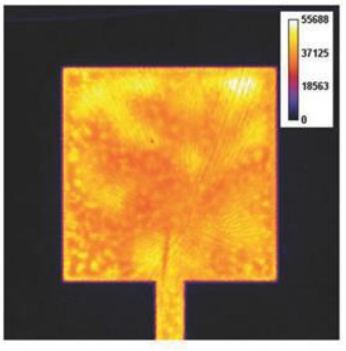

Fig. 10. (a) Schematic representation of $\mathrm{HOCO}-\mathrm{C}_{6} \mathrm{H}_{4}-\mathrm{NH}_{3}{ }^{+} \mathrm{I}^{-}$(PABA) and $\mathrm{HOCO}-\mathrm{C}_{3} \mathrm{H}_{6}-\mathrm{NH}_{3} \mathrm{I}^{-}$(GABA) and the proposed mechanism of amino acid $\mathrm{MAPbI}_{3}$ surface (a) on $\mathrm{PABA}$-treated $\mathrm{TiO}_{2}$, and (b) on $\mathrm{GABA}_{\text {-treated }} \mathrm{TiO}_{2}$. $\mathrm{J}_{-}$ $\mathrm{V}$ curves of the best PSCs based on the $\mathrm{MAPbI}_{3}$ films on bare- $\mathrm{TiO}_{2}$, GABA-treated $\mathrm{TiO}_{2}$, and PABA-treated $\mathrm{TiO}_{2}$. Reproduced with permission. Copyright 2017, WILEY-VCH Verlag GmbH \& Co. KGaA, Weinheim [147]. (b) SEM cross-sectional image of the perovskite cell. J-V curves of the double-side passivated cell with a structure of FTO/cIn-TiO $x / \mathrm{m}-\mathrm{TiO}_{2} / \mathrm{PMMA}$ PCBM/Perovskite/PMMA/Spiro-OMeTAD/Au, and its corresponding PL image. Reproduced with permission. Copyright 2018, WILEY-VCH Verlag GmbH \& Co. KGaA, Weinheim [49].

\subsubsection{Chain length and molecular configuration}

Organic additives with different alkyl chain lengths and end-groups would play a key role in the development of high-quality halide perovskite films, as they participate in 
perovskite formation via dissociated carbon-halogen bonds to generate extra halogen ions. An excessively long alkyl chain length additive could result in steric hindrance for chelation with $\mathrm{Pb}^{2+}$ and an enhanced non-polar nature of the additives [257]. As an example, Zheng et al. (Fig. 11a) demonstrated that the use of alkylamine ligands (AALs) added to the precursor solution suppresses nonradiative carrier recombination and improve the optoelectronic properties of mixed-cation mixed-halide perovskite films, particularly long-alkyl-chain AALs. The resulting AAL surface modified films exhibit a prominent (100) orientation and lower trap-state density, as well as enhanced carrier mobility and diffusion lengths, demonstrating $\mathrm{p}-\mathrm{i}-\mathrm{n}$ structured devices with $>23.0 \%$ efficiency (22.3\% certified) and good operational stability. [75]

Another example is given by Wang et al., who analyzed the chemical environment of functional groups that can be activated for defect passivation. He employed theophylline, caffeine and theobromine, demonstrating PSCs with high efficiency when applying the $\left(\mathrm{FAPbI}_{3}\right)_{\mathrm{x}}\left(\mathrm{MAPbBr}_{3}\right)_{1-\mathrm{x}}$ perovskite. In these molecules, the conjugated structure as well as the dipoles induced by the hetero atoms, tends to increase the intermolecular interaction. The xanthine core also helps maintain the coplanarity of the carbonyl group and the $\mathrm{N}-\mathrm{H}$. Unlike other small molecules with flexible alkyl chains, this rigidity allows to define the configuration and distance between the carbonyl group and $\mathrm{N}-\mathrm{H}$ when they are interacting with the defects (Fig. 11b) [121]. 
(a).

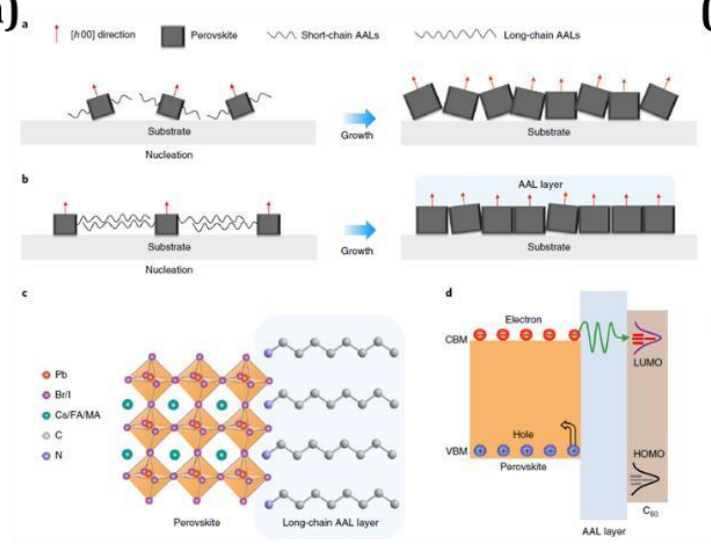

(b)

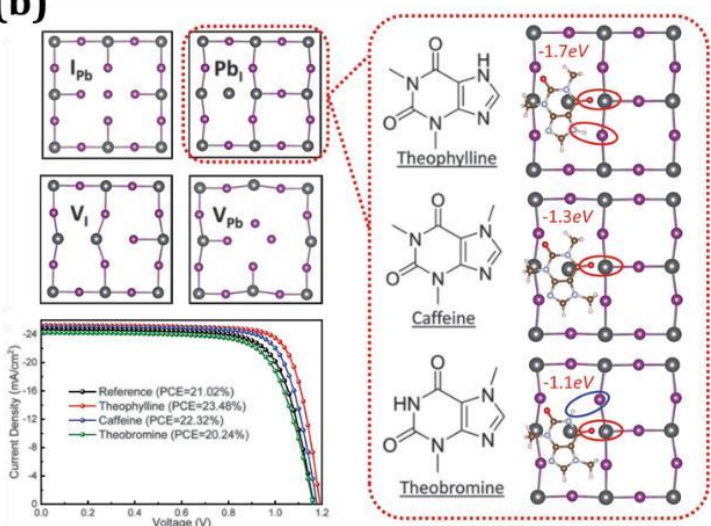

Fig. 11. (a) Illustration of the influence of the short-chain AALs a) and long-chain AALs b) on the crystallization of the perovskite films. Illustration of long-chain AALs assembled on perovskite film surface c) and blocking the holes at the perovskite and C60 interfaces d). Reproduced with permission. Copyright 2020, NATURE ENERGY [75]. (b) top view of the various types of surface defects. Theoretical models of perovskite with molecular surface passivation of $\mathrm{Pb}_{\mathrm{I}}$ antisite with theophylline, caffeine, and theobromine. J-V curves of PSCs with or without small-molecules treatment under reverse scan direction. Reproduced with permission. Copyright 2019, Science [121].

\subsubsection{Application of stable $2 D$ perovskites}

It has been reported recently that the instability of lead halide perovskites, which are promising materials for high efficiency and low-cost solar cells, can be improved by reducing the dimensions of the perovskites from the three-dimensional (3D) bulk to that of two-dimensional (2D) films. To overcome the limited stability of 3D perovskites, the development of two-dimensional (2D) halide perovskites has been proposed due to their own superior stability, but at the expense of lower efficiency, mainly due to their contrasting optoelectronic properties (i.e., energy high exciton binding, less absorption). Reported results demonstrate that $\mathrm{AX}$-terminated $2 \mathrm{D} \mathrm{APbX}_{3}$ are thermodynamically more stable than the $\mathrm{PbX}_{2}$-terminated 2D structures. Although the formation energies of $2 \mathrm{D} \mathrm{CsPbBr} 3$ and $\mathrm{PbI}_{2}$-terminated $\mathrm{MAPbI}_{3}$ are higher than their 3D counterpart, the stability of MAI-terminated 2D MAPbI ${ }_{3}$ becomes comparable to, or even better, than 
their 3D bulk. The stability of 2D AX-terminated perovskites stems from the asymmetric surface properties of these materials: fewer surface dangling bonds and higher AX layer ionicity, as well as significant surface relaxation. These factors lead to a low surface energy for the AX finished surface [258].

The $2 \mathrm{D}$ perovskite materials are prepared by the insertion of larger organic cations which isolate the anionic metal layers disrupting the 3D perovskite structure, for example, $\mathrm{C}_{6} \mathrm{H}_{5}\left(\mathrm{CH}_{2}\right)_{2} \mathrm{NH}_{3}{ }^{+}\left(\mathrm{PEA}^{+}\right)$and $\mathrm{CH}_{3}\left(\mathrm{CH}_{2}\right)_{3} \mathrm{NH}_{3}{ }^{+}\left(\mathrm{BA}^{+}\right)$into the 3D MAPbI

lattice [259]. Cho and co-workers reported a perovskite solar cell employing a thin 2D perovskite layer on top of a 3D perovskite film with improved stability. They applied the phenethylammonium iodide (PEAI) additive to obtain a 2D perovskite in the form of $\mathrm{PEA}_{2} \mathrm{PbI}_{4}$. By intercalating a wide bandgap 2D perovskite layer, the charge carrier recombination at the interface was reduced, and the efficiency was enhanced. The devices retained $85 \%$ of the initial PCE stressed under one sun illumination for 800 hours at $50{ }^{\circ} \mathrm{C}$ (Fig. 12a)[151].

Another study by Wang et al. reported the formation of 2D perovskite platelets, interspersed between highly oriented 3D perovskite grains. Non-radiative recombination was effectively reduced due to interfacial grain boundary passivation when incorporating n-butylammonium cations into a mixed-cation lead mixed-halide $\mathrm{FA}_{0.83} \mathrm{Cs}_{0.17} \mathrm{~Pb}\left(\mathrm{I}_{\mathrm{y}} \mathrm{Br}_{1-\mathrm{y}}\right)_{3} 3 \mathrm{D}$ perovskite. The interface between these heterostructures appears to be electronically clean, and consequently inhibits unwanted trap-assisted recombination, leading to reduced current-voltage hysteresis, enhanced efficiency and significantly improved operational stability in the ensuing solar cells. The best 
performing device shows an efficiency of $19.5 \%$ which maintains $80 \%$ stability of its "post-burn" efficiency after 1,000 h in air, and close to 4,000 h when encapsulated (Fig. 12b) [102].
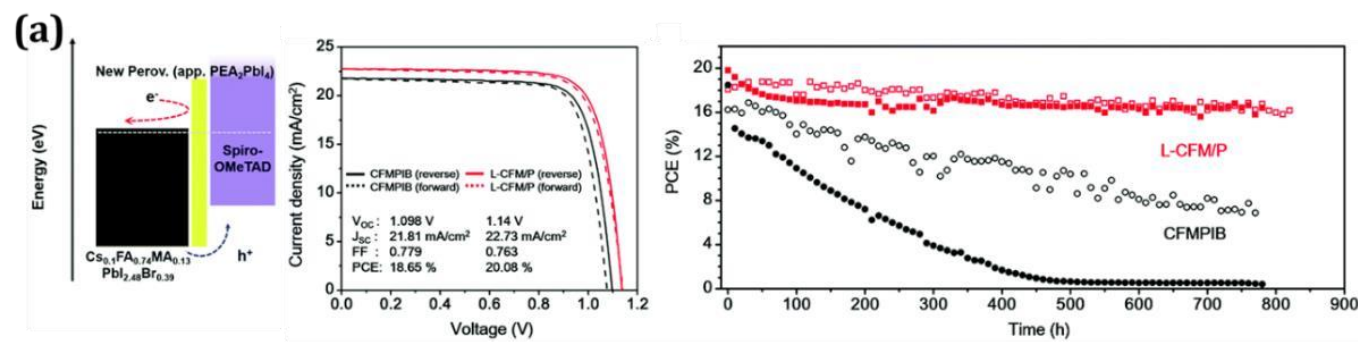

(b)
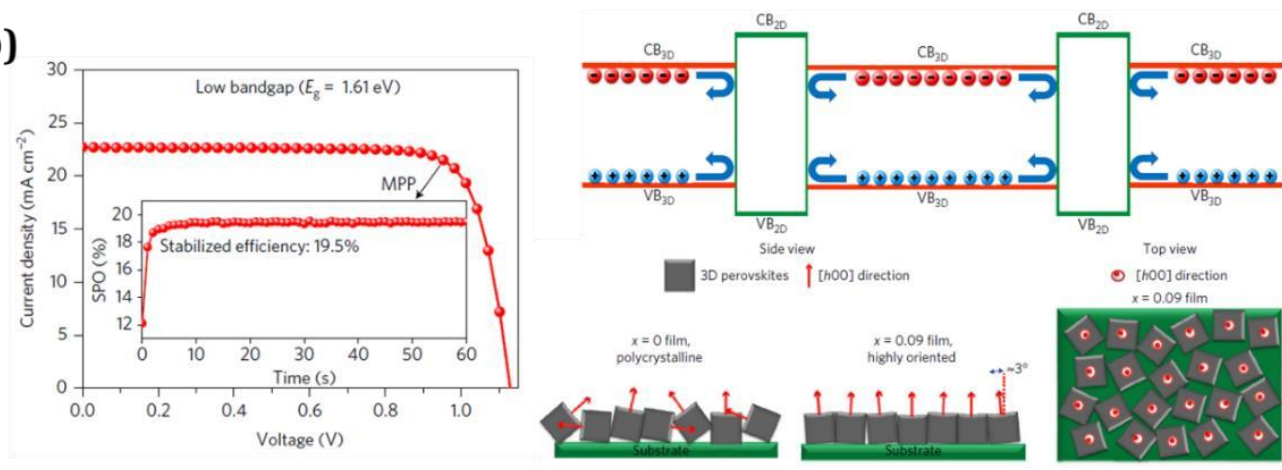

Fig. 12. (a) Energy band diagram of the L-CFM/P (layered perovskite with $\mathrm{Cs}_{0.1} \mathrm{FA}_{0.74} \mathrm{MA}_{0.13} \mathrm{PbI}_{2.48} \mathrm{Br}_{0.39}$ and quasiPEA2 $\mathrm{PbI}_{4}$, a $2 \mathrm{D}$ perovskite) device and description of how the 2D perovskite capping layer improved the PCE. $\mathrm{J}-\mathrm{V}$ curves and hysteresis of PSCs at a scan rate of $25 \mathrm{mV} / \mathrm{s}$. Photo-stability test from maximum power point tracking under $800 \mathrm{~h}$ continuous illumination of full intensity in an inert gas (blank ones) and ambient (filled ones) environment with encapsulated glass. Reproduced with permission. Copyright 2018, The Royal Society of Chemistry [151]. (b) BA-enhanced 3D perovskite crystalline growth. 2D-3D perovskite heterostructure. Device performances of the BA/FA/Cs PSCs. Reproduced with permission. Copyright 2017, NATURE ENERGY [102].

Liu et al. introduced a two-dimensional (2D) $\mathrm{A}_{2} \mathrm{PbI}_{4}$ perovskite layer using pentafluorophenylethylammonium (FEA) as a fluoroarene cation inserted between the 3D light-harvesting perovskite film and the hole-transporting material (HTM) (Fig. 13a). The introduction of (2D) perovskite layer effectively enhances the hole extraction and suppress non-radiative recombination, resulting in a PCE of over $22 \%$. 
In addition, PSC devices retained $90 \%$ of their efficiency during photovoltaic operation for 1000 hours in humid air under simulated sunlight [238]. Cho et al. demonstrated a 2D-3D mixed passivation treatment by using a mixture of bulky organic ammonium iodide (iso-butylammonium iodide, $i \mathrm{BAI}$ ) and formammidinium iodide (FAI) (Fig. 13b). The applied $i \mathrm{BAI} / \mathrm{FAI}$ can efficiently passivate the trap states on surface and the interface of perovskite/CTL, achieving a stabilized power conversion efficiency of $21.7 \%$ and sustaining over $87 \%$ of the original performance after 912 hours storage in ambient environment under $75 \pm 20 \%$ relative humidity [128].

\section{(a)}
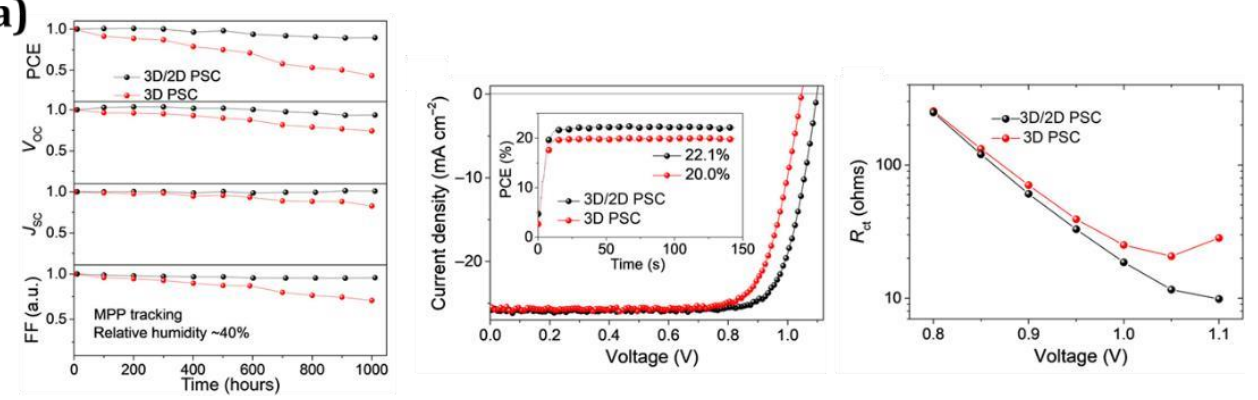

(b)
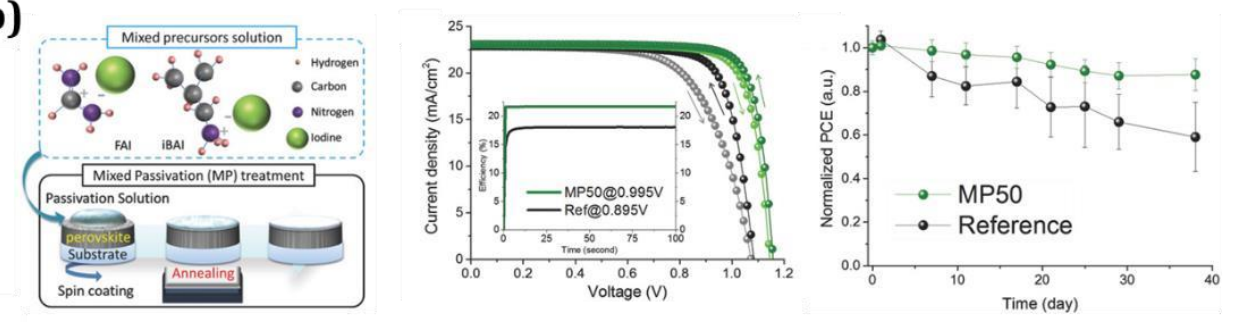

Fig. 13. (a) Ambient atmosphere aging results of a 3D PSC and a 3D/2D PSC, with the relative humidity shown in the inset. I-V curves of a 3D PSC and a 3D/2D PSC, with inset showing MPP tracking. Plot of contact resistance against voltage. Reproduced with permission. Copyright 2019, American Association for the Advancement of Science [238]. (b) schematic of the mixed passivation (MP) treatment method with FAI and iso-butylammonium iodide (iBAI). Champion device J-V curves under reverse (MP50 - green, reference - black) and forward (MP50 bright green, reference gray). Inset: stabilized PCEs. Stability test; PCEs monitored in 75\% RH condition over a period of 38 d. Reproduced with permission. Copyright 2019, WILEY-VCH Verlag GmbH \& Co. KGaA, Weinheim [128].

\section{The role of additives in PSCs fabrication}


The development of PSC has focused on two important issues regarding practical applications. One is photoelectric conversion efficiency and the other is stability. The PCE of PSCs has been increased to over 25\% [7] in just a few years through material design and additive engineering based on the desired optoelectronic properties. Therefore, the great challenge lies in the long-term stability of the PSCs. A high-quality perovskite film is crucial for the fabrication of stable of PSCs. The perovskite film is very sensitive to the external environment conditions leading to the degradation of the PSCs, which is reflected in the considerable PCEs decrease. In general, the stability of the perovskite film depends on its chemical components, crystal structure, and the quality of the perovskite film.

\subsection{Grain size and crystal orientation}

The PSCs performance is highly sensitive to fabrication conditions, which have critical impact on the morphology of perovskite films. Poor morphology of the perovskite thin film has been cited as being highly detrimental to the performance of the device because it not only causes problems such as electrical short circuits, but also affects charge dissociation, charge transport and recombination [260-261]. Due to the sensitive dependence of growth kinetics on interfacial energy, solution concentration, precursor composition, solvent choice and deposition temperature, improving perovskite morphology and coverage through controlling crystallization during film deposition and annealing is an attractive route to device optimization. Optimal perovskite film morphology can be achieved by finding effective ways to manipulate its nucleation and growth [28][260-261]. 
At present, one of the main challenges in perovskite thin film fabrication is the control of grain growth and crystal orientation during bulk perovskite growth applying various additives. Wu et al. proposed an additive engineering strategy that modulates the film morphology and crystalline quality by using an ionic-liquid additive of methylammonium acetate (MAAc) and a molecular additive of thio-semicarbazide (TSC) (Fig. 14a). Their combination allowed fabrication of uniform perovskite films with large crystals, low density of defects, and ultrasmooth surface over inch-sized planar substrates. The introduction of MAAc (10-15\% molar ratio) is capable of generating highly uniform perovskite films with full coverage morphology through a simple one-step spin-coating process and a small amount (3-5\% molar ratio) of addition of TSC to efficiently increase the perovskite crystal size. The high crystalline quality of perovskite is found to simultaneously improves the PCE and durability of PSCs [156]. Fei et al. reported that introducing thiourea into perovskite precursor with two-step ethyl acetate (EA) interfacial processing can grow compact micro-sized and monolithically grained perovskite films (Fig. 14b). The crystal grain size increases substantially from $500 \mathrm{~nm}$ to over $2 \mu \mathrm{m}$, confirmed that thiourea in the precursor has exerted a crucial impact on the nucleation and subsequent crystal growth processes. With the EA post processing, grain boundaries blocked by the intermediate phase were opened resulting in a subtle decrease in grain size. The resulting PSCs with sequential processing demonstrated an impressive power conversion efficiency of $18.46 \%$ and an average steady state PCE of $18.05 \%$. [186] Yang et al. reported the use ethylene diamine tetra acetic acid (EDTA) provides excellent modification of electron 
transporting layers (ETLs) in PSCs owing to its strong chelation function. The EDTAcomplexed $\mathrm{SnO}_{2}(\mathrm{E}-$

$\mathrm{SnO}_{2}$ ) ETLs were prepared by complexing EDTA with $\mathrm{SnO}_{2}$ nanoparticles for planartype PSCs. The electron mobility of $\mathrm{E}_{-} \mathrm{SnO}_{2}$ increases by about three times compared to that of $\mathrm{SnO}_{2}$, leading to negligible current density-voltage $(\mathrm{J}-\mathrm{V})$ hysteresis due to improved electron extraction from the perovskite absorber. Furthermore, it was found that the $\mathrm{SnO}_{2}$ surface becomes more hydrophilic with EDTA treatment, which decreases Gibbs free energy for heterogeneous nucleation, resulting in higher quality perovskite films with larger grains and lower trap density (Fig. 14c) [144]. Bae et al. demonstrated that adding dimethyl sulfoxide (DMSO) and methoxyammonium salt (MeO) simultaneously (dual additives) to a precursor solution is a promising strategy to control PSCs morphology. MeO additive helps the precursors form a stable intermediated $\mathrm{PbI}_{2} \mathrm{DMSO}$ adduct during film formation by retarding the kinetics of conversion of the adduct to the perovskite. $\mathrm{MeO}$ is eliminated during annealing while the optical band gap and crystal structure of PSC are not affected by the addition of the additive. When a small amount of $\mathrm{MeO}$ was added, all devices parameters were enhanced, especially for $\mathrm{MeO} 10$ devices (10\% addition) with a champion $19.71 \%$ PCE achieved $\left(\mathrm{V}_{\mathrm{OC}}=\right.$ $\left.1.13 \mathrm{~V}, \mathrm{~J}_{\mathrm{SC}}=22.89 \mathrm{~mA} \mathrm{~cm}^{-2}, \mathrm{FF}=0.76\right)($ Fig. 14d $)[168]$. 
(a)

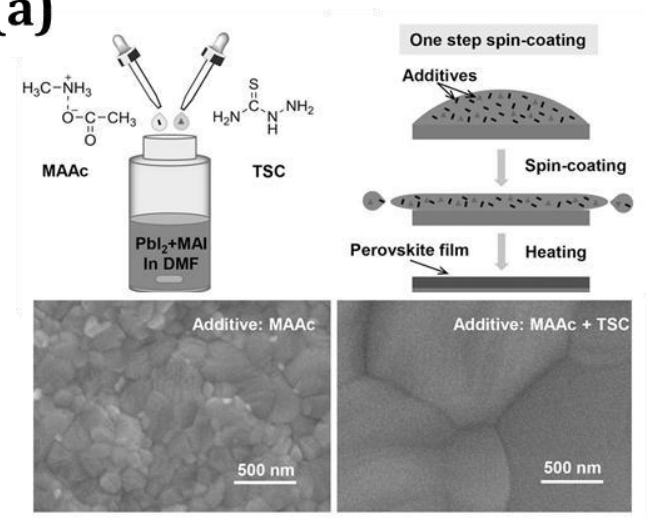

(c)

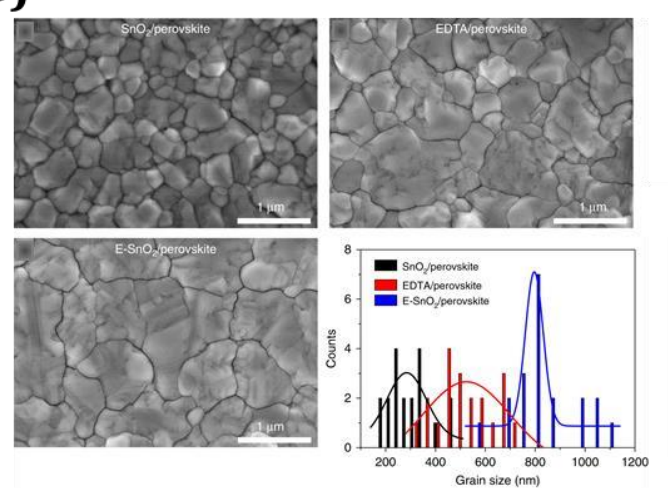

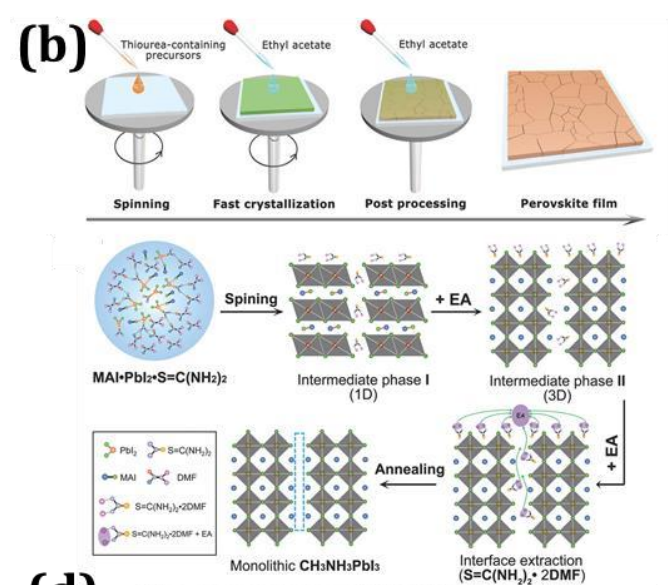

(d)

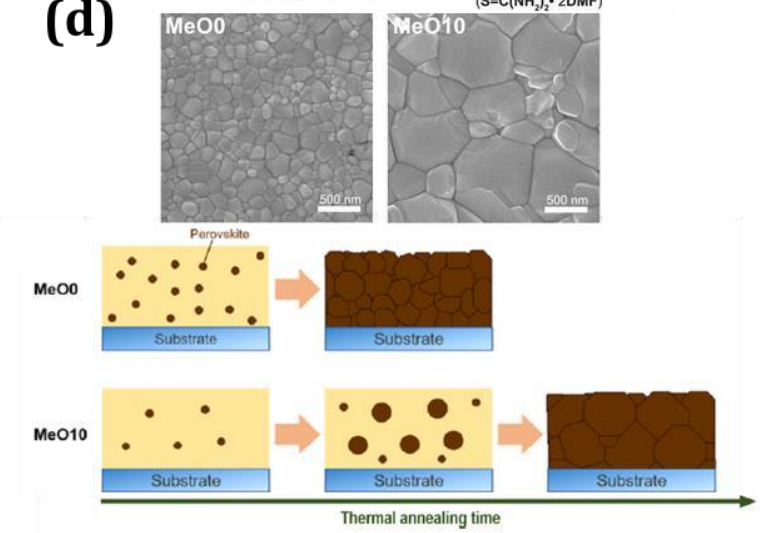

Fig. 14. (a) Additive engineering by combining an ionic additive of MAAc and a molecular additive of TSC in stoichiometric $\mathrm{PbI}_{2} \mathrm{MAI}$ precursor solution with DMF as solvent. Schematic diagram of the additive_assisted one . step deposition of perovskite thin films. Top_view SEM images of MAPbI films fabricated with additives of MAAc. Reproduced with permission. Copyright 2017, WILEY-VCH Verlag GmbH \& Co. KGaA, Weinheim [156]. (b) schematically fabrication process of perovskite films with thiourea_containing precursor and ethyl acetate post processing. Schematic reaction process from the precursor to monolithic perovskite grains. Copyright 2017, WILEYVCH Verlag GmbH \& Co. KGaA, Weinheim [186]. (c) top-view SEM images of perovskite films coated on $\mathrm{SnO}_{2}$, EDTA and $\mathrm{E}-\mathrm{SnO}_{2}$ substrates. The grain size distribution of perovskite deposited on various substrates. Reproduced with permission. Copyright 2018, NATURE COMMUNICATIONS [144]. (d) SEM images of perovskite films prepared using $\mathrm{MeO0}$ and $\mathrm{MeO} 10$. Schematic representation for the formation of $\mathrm{MAPbI}_{3}$ perovskite films using different amounts of $\mathrm{MeO}$ additives during annealing. Reproduced with permission. Copyright 2019, American Chemical Society [168].

In another report, Han et al. applied methylammonium thiocyanate (MASCN) as an additive to the precursor and a rapid vacuum-based drying approach, high quality $\mathrm{MAPbI}_{3}$ films were achieved (Fig. 15a). Result indicated that the Thiocyanate $\left(\mathrm{SCN}^{-}\right)$ anion, rather than the $\mathrm{MA}^{+}$cation, plays the critical role in increasing grain size at room 
temperature. At a sufficiently high centration, $\mathrm{SCN}^{-}$likely reduces the interaction between $\mathrm{Pb}^{2+}$ ions and DMSO through $\mathrm{Pb}^{2+}$ ion coordination (i.e., $\mathrm{SCN}$ out-competes DMSO for coordination sites), enabling more facile DMSO removal under mild vacuum conditions [175]. The fabrication of efficient, stable, and reproducible PSCs is possible through the application of triple A-cation perovskites based on methylammonium (MA), formamidinium (FA), and caesium (Cs) (Fig. 15b) [105].

However, fast nucleation and growth rate of the perovskite film due to the presence of Cs atoms result in a thin film with small grain size, which can increase the carrier recombination and decrease its diffusion length. To address this issue, $\mathrm{MACl}$, was added into the perovskite solution before deposition of planar triple A-cation (Cs/MA/FA) PSC using a structure based on $\mathrm{FTO} / \mathrm{TiO}_{2} / \mathrm{SnO}_{2} /$ perovskite/spiroOMeTAD/Au. The effect of the additive was an increase in grain size from 200 to over $1000 \mathrm{~nm}$ (Fig. 15c), where the $\mathrm{MACl}$ has no effect on the absorption or photoluminescence (PL) spectra of the perovskite films [149].

As we mentioned earlier, searching for high crystalline quality of perovskite thin film is essential for efficient PSCs. Recently, Wu et al. reported the use of an anti-solvent wash treatment using a versatile electron-rich heterocycle (phenothiazine, PTZ) as an additive in sec-butyl alcohol enhances $\mathrm{MAPbI}_{3}$ perovskite crystals growth. The strong interaction between $\mathrm{PTZ}$ and $\mathrm{Pb}^{2+}$ ions not only promote the size of the $\mathrm{MAPbI}_{3}$ crystals from $0.58 \mathrm{~mm}$ to $0.73 \mathrm{~mm}$ (Fig. 15d), but also is beneficial for the formation of a preferential orientation perovskite film, thereby delivering improved electronic 
properties. As can be seen from X-ray diffraction (XRD) patterns, both films possess the dominant [110] lattice reflection, which is the main preferential orientation for the $\mathrm{MAPbI}_{3}$ films. They defined $\mathrm{C}$ as the ratio of the intensity of [110] and [222] peaks, namely, $\square=I_{[110]} / I_{[222]}$, where the calculations suggest that the $\square$ values of the PSC films upon incorporation of PTZ increased to 2.93 from 2.42 in reference samples. This consequence indicates that the [110] crystals grow larger while other randomly oriented neighboring grains are suppressed. The oriented growth of the grains in the PSC films also promotes to both the decrement of defect density and enhancement of charge transport of the device. Thus, the enhancement of absorption of PSC layer may result from the more preferential orientation crystallinity and larger crystal size by introducing a certain content of PTZ [173]. 
(a)
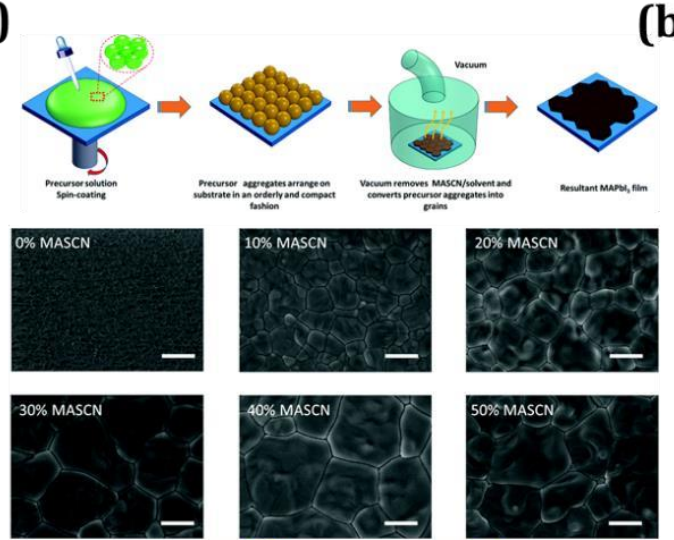

(c)
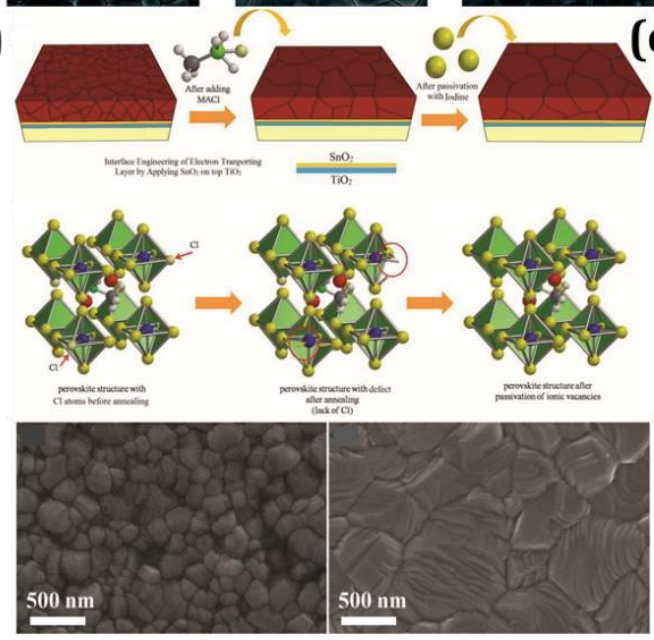

(b)
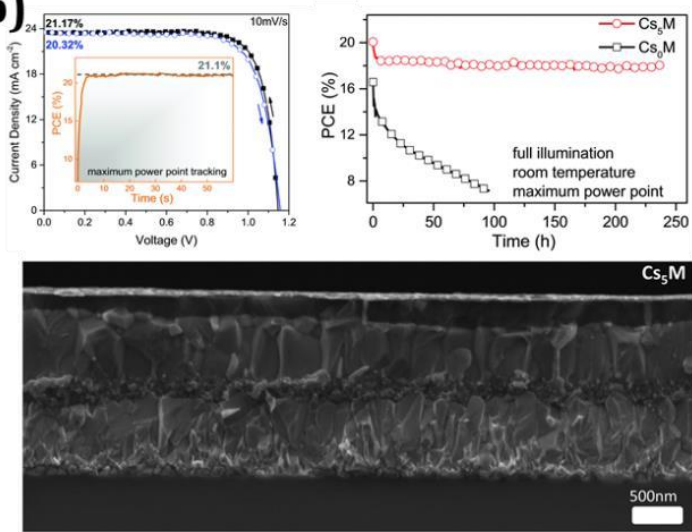

(d)
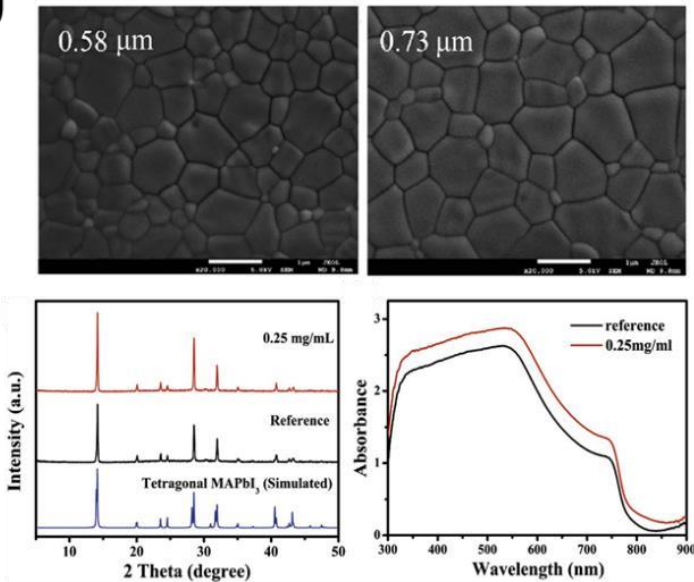

Fig. 15. (a) Schematic flow diagram of the room-temperature process to deposit $\mathrm{MAPbI}_{3}$ films and top view SEM images of perovskite thin films with MASCN addition. Reproduced with permission. Copyright 2017, The Royal

Society of Chemistry [175]. (b) current-voltage scans for the best performing Cs5M device showing PCEs exceeding $21 \%$. The inset shows the power output under maximum power point tracking for $60 \mathrm{~s}$. Aging for $250 \mathrm{~h}$ of a high performance $\mathrm{Cs}_{5} \mathrm{M}$ and $\mathrm{Cs}_{0} \mathrm{M}$ devices in a nitrogen atmosphere held at room temperature under constant illumination and maximum power point tracking. Cross-sectional scanning electron microscopy (SEM) images of low magnification Cs5M devices. Reproduced with permission. Copyright 2016, The Royal Society of Chemistry [115]. (c) schematics of the triple A-cation perovskite films without and with $\mathrm{MACl}$ additive, and after passivation with iodine. Crystal structure of perovskite films with $\mathrm{MACl}$ additive before annealing, after annealing, and after passivation of ionic vacancies. Top-view SEM images of triple A-cation perovskite films without and with MACl additive in the starting solution. Reproduced with permission. Copyright 2019, WILEY-VCH Verlag GmbH \& Co. KGaA, Weinheim [149]. (d) SEM images of $\mathrm{MAPbI}_{3}$ and optimized PTZ-modified $\mathrm{MAPbI}_{3}$ films. XRD of MAPbI${ }_{3}$, optimized PTZ-modified $\mathrm{MAPbI}_{3}$ films and simulated powder tetragonal $\mathrm{MAPbI}_{3}$, and absorption spectra of $\mathrm{MAPbI}_{3}$ and optimized PTZ-modified MAPbI 3 films. Reproduced with permission. Copyright, 2020, Elsevier B.V [173].

\subsection{Grain boundaries and surface passivation}


Recently, many studies have focused additive engineering to passivate grain boundaries (GBs) and grain surfaces to further increase the power conversion efficiency and open circuit voltage $\left(\mathrm{V}_{\mathrm{OC}}\right)$ of PSCs, because GBs and surfaces are the main sources of recombination sites. An additive used is the PTAA \{poly [bis (4-phenyl) $(2,4,6$ trimethylphenyl) amine] $\}$ that improved the interfacial trap-states passivation, the transfer and collection of the carrier significantly due to the formation of the mixed interlayer of perovskite [51]. As mentioned above, $\mathrm{MACl}$ was used to obtain highquality perovskite film, but to further improve the performance of the triple Acation PSC device, the researchers passivated the surface of the perovskite film with iodine dissolved in Isopropyl alcohol to mitigate recombination sites and vacancies of iodide on the perovskite layer surface (Fig. 16c). The final device performance demonstrates that the additive plays an important role in obtaining a highly efficient PSC with a potential loss of only $\approx 370 \mathrm{mV}$ [149]. Jiang et al. [26] reported the use of an organic halide salt, phenethylammonium iodide (PEAI), for post-treatment of mixed perovskites $\mathrm{FA}_{1-\mathrm{x}} \mathrm{MA}_{\mathrm{x}} \mathrm{PbI}_{3}\left(\mathrm{FA}: \mathrm{HC}\left(\mathrm{NH}_{2}\right)_{2} ; \mathrm{MA}: \mathrm{CH}_{3} \mathrm{NH}_{3}\right)$ to suppress the surface defects of perovskite polycrystalline films for efficient solar cells, with a device structure of glass/ITO/SnO $2 /$ perovskite/spiro-OMeTAD/Au. They showed that the additive molecules were not incorporated into the perovskite crystal lattice and likely resided at the GBs and surfaces. Therefore, this reduces the height difference between the grain surface and the GBs and provides an efficient and simple method for passivation of the perovskite surface through which the defects are significantly reduced, and the recombination is suppressed. As a result, they showed a certified efficiency of 
$23.32 \%$ by adopting a flat structure processed in a low temperature (Fig. 16a). Fu et al. [206] prepared high-performance PSCs incorporated a pyridine-2carboxylic lead salt $\left(\mathrm{PbPyA}_{2}\right)$. The pyridine and carboxyl groups on $\mathrm{PbPyA}_{2}$ can not only control crystallization, but also passivate GBs, which result in the high-quality perovskite film with larger grains and fewer defects. During the film preparation, the pyridine and carboxyl groups of $\mathrm{PyA}^{-}$have strong interaction with $\mathrm{Pb}^{2+}$ and $\mathrm{MA}^{+}$ions, thereby control perovskite crystallization to suppress the morphological defect formation. After the perovskite deposition, the $\mathrm{PbPyA}_{2}$ molecules mainly distribute around GBs and not only interact with the GBs by the organic acid ions, but also the excess $\mathrm{Pb}^{2+}$ ions around GBs. This can cap the volatile composition to decrease the deep defects, thereby benefits for suppressing ions migration, depressing composition volatilization and insolating external violation, leading to lower hysteresis and increased $V_{O C}$ in PSCs (Fig. 16b). Zuo et al. demonstrated the use of polymers with coordination groups to improve the performance of PSCs. They proposed that the binding interaction between perovskite and polymers is a key parameter that affects passivation. The mechanism regarding the performance of the device is attributed to the passivation of the trap states in the GBs throughout the perovskite films with different polymers. The use of these polymer modifiers results in a remarkable change in the electronic properties of the films, as measured by both carrier dynamics and overall device performance. The devices grown with the polymer poly(4-vinylpyridine) (PVP) showed significantly enhanced power conversion efficiency from $16.9 \pm 0.7 \%$ to $18.8 \pm 0.8 \%$ (champion efficiency, 20.2\%) from a reverse scan and stabilized champion efficiency from 17.5 to 
19.1\% compared to controls without any passivation (Fig.16c) [37]. Yang et al. showed the influence of molecular structure of molecules on their passivation effect to hybrid perovskites. They systematically designed the structures of molecular functional groups, including carboxyl, amine, isopropyl, phenethyl, and tertbutylphenethyl groups. Results demonstrated that the carboxyl and amine groups would heal charged defects through electrostatic interactions, and defects related to neutral iodine can be reduced by aromatic structures. The defect passivation in the interfaces and surfaces reduces the $\mathrm{V}_{\mathrm{OC}}$ deficit of the $\mathrm{p}-\mathrm{i}-\mathrm{n}$ structured device to $0.34 \mathrm{~V}$ and boosts the efficiency to $21.4 \%$ (Fig. 16d) [226].

(a)

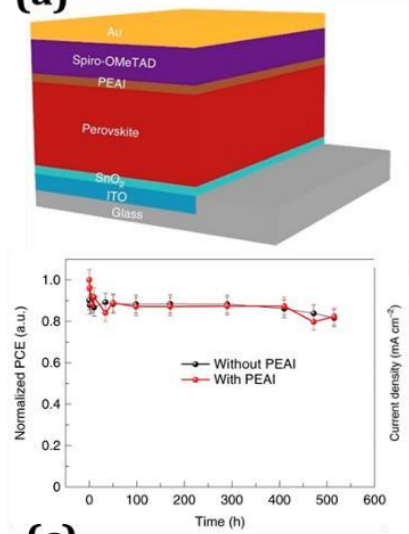

(c)
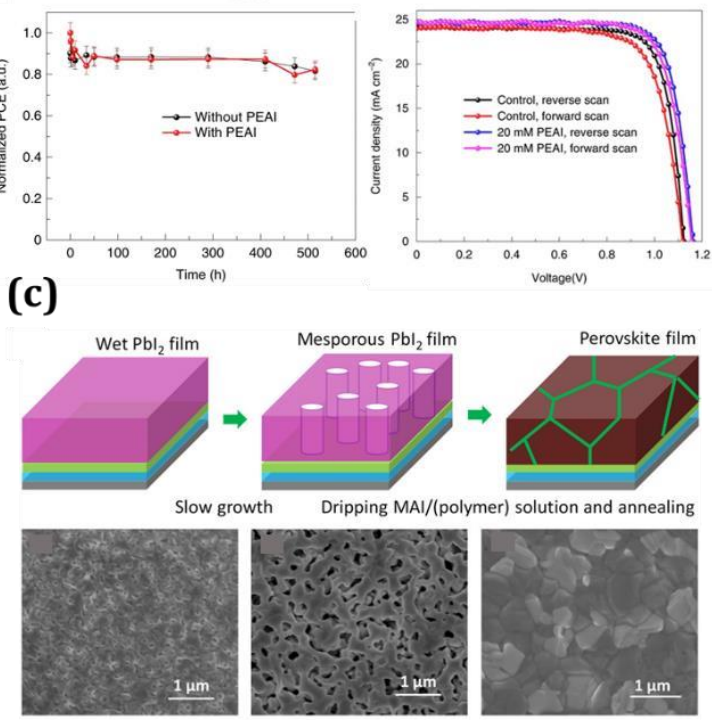
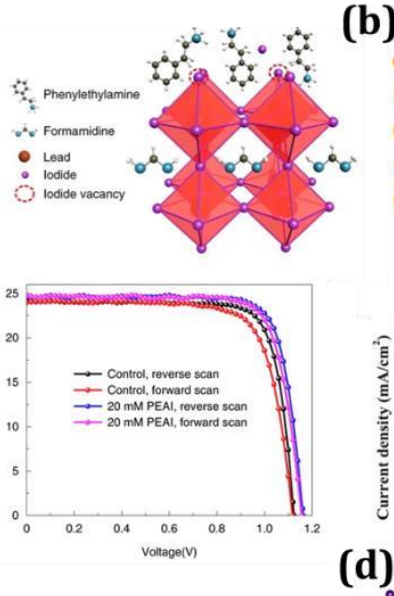

(d)

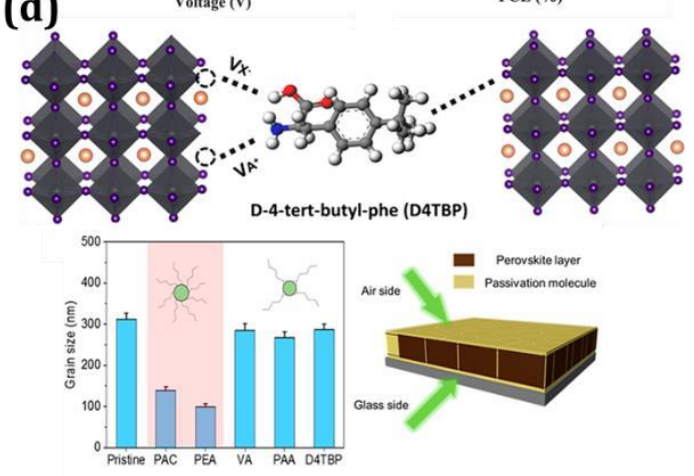

(b)
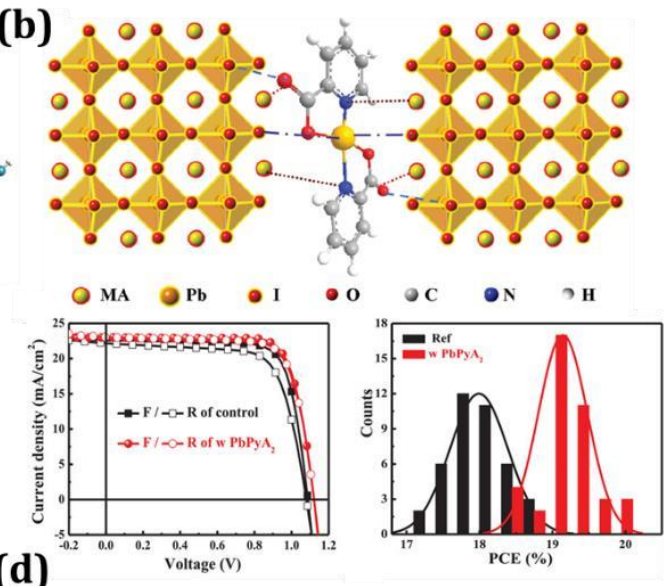

Fig. 16. (a) Device structure. Passivation mechanism of the PEAI layer for the perovskite film. The thermal stability $\left(85^{\circ} \mathrm{C}\right)$ of the devices with and without PEAI layers. The typical J-V curve of the device with PEAI (20 mM) and without PEAI treatment under one-sun $\left(100 \mathrm{~mW} \mathrm{~cm}^{-2}\right)$ conditions. Reproduced with permission. Copyright 2019, NATURE PHOTONICS [26]. (b) the schematic illustration of $\mathrm{PbPyA}_{2}$ molecules located at the GBs after film formation and strongly interacted with perovskite component to passivate GBs. The J-V curses of champion devices 
from the bare and doped films. Reproducibility analysis of the device's efficiency. Reproduced with permission. Copyright 2019, WILEY-VCH Verlag GmbH \& Co. KGaA, Weinheim [206]. (c) schematic diagram for incorporating the polymer into the perovskite films. SEM images of homogeneous $\mathrm{PbI}_{2}$ film without slow growth, mesoporous $\mathrm{PbI}_{2}$ film with slow growth, and perovskite film processed from slowly grown $\mathrm{PbI}_{2}$ with $\mathrm{PVP}$ polymer. Reproduced with permission. Copyright 2017, American Association for the Advancement of Science [37]. (d) schematic illustration of the origin of D4TBP passivation effect on different defect sites. Reproduced with permission. Grain size distribution of the perovskite films. Insets show the adsorption of monodentate and bidentate ligands affected by the steric effects. Schematic of the PL measurement of the grain boundary passivated perovskite films. Copyright 2019, American Chemical Society [226].

Shao et al. (Fig. 17a) showed that the trap states on the surface and grain boundaries of the perovskite materials are the origin of photocurrent hysteresis and reported that the fullerene layers deposited on perovskites can effectively passivate these charge trap states and eliminate the notorious photocurrent hysteresis. This conclusion is due to the higher response speed of the device after passivation. The control devices without

PCBM show a slow rising of photocurrent to maximum value during a long duration (75 s) on turning on the illumination, corresponding to the trap filling process, while the photocurrent rises almost instantly to the maximum in the optimized devices [83]. However, Zheng et al. demonstrated the use of quaternary ammonium halides can effectively passivate ionic defects in several different types of hybrid perovskite, compared with the devices with PCBM passivation. These quaternary ammonium halides (QAHs) with a structure of $\mathrm{NR}^{+}{ }_{4} \mathrm{X}^{-}$, where $\mathrm{R}$ is an alkyl or aryl group and $\mathrm{X}$ is halide, can efficiently passivate negative and positive charged defects in HPs with quaternary ammonium and halide ions. The QAH passivation remarkably reduces the trap density and prolongs the carrier lifetime, which universally enhances the $\mathrm{V}_{\mathrm{OC}}$ of 
the HP planar heterojunction devices with different bandgaps and consequently increases the PCE by $10 \%-35 \%$ [194].

(a)
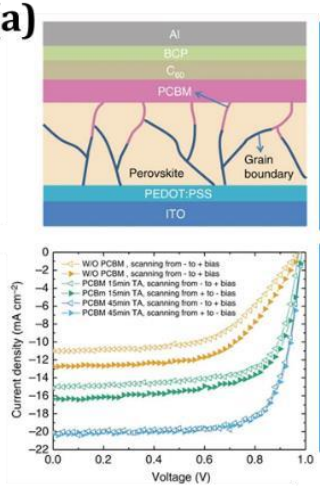
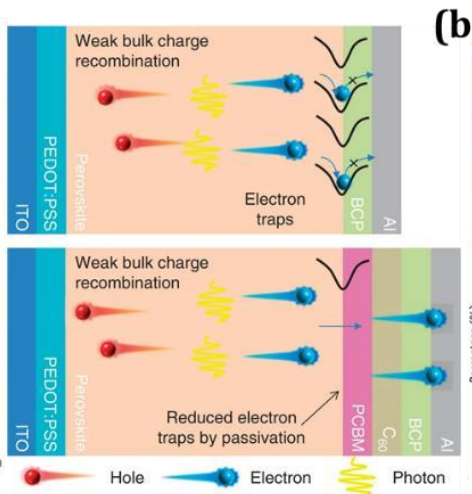

(b)

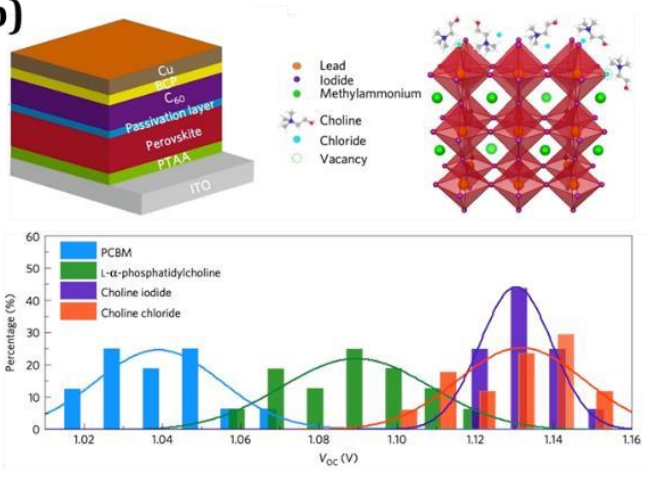

Fig. 17. (a) Device structure with PCBM layer. Photocurrents for devices without a PCBM layer (orange), with PCBM layers thermally annealed for $15 \mathrm{~min}$ (green) and $45 \mathrm{~min}$ (blue), respectively. Schematic of the surface recombination reduction by passivating the trap states. Reproduced with permission. Copyright 2014, NATURE COMMUNICATIONS [83]. (b) the device structure of perovskite planar heterojunction solar cells. Schematic illustration of quaternary ammonium halides (QAHs) assembled on the defect sites. The statistics of $V_{\text {oc }}$ distribution for devices with PCBM (blue), L- $\alpha$-phosphatidylcholine (green), choline iodide (violet) and choline chloride (red). The solid lines represent the Gauss distribution fitting for the statistic of voc. Reproduced with permission. Copyright 2017, NATURE ENERGY [194].

\section{Impact of additive on the stability of PSCs}

One of the most important criteria for a PSC today is the ability to maintain a stable power output under standard working conditions. Therefore, the real challenge lies on the long-term stability of the PSCs. Non-encapsulated PSCs have demonstrated hundreds of hours of stability when stored in the dark and measured every several hours or days. To be marketable within the industry, PSCs must be able to operate continuously for about 25 years under real outdoor conditions. However, PSCs are prone to decomposition when exposed to moisture, oxygen, heat, light, etc. [262]. Recently published ISOS protocols for stability assessment of PSCs suggest that a PSC 
can only be called "stable" if it can stand more than $1000 \mathrm{~h}$ under continuous light irradiation under 1 Sun (ISOS-1-L) without losing more than $10 \%$ of their initial efficiency [263-265]. Some reported stability studies made to PSCs showing no more than $\square 10 \%$ performance loss after $\square 1000 \mathrm{~h}$ stability analysis under continuous 1 sun AM 1.5G illumination are summarized in Fig. 18. The graph indicates that long operational stability can be achieved (i) in any of the three PSCs configurations (Fig. 18a): normal (green area), inverted (yellow area) and C-based (purple area); (ii) applying 3D, 3D/2D [266] and 2D [267] halide perovskites (HPs) structures containing Cs, Rb, methylammonium (MA) and/or formamidinium (FA) cations (Fig. 18b), as in $\mathrm{MAPbI}_{3}$ [268-270], double cation MAFA [271] or CsFA [272][209], triple cation RbCsFA [273] or CsMAFA [274-275] and quadruple cation RbCsMAFA (this work) (iii) by replacing the unstable Spiro-OMeTAD with novel organic hole transporting materials (HTMs) like EH44 [275], BDPSO [270] and PDCBT [271] (Fig. 18c); (iv) if metal oxides are applied as transporting layers in the form of doped [269][271], complex oxides [268], as oxide multilayers [266][276] or as metal oxide layers functionalized with organic molecules [275], polymers [271][273] or $\mathrm{C}_{60}$ derivatives [269][271][277] (Fig. 18d); or (v) by the application of additives for the controlled crystal growth of the perovskite absorbers [266][209][276]. 
(a) Back Metal Electrode

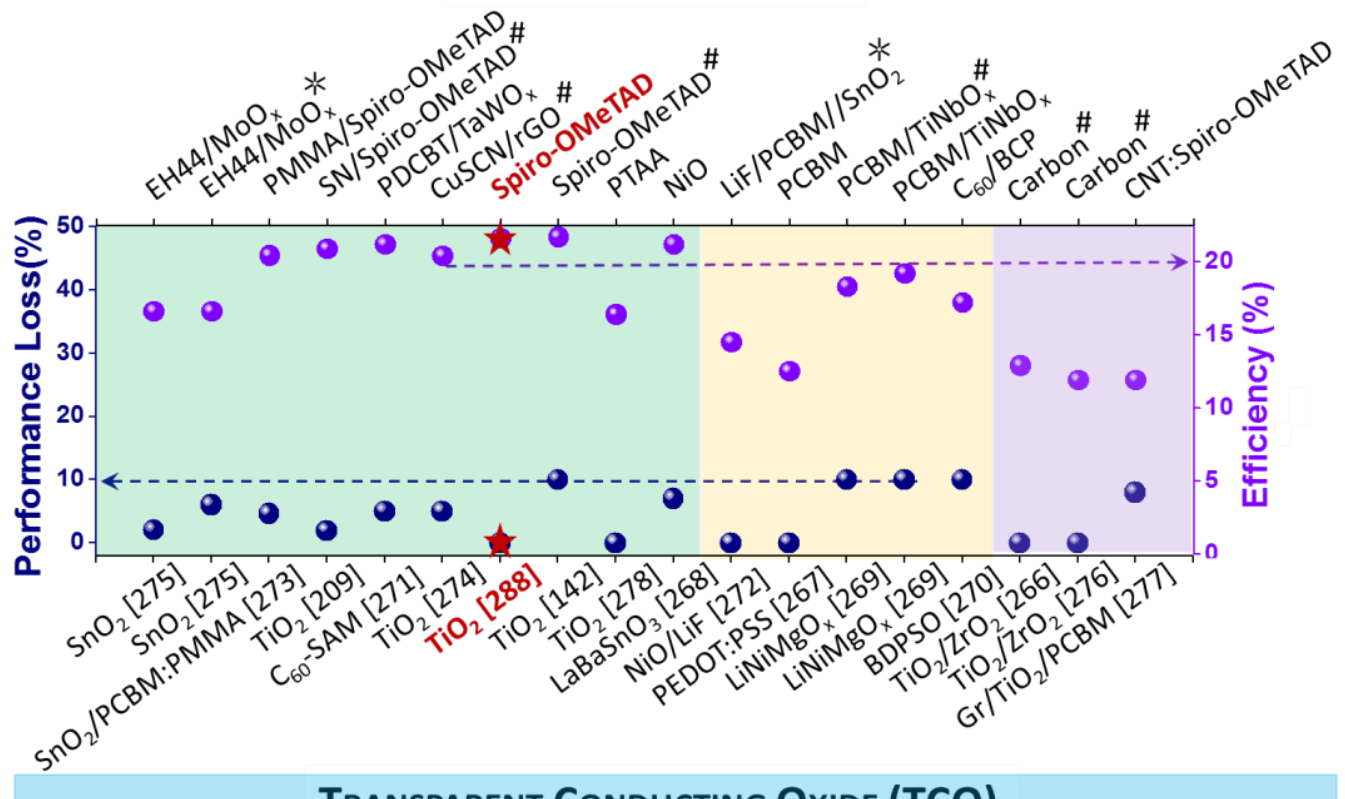

Transparent Conducting Oxide (TCO)

NORMAL

INVERTED

C-BASED

$\star$ ICN2's PSC

(b)

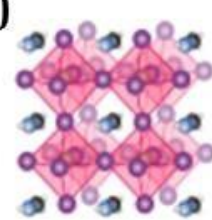

Cations in Halide Perovskites
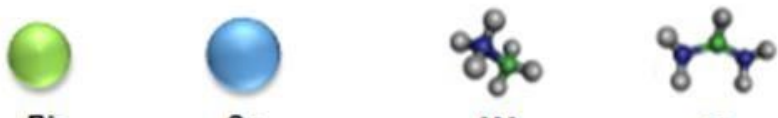

$\mathrm{Rb}$

MA

FA
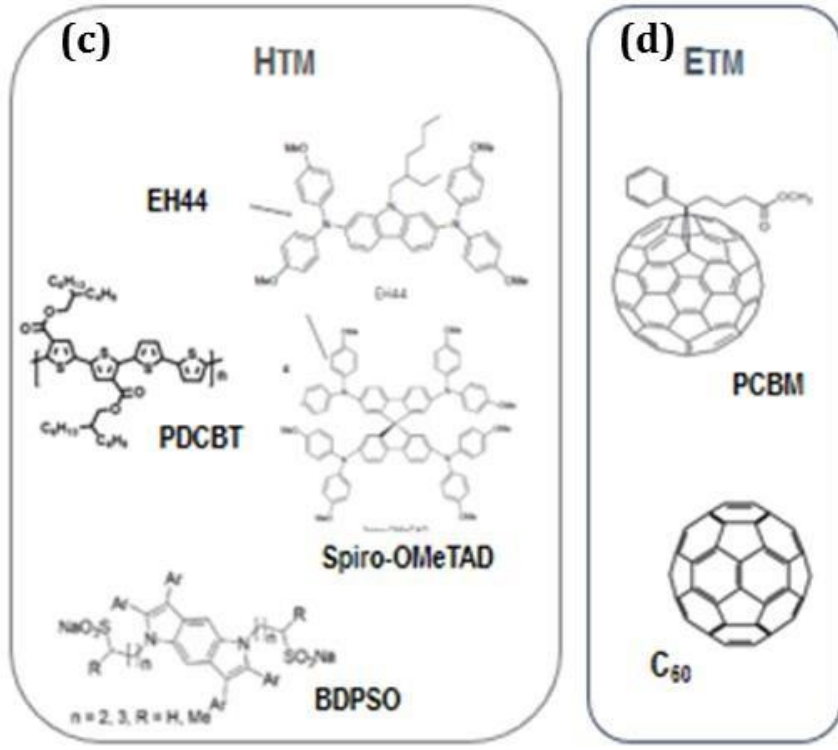

(e)

ADDITIVES

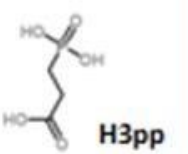

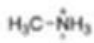

$$
\begin{gathered}
\text { O. } \mathrm{C}-\mathrm{CH}_{3} \\
\text { MAAC }
\end{gathered}
$$<smiles>C[C@H](N)[C@H](C)N</smiles>

TSC

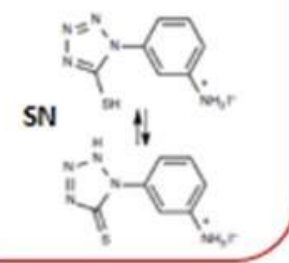

Fig. 18. Operational stability of halide perovskite solar cells under continuous illumination of 1 sun. (a) PSC with normal (green area), inverted (yellow area) and C-based (purple area) configurations. Materials applied in PSCs (b) HP cations (c), HTMs other than metal oxides (d) and ETMs other than metal oxides (e) additives. Results from ICN2 are represented by red stars. 
Although a great variety of materials and device configurations are displayed in Fig.

18a, the recipe to achieve high efficiencies maintaining long operational stability $(\geq$ $1000 \mathrm{~h}$ ) with minimal performance loss $(\leq 10 \%)$, seems to reside in the engineering and passivation of defects that can be found at the transport layers, interfaces or within the HP absorbers [279-282]. The reduction of defect density mitigates recombination and prolongs the lifetime of charges, leading to efficient and stable PSCs. Less defect concentration is found in perovskite absorbers if synthesized as single crystals. Their superior properties in comparison to polycrystalline thin films are due to the presence of $2-4$ orders of magnitude lower trap densities [283]. Nevertheless, the use of single crystals is incompatible with solution processing and large-scale device fabrication. Thus, the use of additives, usually incorporated in the perovskite solution before thin film deposition, has become one of the most popular methods to enhance PSC performance and lifetime. For example, the addition of the ionic-liquid methylammonium acetate (MAAc)/thio-semicarbazide (TSC) additive in $\mathrm{MAPbI}_{3}$ (MAPI)[284] or the application of 3-(5-mercapto-1H-tetrazol-1-yl)benzenaminium iodide (SN)[209] results in thin films with large grain size and low density of defects and thus, highly efficient and stable PSCs.

\subsection{Decoupling the effect of defects governing efficiency and stability}

Halide perovskite are ionic-electronic conductors and "soft" nanomaterials [285-286]. They are characterized by their weak ionic bonds and van der Waals interactions which are highly sensitive to the stress factors usually found under long-term operational solar 
cell conditions (light, heat, humidity, electric field, etc.). Their ionic nature translates into high ionic motion, hysteresis and device degradation. Polycrystalline thin films fabricated by solution processing methods, result in high defect concentration which are undesirable in high quality solar cell devices and should be engineered in order to eliminate or reduce their presence in the film. We can find many types of point defects in halide perovskites. Deep level traps are under coordinated halides ions, under coordinated $\mathrm{Pb}^{2+}$ ions, lead clusters, among others, while shallow level traps can be I or MA vacancies in the bulk of the materials. Deep defects have strong impact in nonradiative recombination affecting $\mathrm{V}_{\mathrm{oc}}$ and power conversion efficiency of the solar cell.

Shallow defects are no related to non-radiative recombination but affect the ionic constituents of the halide perovskite characterized by their low activation energies for ionic motion (0.58 eV for $\mathrm{I}^{-}, 0.84 \mathrm{eV}$ for $\mathrm{MA}^{+}$, and $2.31 \mathrm{eV}$ for $\mathrm{Pb}^{2+}$ ) [287]. Thus, shallow defects can intensify the degradation of the long-term stability of PSCs under various operational conditions. Although the science behind point defects and defect passivation is ample and complex, we can relate the efficiency of the PSC to deep defects and thus, increasing the efficiency of the PSC should include passivation of defects through chemical bonding (coordination or ionic). To enhance the long-term stability of solar cell under operational conditions, we should avoid ion migration and phase segregation and thus, one should look for the passivation, annihilation or attenuation of shallow point defects. 
The equilibrium between high power conversion efficiency and long-term operational stability is not an easy task and very few publications can be found in the literature achieving this goal (See Table 1). Especially rare are the reports under high temperature $\left(60-85^{\circ} \mathrm{C}\right)$ conditions [274]. In general, we have observed different scenarios followed by the PV community:

Most published work search for additive engineering for deep-defect passivation which results in enhanced power conversion efficiency of the PSC. However, without ion immobilization the devices are not always highly stable [94][159][173].

Very recent results have shown that the engineering of shallow defects through additive manipulation can greatly enhanced the long-term stability of the PSCs [288]. In these cases, the efficiency of the PSC applying additives is good (> 20\%) but not superior than the control device (without additive). We believe the latter has limited the publication of such results in the literature. However, a careful optimization of the additive concentration that can passivate shallow defects, could permit to obtain excellent PSC's efficiencies safeguarding, at the same time, the long-term stability. The application of halide perovskites with passivated/compensated shallow defects to inhibit ion migration in the original halide perovskite material is a method very recently proposed [248][288-290].

Very few literature examples report on simultaneous ion immobilization and defect passivation/compensation showing superior PCE and also excellent long-term stability [289]. Some examples include PSC with additives such as ionic liquids [181][291-293]. Therefore, the understanding of the influence of the additives on the environmental, light and thermal stability of PSCs is of utmost importance in order to develop 
reproducible techniques for highly efficient and stable PSCs. In this section, we will describe the influence of additives on PSCs stability due to environmental aspects (presence of oxygen and moisture), UV light irradiation or heat.

\subsection{Influence of additive on environmental stability of PSCs}

PSCs offer simple processing and extremely high photoconversion efficiency. Unfortunately, during the process of assembling and testing, such devices are impeded by the poor stability of the components. A major source of instability is the exposure to oxygen and moisture. The process of photo-oxidation, where an excited electron in the conduction band can be oxidized by molecular oxygen, is almost inevitable. Other investigations deal with the formation of reactive super-oxide species, attributed to charge transfer between $\mathrm{O}_{2}$ molecules and photo-excited perovskite. While oxidation and photo-oxidation are commonly seen in a wide range of semiconductors, the current class of hybrid perovskites faces another challenge: they are extremely unstable to water or even moisture in the air. First, due to the high sensitivity of $\mathrm{CH}_{3} \mathrm{NH}_{3} \mathrm{PbI}_{3}$ to water, halide perovskite tends to hydrolyze in the presence of moisture, which leads to the degradation, as shown in the following:

$$
\begin{aligned}
& \mathrm{CH}_{3} \mathrm{NH}_{3} \mathrm{PbI}_{3}(s) \leftrightarrow \mathrm{PbI}_{2}(s)+\mathrm{CH}_{3} \mathrm{NH}_{3} \mathrm{I}(a q) \\
& \mathrm{CH}_{3} \mathrm{NH}_{3} \mathrm{I}(a q) \leftrightarrow \mathrm{CH}_{3} \mathrm{NH}_{2}(a q)+\mathrm{HI}(a q) \\
& 4 \mathrm{HI}(a q)+\mathrm{O}_{2}(g) \leftrightarrow 2 \mathrm{I}_{2}(s)+2 \mathrm{H}_{2} \mathrm{O}(l) \\
& 2 \mathrm{HI}(a q) \leftrightarrow \mathrm{H}_{2}(g)+\mathrm{I}_{2}(s)
\end{aligned}
$$


Furthermore, equilibration of reaction (la) leads to the coexistence of $\mathrm{CH}_{3} \mathrm{NH}_{3} \mathrm{I}$, $\mathrm{CH}_{3} \mathrm{NH}_{2}$ and $\mathrm{HI}$ in the films. There are two paths for $\mathrm{HI}$ to degrade in the next step. One path is a redox reaction in the presence of oxygen $(1 b)$; The other method is a photochemical reaction, in which $\mathrm{HI}$ can be broken down into $\mathrm{H}_{2}$ and $\mathrm{I}_{2}$ under UV radiation (1c). HI consumption, according to reactions (1b) and (1c), drives the entire degradation process [294].

Zhao et al. reported perovskite solar cell architecture based on an insulating polymer Polyethylene glycol (PEG)-scaffold structure. PEG plays an important role by forming tangled long-chain molecules, which act as a three-dimensional skeleton to support perovskite crystals, enabling the coverage on the substrate more uniformly. The improved stability and self-healing effect of the PSC devices can be ascribed to the excellent hygroscopicity of the PEG molecules and their strong interaction with the perovskite. The omnipresent PEG molecules can absorb water efficiently to form a compact moisture barrier around perovskite grains with little water penetrating into the film. The instant decomposition-regeneration mechanism explains the fast self-healing process in the PEG scaffold perovskite film (Fig. 19a) [47].

Bi et al. used an aliphatic fluorinated amphiphilic additive $\left(\mathrm{CF}_{3} \mathrm{CH}_{2} \mathrm{NH}_{3} \mathrm{I}\right)$ in $\mathrm{MAPbI}_{3}$ perovskite, to enhance the stability and performance of the PSCs. More importantly, moisture resistance is enhanced without formation of 2D perovskite (sacrificing performance) due to the hydrophobic $-\mathrm{CF}_{3}$ terminal group over the surface of the $3 \mathrm{D}$ 
perovskite. A significant enhancement from average PCE of $15.6 \%$ to $18.0 \%$ was achieved by introducing $3 \mathrm{~mol} \%$ aliphatic fluorinated amphiphilic (FEAI) additive into the perovskite precursor solutions to improve the morphology of perovskite thin films

(Fig. 19b) [200].

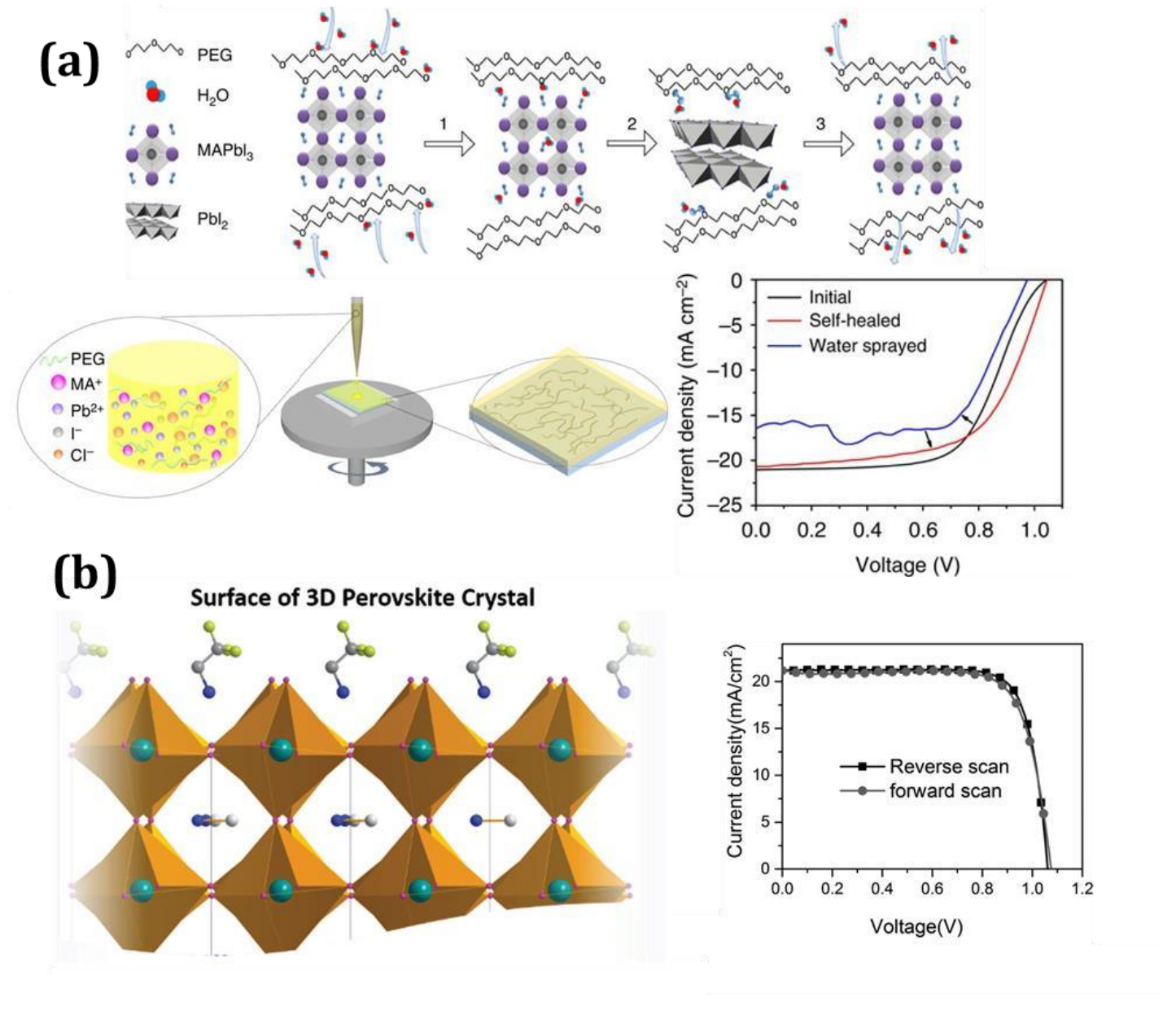

Fig. 19. (a) Schematic diagram to show mechanisms for the self-healing properties in PPSCs: (1) Water absorb on perovskite; (2) Perovskite hydrolysis into $\mathrm{PbI}_{2}$ and $\mathrm{MAI}-\mathrm{H}_{2} \mathrm{O}$ by water; (3). Restrained MAI by PEG react with nearby $\mathrm{PbI}_{2}$ to form perovskite again after water evaporates. PEG has a strong interaction with MAI, preventing it from evaporating, subsequently $\mathrm{MAI}$ and $\mathrm{PbI}_{2}$ react in situ to form perovskite after the film was removed away from the vapour source. Schematic diagram showing the fabrication process of perovskite film with polymer scaffold using one-step spin coating method. J-V curves of PSCs before and after water spray, revealing a complete recover of the cells in one minute when it puts back to ambient air. Reproduced with permission. Copyright 2016, NATURE COMMUNICATIONS [47]. (b) schematic model of the FEAI intercalating on the crystal surface of a 3D perovskite $\mathrm{MAPbI}_{3}$. Current-voltage $(\mathrm{J}-\mathrm{V})$ curves for one optimized device with respect to forward and reverse scan direction at a scan rate of $5 \mathrm{mV} / \mathrm{s}$ under simulated AM1.5G solar illumination. Reproduced with permission. Copyright 2016, WILEY-VCH Verlag GmbH \& Co. KGaA, Weinheim [200]. 
Quan and co-workers reported reduced-dimensionality (quasi-2D) perovskite films that exhibit improved stability while retaining the high performance of conventional threedimensional perovskites. The intermediates between $3 \mathrm{D}$ and $2 \mathrm{D}$ are layered perovskites systematically synthesized by introducing a large organic cation, phenylethylammonium (PEA, $\mathrm{C}_{8} \mathrm{H}_{9} \mathrm{NH}_{3}$ ). The dimensionality of metal halide perovskite compounds can be continuously adjusted by mixing stoichiometric amounts of lead iodide $\left(\mathrm{PbI}_{2}\right)$, methylammonium iodide (MAI, $\left.\mathrm{CH}_{3} \mathrm{NH}_{3} \mathrm{I}\right)$ and phenylethylammonium iodide (PEAI), to produce compounds with different values of (n) in the series $\mathrm{PEA}_{2}\left(\mathrm{CH}_{3} \mathrm{NH}_{3}\right)_{\mathrm{n}-1} \mathrm{PbnI}_{3 \mathrm{n}+1}$. In this notation, the limit $\mathrm{n}=\infty$ corresponds to the $3 \mathrm{D}$ cubic perovskite, $\mathrm{CH}_{3} \mathrm{NH}_{3} \mathrm{PbI}_{3}$, while the other values describe $2 \mathrm{D}$ perovskite structures $(n=1)$ or quasi-2D $(n>1)$. PEA inserted perovskite (2D) showed large stability in water or humidity because the energy required to remove PEA from perovskite is more than MA due to its high formation energy (Fig. 20a) [152]. Gao et al. showed a novel method for improving the stability by introducing thiourea. Thiourea passivates perovskite by the formation of the $\mathrm{Pb}-\mathrm{S}$ bond on the outermost layer of perovskite and lath-shaped grains among perovskites, which contributes to the improvement of oxygen, light, thermal stability, and little hysteresis. The unencapsulated devices retain $98 \%$ and $93 \%$ of original efficiencies after two months under air conditions for active areas of 0.1 and $1.0 \mathrm{~cm}^{2}$, respectively (Fig. 20b) [189]. 
(a)
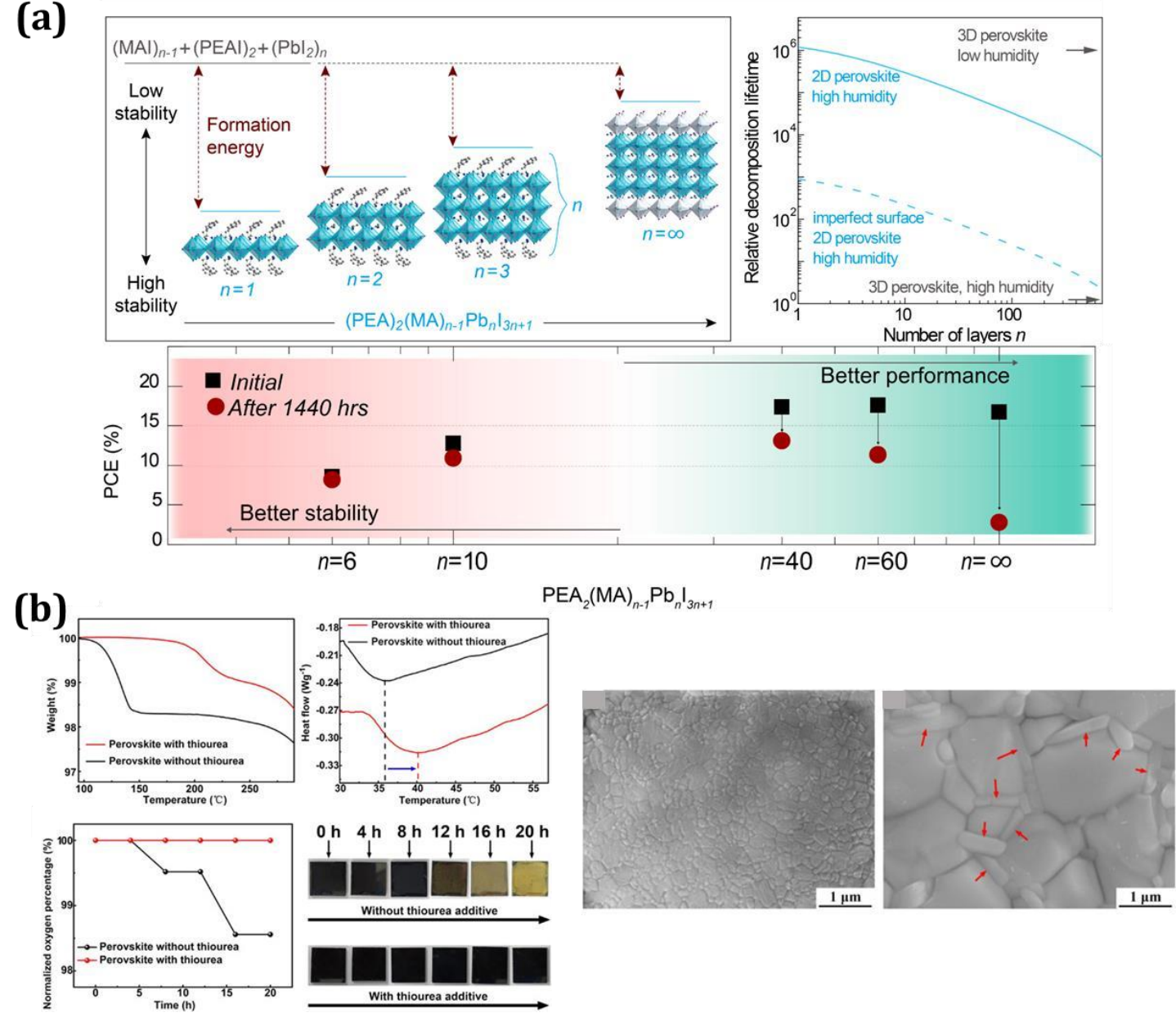

Fig. 20. (a) Unit cell structure of $\left(\mathrm{C}_{8} \mathrm{H}_{9} \mathrm{NH}_{3}\right)_{2}\left(\mathrm{CH}_{3} \mathrm{NH}_{3}\right)_{n_{-}} \mathrm{PbnI}_{3 n+l}$ perovskites with different $\mathrm{n}$ values, showing the evolution of dimensionality from $2 \mathrm{D}(n=1)$ to $3 \mathrm{D}(n=\infty)$. DFT simulation of the formation energy of perovskite with different $n$ values in different atmospheres. Device performance as a function of $n$ value, which shows that increased performance was achieved with increased $n$ value; however, in the meantime, stability was decreased. Reproduced with permission. Copyright 2016, American Chemical Society [152]. (b) TG spectra, DSC spectra, schematic diagram of oxygen content measurement, photographs of the perovskite films with and without a thiourea additive. SEM morphologies of the perovskite film without thiourea and the perovskite film with thiourea.

Reproduced with permission. Copyright 2018, WILEY-VCH Verlag GmbH \& Co. KGaA, Weinheim [189]. 4.3.

Influence of additive on ultraviolet (UV)-light stability of PSCs

In PSCs, the most widely used photoanodes are composed of compact or mesoporous $\mathrm{TiO}_{2}$. However, instability in $\mathrm{TiO}_{2}$-based PSCs is attributed to light-induced desorption of oxygen molecules adsorbed on the surface. A possible proposed mechanism to explain the degradation process in the film under exposure to light is as follows: (1) 
$\mathrm{TiO}_{2}$ contain many oxygen vacancies $\left(\mathrm{Ti}_{3}{ }^{+}\right)$"particularly at the surface" and it acts as deep electron-donating sites which have placed at approximately $1 \mathrm{eV}$ below the $\mathrm{CB}$ edge. These deep electron-donating sites adsorb oxygen molecules by donating electrons to oxygen molecules and formed a resultant complex $\left(\mathrm{O}^{2-}-\mathrm{Ti}^{4+}\right)$. (2) Upon UV light exposure, photo-carriers are generated (photoelectrons in $\mathrm{CB}$ and holes in VB). These photo-generated holes further react with the oxygen radicles which have placed below the $\mathrm{CB}$ sites (oxygen vacancy sites). Molecular oxygen desorbed by leaving unoccupied states and free electrons per sites. These free electrons further recombined by hole conducting material and hence leads to instability in $\mathrm{TiO}_{2}$ based PSC devices under the explosion of ultraviolet (UV)-light [295]. Cesium bromide (CsBr), as an interface modifier between the electron collection layer and the $\mathrm{CH}_{3} \mathrm{NH}_{3} \mathrm{PbI}_{3-\mathrm{x}} \mathrm{Cl}_{\mathrm{x}}$ absorber layer, has been shown to effectively improve the stability of planar heterojunction devices under UV light soaking. The $\mathrm{CsBr}$ modification (coating) reduces the areal density of pinholes the FTO and results in a negative shift in the work of function of $\mathrm{c}-\mathrm{TiO}_{2}$ from 4.07 to $3.90 \mathrm{eV}$. Most significantly, the $\mathrm{CsBr}$ modification dramatically inhibits UV-induced degradation of perovskite films and devices. The presence of $\mathrm{CsBr}$ retards the PL decay process with the fast decay component lifetime $\square_{\text {fast }}$, increasing from 5.0 to $20.8 \mathrm{~ns}$ and the slow component, $\square_{\text {slow }}$, from 118.0 to 177.6 ns (Fig. 21a) [106]. Recently, Chen et al. reported that a synthesized luminescent $\mathrm{EuTiO}_{2}$ thin films via chemical-bath deposition at low-temperature $\left(70{ }^{\circ} \mathrm{C}\right)$, not only function as efficient charge transport layers but also effectively convert damaging UV light to extra visible luminescence. The controllable doping of $\mathrm{Eu}^{3+}$ also leads to a more optimized energy band alignment and therefore facilitates the electron extraction of 
$\mathrm{EuTiO}_{2}$ - based PSCs. This results in an increased photocurrent and open-circuit voltage, yielding an enhanced PCE of $21.40 \%$ with relative to pristine $\mathrm{TiO}_{2}$ device $(19.22 \%)$. PSCs based on Eu- $\mathrm{TiO}_{2}$ exhibited remarkably improved long-term UV stability, retaining $75 \%$ of the peak PCE after $500 \mathrm{~h}$ under continuous UV light illumination (5 $\mathrm{mW} \mathrm{cm}{ }^{-2}$ ) (Fig. 21b) [93].
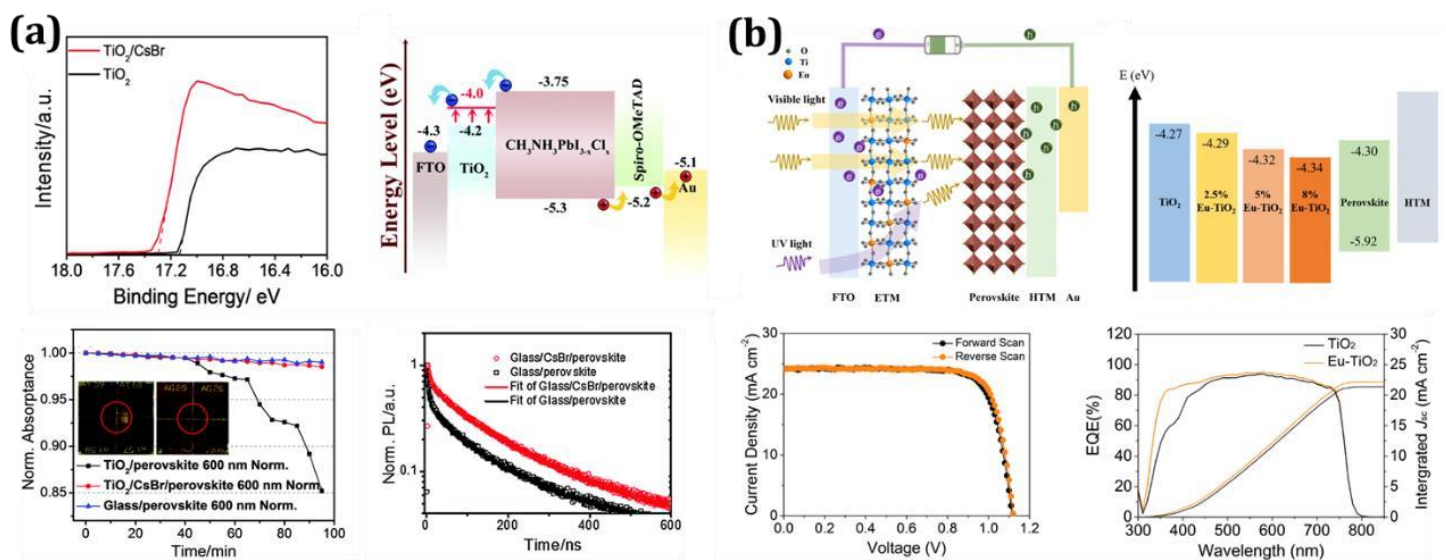

Fig. 21. (a) UPS spectra of c- $\mathrm{TiO}_{2}$ with (w) and without (w/o) $\mathrm{CsBr}$ modification. Energy level diagram of the device with the structure of $\mathrm{FTO} / \mathrm{c}-\mathrm{TiO}_{2}(\mathrm{CsBr}) /$ perovskite/spiro-OMeTAD/Au. Time-resolved photoluminescence spectra of perovskite thin films on glass collected at $400 \mathrm{kHz}$. Reproduced with permission. Copyright 2016, The Royal Society of Chemistry [106]. (b) schematic illustrations of the device configuration of n-i-p planar PSCs employing Eu- $\mathrm{TiO}_{2}$. Energy band alignment diagram of different layers of PSCs. The J-V curves of the champion device based on $5 \% \mathrm{Eu}-\mathrm{TiO}_{2}$ film under forward and reverse scans, IPCE measurement and the integrated $\mathrm{J}_{\mathrm{sc}}$ of PSCs based on $\mathrm{TiO}_{2}$ and 5\% Eu-TiO 2 films. Reproduced with permission. Copyright, 2019, Elsevier B.V [93].

\subsection{Influence of additive on thermal stability of PSCs}

As already mentioned, PSCs have attracted enormous attention in the last few years due to their rapid improvement and high certified efficiencies over $20 \%$. However, PSC thermal stability is still an obstacle to their commercialization. At low temperatures, the devices present very stable values (average loss $<5 \%$ ), but as the temperature increases significant decreases in the open circuit potential and short-circuit current are observed. 
Temperature is particularly critical as the normal operating environment for photovoltaic devices is under direct sunlight, which means the cell temperature can be up to $45^{\circ} \mathrm{C}$ or even to $85^{\circ} \mathrm{C}$ in desert. To date, temperature dependent studies on PSCs have been very limited compared with the numerous studies on improving their power output at room temperature. In attempts to overcome thermal instability, different additives have been applied to perovskites. Li et al. introduced an additive of ethyl 2cyanoacrylate (E2CA) to $\mathrm{MAPbI}_{3} \mathrm{PSCs}_{\mathrm{S}}$ E2CA was found and chemically anchored to GB in perovskite films due to its coordination effect with $\mathrm{PbI}_{2}$, effectively passivating the defects at GBs. As a result, E2CA PSCs exhibited improved stability, retaining $90 \%$ of maximum efficiency after aging over $1000 \mathrm{~h}$. Furthermore, even at high temperature $\left(85^{\circ} \mathrm{C}\right)$ in moisture air, unencapsulated $\mathrm{MAPbI}_{3}-\mathrm{E} 2 \mathrm{CA}$ devices still showed good thermal stability, retaining over $90 \%$ of the post burn-in efficiency after aging $200 \mathrm{~h}$ (Fig. 22a) [38]. On the other hand, Li et al. reported a chemical bond modulation of state-of-the-art triple cation perovskite $\left(\mathrm{Cs}_{0.05} \mathrm{FA}_{0.54} \mathrm{MA}_{0.41}\right) \mathrm{Pb}\left(\mathrm{I}_{0.98} \mathrm{Br}_{0.02}\right)_{3}$ through the addition of a small amount of alkaline halide, sodium fluoride $(\mathrm{NaF}) . \mathrm{NaF}$ is present on the perovskite film and forms hydrogen bonds with organic cations within the perovskite crystals, retarding the diffusion of these cations and their dissociation. Fluoride ions also form the ionic bonds with $\mathrm{Pb}^{2+}$, immobilizing both organic cations and halide anions. In this way, the fluoride ions effectively block the materials degradation pathway at the corresponding interfaces by passivating the surfaces and grain boundaries through chemical bonding. The resulted CsFAMA-F-based devices retain $90 \%$ of their initial PCE after annealing at $85^{\circ} \mathrm{C}$ for 1,000h, while CsFAMA PSCs retain only 50\% of their initial PCE (Fig. 22b) [130]. 

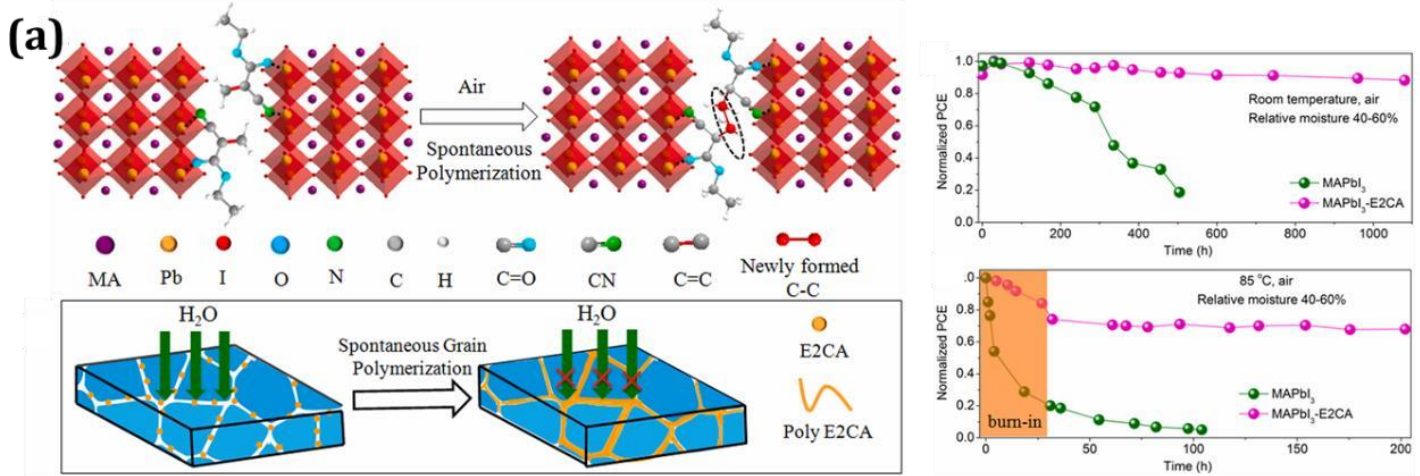

(b)
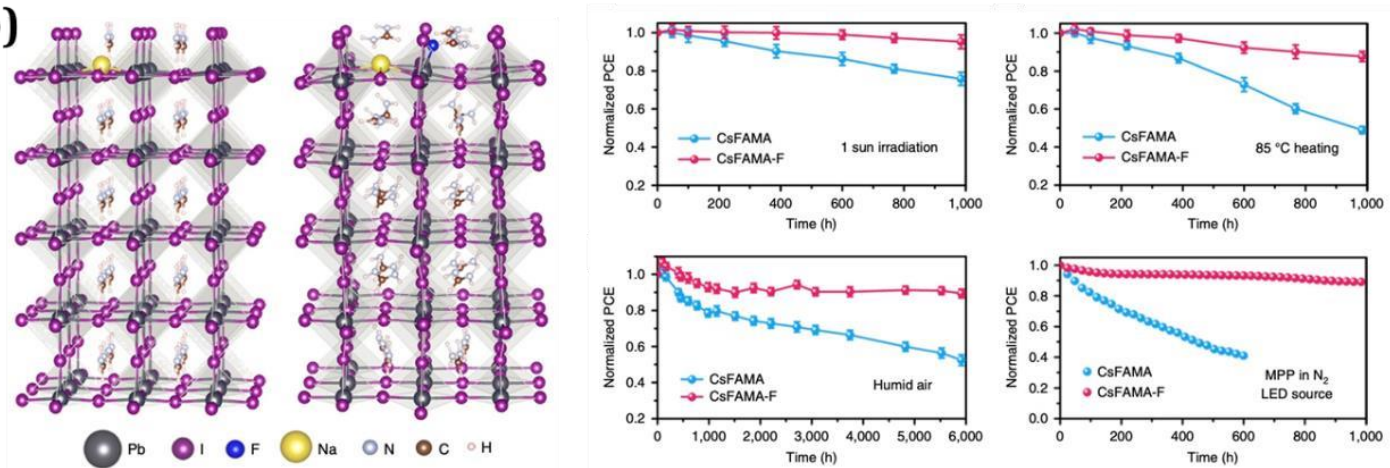

Fig. 22. (a) Schematic representation of spontaneous grain polymerization in MAPbI3-E2CA films. E2CA chemically anchors to $\mathrm{GBs}$ with $\mathrm{C}=\mathrm{O}$ and $\mathrm{C} \equiv \mathrm{N}$ groups and spontaneously polymerizes to a polymer at $\mathrm{GBs}$ when exposed in moisture air. Proposed working mechanism of E2CA in perovskite films. Moisture stability of PSCs stored in air (relative humidity: 40-60\%). Thermal stability of PSCs stored at $85^{\circ} \mathrm{C}$ in air (relative humidity: 40 60\%). Reproduced with permission. Copyright, 2019, Elsevier B.V [38]. (b) optimized structures of a Na-I unit and a Na-F unit adjacent to the $\mathrm{FAPbI}_{3}$ surface. Stability performance of PSCs under various conditions. Reproduced with permission. Copyright 2019, NATURE ENERGY [130].

\section{Conclusion and perspectives}

Due to the soft chemical nature of halide perovskites, their fabrication as polycrystalline thin films, when fabricated by solution processing methods, results in the unavoidable formation of defects (interstitials, vacancies). Defects are responsible for charge recombination and ion migration that reduce PSC efficiency and stability, respectively. The application of additives, organic or inorganic, are employed to eliminate or reduce the presence of defects. Additives, through their functional groups, can form robust chemical bonds with the halide perovskite, act as a redox shuttle or occupy the interstitial sites, suppressing defects and immobilization ions, leading to 
enhanced efficiency and stability. One of the main roles of additives in PSCs is to promote large grain size formation and crystal orientation and to passivate grain boundaries and interfaces. Although numerous studies on additives in PSCs are reported, the understanding of the type of bonding between perovskite and additives, especially those organic additives with multi-functional groups, is still limited. Currently, the progress of additives is mainly based on the trial-and-error method and effective design rules are still needed. The challenge lies in the difficulties to know the exact defect types present in the halide perovskite film which will require the compilation of databases of additives. Another important issue is the screen criteria of additives for PSCs. Additives should improve the initial efficiency and environmental stability of PSCs, but also improve the thermal stability of PSCs under $65-85^{\circ} \mathrm{C}$ (some additives may evaporate or react with transporting layers under elevated temperature and lose their effect). The ultimate aim of the additive should be to enable operational stability of PSCs under continuous light irradiation of one sun at $65-85^{\circ} \mathrm{C}$ under maximum power point (MPP) tracking without reducing the device efficiency. Should the design rules and the database of additives were constructed and the strict screen criteria of additives was applied, the stability of PSCs will be further improved and the commercialization of PSCs will be one step approaching.

\section{Acknowledgments}

We thank the Spanish MINECO through the Severo Ochoa Centers of Excellence Program under Grant SEV-2013-0295 for the postdoctoral contract to H.X. To the SolarEra.Net Cofund 2 (EU) and the AEI (Spain) for the project PrOperPhotoMiLe (Ref 12 and PCI2020-112185). To the Spanish Ministry of Science and Innovation for the grant GraPErOs (ENE2016-79282-C5-2-R), Self-Power (PID2019-104272RB-C54) and the OrgEnergy Excellence Network (CTQ2016-81911-REDT). To the Agència de 
Gestiód'Ajuts Universitaris i de Recerca (AGAUR) for the support to the consolidated

Catalonia research group 217 SGR 329 and the Xarxa d'R+D+I Energy for Society (XRE4S). Part of this work is under the Materials Science Ph.D. programme for C.P. of the Universitat Autonoma de Barcelona (UAB, Spain). We thank CONACYT for the scholarship to C.P. ICN2 is supported by the Severo Ochoa program from Spanish MINECO (Grant No. SEV-2017-0706) and is funded by the CERCA Programme / Generalitat de Catalunya.

\section{References}

[1] C. Ran, J. Xu, W. Gao, C. Huang, and S. Dou, "Defects in metal triiodide perovskite materials towards high-performance solar cells: Origin, impact, characterization, and engineering," Chemical Society Reviews, vol. 47, no. 12. Royal Society of Chemistry, pp. 4581-4610, 21-Jun-2018.

[2] A. Rajagopal, K. Yao, and A. K. Y. Jen, "Toward Perovskite Solar Cell Commercialization: A Perspective and Research Roadmap Based on Interfacial Engineering," Advanced Materials. 2018. [3] H. Zhang, M. K. Nazeeruddin, and W. C. H. Choy, "Perovskite Photovoltaics:

The Significant Role of Ligands in Film Formation, Passivation, and Stability," Advanced Materials. 2019.

[4] J. W. Lee and N. G. Park, "Chemical Approaches for Stabilizing Perovskite Solar Cells," Advanced Energy Materials. 2020.

[5] M. V. Khenkin et al., "Consensus statement for stability assessment and reporting for perovskite photovoltaics based on ISOS procedures," Nat. Energy, vol. 5, no. 1, pp. 35-49, Jan. 2020.

[6] N. G. Park, "Perovskite solar cells," RSC Energy Environ. Ser., vol. 2014-Janua, no. 11, pp. 242-257, Jan. 2014.

[7] F. Zhang and K. Zhu, "Additive Engineering for Efficient and Stable Perovskite Solar Cells," Advanced Energy Materials. Wiley-VCH Verlag, p. 1902579, 04Oct-2019.

[8] D. Weber, "Das Perowskitsystem CH3NH3 [PbnSn1-3X3] (X = Cl, Br, I)," Zeitschrift fur Naturforsch. - Sect. B J. Chem. Sci., vol. 34, no. 7, pp. 939-941, Jul. 1979.

[9] D. Weber, "CH3NH3SnBrxI3-x ( $\mathrm{x}=0$-3), ein Sn(II)-System mit kubischer Perowskitstruktur," Zeitschrift fur Naturforsch. - Sect. B J. Chem. Sci., vol. 33, no. 8, pp. 862-865, Aug. 1978. 
[10] D. Weber, "CH3NH3PbX3, ein Pb(II)-System mit kubischer Perowskitstruktur," Zeitschrift fur Naturforsch. - Sect. B J. Chem. Sci., vol. 33, no. 12, pp. 14431445, Dec. 1978.

[11] A. Kojima, K. Teshima, Y. Shirai, and T. Miyasaka, "Organometal halide perovskites as visible-light sensitizers for photovoltaic cells," J. Am. Chem. Soc., vol. 131, no. 17, pp. 6050-6051, May 2009.

[12] J. H. Im, C. R. Lee, J. W. Lee, S. W. Park, and N. G. Park, " $6.5 \%$ efficient perovskite quantum-dot-sensitized solar cell," Nanoscale, vol. 3, no. 10, pp. 4088-4093, Oct. 2011.

[13] H. S. Kim et al., "Lead iodide perovskite sensitized all-solid-state submicron thin film mesoscopic solar cell with efficiency exceeding 9\%," Sci. Rep., vol. 2, no. 1, pp. 1-7, Aug. 2012.

[14] M. M. Lee, J. Teuscher, T. Miyasaka, T. N. Murakami, and H. J. Snaith, "Efficient hybrid solar cells based on meso-superstructured organometal halide perovskites," Science (80-. )., vol. 338, no. 6107, pp. 643-647, Nov. 2012.

[15] NREL, "Best Research-Cell Efficiency Chart | Photovoltaic Research | NREL," Best Research-Cell Efficiency Chart | Photovoltaic Research | NREL, 2019. [Online]. Available: https://www.nrel.gov/pv/cell-efficiency.html. [Accessed: 05-Mar-2020].

[16] J. H. Heo et al., "Efficient inorganic-organic hybrid heterojunction solar cells containing perovskite compound and polymeric hole conductors," Nat. Photonics, vol. 7, no. 6, pp. 486-491, Jun. 2013.

[17] J. Burschka et al., "Sequential deposition as a route to high-performance perovskite-sensitized solar cells," Nature, vol. 499, no. 7458, pp. 316-319, Jul. 2013.

[18] M. Liu, M. B. Johnston, and H. J. Snaith, "Efficient planar heterojunction perovskite solar cells by vapour deposition," Nature, vol. 501, no. 7467, pp. 395398, Sep. 2013.

[19] N. J. Jeon, J. H. Noh, Y. C. Kim, W. S. Yang, S. Ryu, and S. Il Seok, "Solvent engineering for high-performance inorganic-organic hybrid perovskite solar cells," Nat. Mater., vol. 13, no. 9, pp. 897-903, Jul. 2014.

[20] N. J. Jeon et al., "Compositional engineering of perovskite materials for highperformance solar cells," Nature, vol. 517, no. 7535, pp. 476-480, Jan. 2015.

[21] W. S. Yang et al., "High-performance photovoltaic perovskite layers fabricated through intramolecular exchange," Science (80-. )., vol. 348, no. 6240, pp. 12341237, Jun. 2015.

[22] M. Saliba et al., "Cesium-containing triple cation perovskite solar cells: Improved stability, reproducibility and high efficiency," Energy Environ. Sci., vol. 9, no. 6, pp. 1989-1997, Jun. 2016.

[23] M. Saliba et al., "Incorporation of rubidium cations into perovskite solar cells improves photovoltaic performance," Science (80-. )., vol. 354, no. 6309, pp. 206-209, Oct. 2016. 
[24] W. S. Yang et al., "Iodide management in formamidinium-lead-halide-based perovskite layers for efficient solar cells," Science (80-. )., vol. 356, no. 6345, pp. 1376-1379, Jun. 2017.

[25] E. H. Jung et al., "Efficient, stable and scalable perovskite solar cells using poly(3-hexylthiophene)," Nature, vol. 567, no. 7749. Nature Publishing Group, pp. 511-515, 28-Mar-2019.

[26] Q. Jiang et al., "Surface passivation of perovskite film for efficient solar cells," Nat. Photonics, pp. 1-25, 2019.

[27] J. Y. Jeng et al., "CH3NH3PbI3 perovskite/fullerene planar-heterojunction hybrid solar cells," Adv. Mater., vol. 25, no. 27, pp. 3727-3732, Jul. 2013.

[28] H. Zhou et al., "Interface engineering of highly efficient perovskite solar cells," Science (80-. )., vol. 345, no. 6196, pp. 542-546, Aug. 2014.

[29] J. Y. Jeng et al., "Nickel oxide electrode interlayer in $\mathrm{CH} 3 \mathrm{NH} 3 \mathrm{PbI} 3$ perovskite/PCBM planar-heterojunction hybrid solar cells," Adv. Mater., vol. 26, no. 24, pp. 4107-4113, Jun. 2014.

[30] H. Choi et al., "Conjugated polyelectrolyte hole transport layer for inverted-type perovskite solar cells," Nat. Commun., vol. 6, no. 1, pp. 1-6, Jun. 2015.

[31] N. K. Noel et al., "Enhanced photoluminescence and solar cell performance via Lewis base passivation of organic-inorganic lead halide perovskites," ACS Nano, vol. 8, no. 10, pp. 9815-9821, Oct. 2014.

[32] F. Zuo, S. T. Williams, P. W. Liang, C. C. Chueh, C. Y. Liao, and A. K. Y. Jen, "Binary-Metal Perovskites Toward High-Performance Planar-Heterojunction Hybrid Solar Cells," Adv. Mater., vol. 26, no. 37, pp. 6454-6460, Oct. 2014.

[33] P.-W. Liang et al., "High-Performance Planar-Heterojunction Solar Cells Based on Ternary Halide Large-Band-Gap Perovskites," Adv. Energy Mater., vol. 5, no. 1, p. 1400960, Jan. 2015.

[34] D. P. McMeekin et al., "A mixed-cation lead mixed-halide perovskite absorber for tandem solar cells," Science (80-. )., vol. 351, no. 6269, pp. 151-155, Jan. 2016.

[35] J. H. Im, I. H. Jang, N. Pellet, M. Grätzel, and N. G. Park, "Growth of CH3 NH3 PbI3 cuboids with controlled size for high-efficiency perovskite solar cells," Nat. Nanotechnol., vol. 9, no. 11, pp. 927-932, Nov. 2014.

[36] W. Nie et al., "High-efficiency solution-processed perovskite solar cells with millimeter-scale grains," Science (80-. )., vol. 347, no. 6221, pp. 522-525, Jan. 2015.

[37] L. Zuo et al., "Polymer-modified halide perovskite films for efficient and stable planar heterojunction solar cells," Sci. Adv., vol. 3, no. 8, pp. 1-12, 2017.

[38] X. Li, W. Zhang, W. Zhang, H. Q. Wang, and J. Fang, "Spontaneous grain polymerization for efficient and stable perovskite solar cells," Nano Energy, vol. 58, no. December 2018, pp. 825-833, 2019.

[39] X. Li, W. Zhang, W. Zhang, H. Q. Wang, and J. Fang, "Spontaneous grain polymerization for efficient and stable perovskite solar cells," Nano Energy, vol. 58, no. January, pp. 825-833, 2019. 
[40] M. Kim, S. G. Motti, R. Sorrentino, and A. Petrozza, "Enhanced solar cell stability by hygroscopic polymer passivation of metal halide perovskite thin film," Energy Environ. Sci., vol. 11, no. 9, pp. 2609-2619, 2018.

[41] J. Yang et al., "Extremely Low-Cost and Green Cellulose Passivating Perovskites for Stable and High-Performance Solar Cells," ACS Appl. Mater. Interfaces, vol. 11, no. 14, pp. 13491-13498, 2019.

[42] D. Bi et al., "Polymer-templated nucleation and crystal growth of perovskite films for solar cells with efficiency greater than 21\%," Nat. Energy, vol. 1, no. 10, pp. 1-5, 2016.

[43] L. Meng et al., "Tailored Phase Conversion under Conjugated Polymer Enables Thermally Stable Perovskite Solar Cells with Efficiency Exceeding 21\%," J. Am. Chem. Soc., vol. 140, no. 49, pp. 17255-17262, 2018.

[44] C. Liang et al., "Controlling films structure by regulating 2D Ruddlesden-Popper perovskite formation enthalpy for efficient and stable tri-cation perovskite solar cells," J. Mater. Chem. A, pp. 5874-5881, 2020.

[45] J. Jiang et al., "Polymer Doping for High-Efficiency Perovskite Solar Cells with Improved Moisture Stability," Adv. Energy Mater., vol. 8, no. 3, pp. 1-9, 2018.

[46] X. Li, W. Zhang, Y. C. Wang, W. Zhang, H. Q. Wang, and J. Fang, "In-situ crosslinking strategy for efficient and operationally stable methylammoniun lead iodide solar cells," Nat. Commun., vol. 9, no. 1, pp. 1-10, 2018.

[47] Y. Zhao et al., "A polymer scaffold for self-healing perovskite solar cells," Nat. Commun., vol. 7, pp. 1-9, 2016.

[48] H. Zheng et al., "The multiple effects of polyaniline additive to improve the efficiency and stability of perovskite solar cells," J. Mater. Chem. C, vol. 7, no. 15, pp. 4441-4448, Apr. 2019.

[49] J. Peng et al., "A Universal Double-Side Passivation for High Open-Circuit Voltage in Perovskite Solar Cells: Role of Carbonyl Groups in Poly(methyl methacrylate)," Adv. Energy Mater., vol. 8, no. 30, pp. 1-9, 2018.

[50] C. Zhang et al., "Polarized Ferroelectric Polymers for High _Performance Perovskite Solar Cells," Adv. Mater., vol. 31, no. 30, p. 1902222, Jun. 2019.

[51] Y. Wu et al., "Heterojunction Engineering for High Efficiency Cesium Formamidinium Double-Cation Lead Halide Perovskite Solar Cells," ChemSusChem, vol. 11, no. 5, pp. 837-842, Mar. 2018.

[52] J. J. Yoo et al., "An interface stabilized perovskite solar cell with high stabilized efficiency and low voltage loss," Energy Environ. Sci., vol. 12, no. 7, pp. 21922199, 2019.

[53] Y. Yang et al., "Bi-functional additive engineering for high-performance perovskite solar cells with reduced trap density," J. Mater. Chem. A, vol. 7, no. 11, pp. 6450-6458, 2019.

[54] Z. Arain et al., "Low-Temperature Annealed Perovskite Films: A Trade-Off between Fast and Retarded Crystallization via Solvent Engineering," ACS Appl. Mater. Interfaces, vol. 11, no. 18, pp. 16704-16712, 2019. 
[55] M. Feng, S. You, N. Cheng, and J. Du, "High quality perovskite film solar cell using methanol as additive with $19.5 \%$ power conversion efficiency," Electrochim. Acta, vol. 293, pp. 356-363, 2019.

[56] M. Guan et al., "Employing tetraethyl orthosilicate additive to enhance trap passivation of planar perovskite solar cells," Electrochim. Acta, vol. 293, pp. 174-183, 2019.

[57] X. Yang et al., "Mixed-steam annealing treatment for perovskite films to improve solar cells performance," Sol. Energy, vol. 177, no. October 2018, pp. 299-305, 2019.

[58] S. You et al., "Additive-Enhanced Crystallization of Solution Process for Planar Perovskite Solar Cells with Efficiency Exceeding 19\%," Chem. - A Eur. J., vol. 23, no. 72, pp. 18140-18145, 2017.

[59] C. G. Wu, C. H. Chiang, Z. L. Tseng, M. K. Nazeeruddin, A. Hagfeldt, and M. Grätzel, "High efficiency stable inverted perovskite solar cells without current hysteresis," Energy Environ. Sci., vol. 8, no. 9, pp. 2725-2733, 2015.

[60] C. H. Chiang, M. K. Nazeeruddin, M. Grätzel, and C. G. Wu, "The synergistic effect of $\mathrm{H} 2 \mathrm{O}$ and DMF towards stable and $20 \%$ efficiency inverted perovskite solar cells," Energy Environ. Sci., vol. 10, no. 3, pp. 808-817, 2017.

[61] J. Lee et al., "Green-Solvent-Processable, Dopant-Free Hole-Transporting Materials for Robust and Efficient Perovskite Solar Cells," J. Am. Chem. Soc., vol. 139, no. 35, pp. 12175-12181, 2017.

[62] W. Chen et al., "Precise Control of Crystal Growth for Highly Efficient $\mathrm{CsPbI} 2$ Br Perovskite Solar Cells," Joule, vol. 3, no. 1, pp. 191-204, 2019.

[63] L. Li, Y. Chen, Z. Liu, Q. Chen, X. Wang, and H. Zhou, "The Additive Coordination Effect on Hybrids Perovskite Crystallization and HighPerformance Solar Cell," Adv. Mater., vol. 28, no. 44, pp. 9862-9868, 2016.

[64] C. Qin, T. Matsushima, T. Fujihara, and C. Adachi, "Multifunctional Benzoquinone Additive for Efficient and Stable Planar Perovskite Solar Cells," Adv. Mater., vol. 29, no. 4, pp. 1-8, 2017.

[65] F. Wang et al., "Phenylalkylamine Passivation of Organolead Halide Perovskites Enabling High-Efficiency and Air-Stable Photovoltaic Cells," Adv. Mater., vol. 28, no. 45, pp. 9986-9992, 2016.

[66] J. Feng et al., "Record Efficiency Stable Flexible Perovskite Solar Cell Using Effective Additive Assistant Strategy," Adv. Mater., vol. 30, no. 35, pp. 1-9, 2018.

[67] S. N. Habisreutinger, N. K. Noel, H. J. Snaith, and R. J. Nicholas, "Investigating the Role of 4-Tert Butylpyridine in Perovskite Solar Cells," Adv. Energy Mater., vol. 7, no. 1, pp. 1-8, 2017.

[68] F. Yang et al., "Dependence of Acetate-Based Antisolvents for High Humidity Fabrication of CH3NH3PbI3 Perovskite Devices in Ambient Atmosphere," ACS Appl. Mater. Interfaces, vol. 10, no. 19, pp. 16482-16489, 2018. 
[69] X. Liu, J. Wu, Y. Yang, T. Wu, and Q. Guo, "Pyridine solvent engineering for high quality anion-cation-mixed hybrid and high performance of perovskite solar cells," J. Power Sources, vol. 399, no. April, pp. 144-150, 2018.

[70] Y. H. Wu et al., "Incorporating 4-tert-Butylpyridine in an Antisolvent: A Facile Approach to Obtain Highly Efficient and Stable Perovskite Solar Cells," ACS Appl. Mater. Interfaces, vol. 10, no. 4, pp. 3602-3608, 2018.

[71] W. Q. Wu et al., "Bilateral alkylamine for suppressing charge recombination and improving stability in blade-coated perovskite solar cells," Sci. Adv., vol. 5, no. 3, pp. 1-10, 2019.

[72] Y. Luan et al., "High-Performance Planar Perovskite Solar Cells with Negligible Hysteresis Using 2,2,2-Trifluoroethanol-Incorporated SnO2," iScience, vol. 16, pp. 433-441, 2019.

[73] F. Yang et al., "Dependence of Acetate-Based Antisolvents for High Humidity Fabrication of CH3NH3PbI3 Perovskite Devices in Ambient Atmosphere," ACS Appl. Mater. Interfaces, vol. 10, no. 19, pp. 16482-16489, 2018.

[74] T. Zhang et al., "Bication lead iodide 2D perovskite component to stabilize inorganic a-CsPbI3 perovskite phase for high-efficiency solar cells," Sci. Adv., vol. 3, no. 9, pp. 1-7, 2017.

[75] X. Zheng et al., "Managing grains and interfaces via ligand anchoring enables 22.3\%-efficiency inverted perovskite solar cells," Nat. Energy, vol. 5, no. 2, pp. 131-140, 2020.

[76] J. Zhen et al., "Pyridine-functionalized fullerene additive enabling coordination interactions with $\mathrm{CH} 3 \mathrm{NH} 3 \mathrm{PbI} 3$ perovskite towards highly efficient bulk heterojunction solar cells," J. Mater. Chem. A, vol. 7, no. 6, pp. 2754-2763, 2019. [77] Z. Li, J. Dong, C. Liu, J. Guo, L. Shen, and W. Guo, "Surface Passivation of

Perovskite Solar Cells Toward Improved Efficiency and Stability," Nano-Micro Lett., vol. 11, no. 1, 2019.

[78] C. Liu, K. Wang, P. Du, C. Yi, T. Meng, and X. Gong, "Efficient SolutionProcessed Bulk Heterojunction Perovskite Hybrid Solar Cells," Adv. Energy Mater., vol. 5, no. 12, pp. 1-7, 2015.

[79] I. Jeon et al., "Lithium-Ion Endohedral Fullerene (Li+@C60) Dopants in Stable Perovskite Solar Cells Induce Instant Doping and Anti-Oxidation," Angew. Chemie - Int. Ed., vol. 57, no. 17, pp. 4607-4611, 2018.

[80] C. Liu, W. Li, H. Li, C. Zhang, J. Fan, and Y. Mai, "C60 additive-assisted crystallization in $\mathrm{CH} 3 \mathrm{NH} 3 \mathrm{~Pb} 0.75 \mathrm{Sn} 0.25 \mathrm{I} 3$ perovskite solar cells with high stability and efficiency," Nanoscale, vol. 9, no. 37, pp. 13967-13975, 2017.

[81] K. Wang, C. Liu, P. Du, J. Zheng, and X. Gong, "Bulk heterojunction perovskite hybrid solar cells with large fill factor," Energy Environ. Sci., vol. 8, no. 4, pp. 1245-1255, 2015.

[82] M. Li et al., "Enhanced crystallization and stability of perovskites by a crosslinkable fullerene for high-performance solar cells," J. Mater. Chem. A, vol. 4, no. 39, pp. 15088-15094, 2016. 
[83] Y. Shao, Z. Xiao, C. Bi, Y. Yuan, and J. Huang, "Origin and elimination of photocurrent hysteresis by fullerene passivation in $\mathrm{CH} 3 \mathrm{NH} 3 \mathrm{PbI} 3$ planar heterojunction solar cells," Nat. Commun., vol. 5, pp. 1-7, 2014.

[84] J. Xu et al., "Perovskite-fullerene hybrid materials suppress hysteresis in planar diodes," Nat. Commun., vol. 6, no. May, pp. 1-8, 2015.

[85] C. H. Chiang and C. G. Wu, "Bulk heterojunction perovskite-PCBM solar cells with high fill factor," Nat. Photonics, vol. 10, no. 3, pp. 196-200, 2016.

[86] F. Zhang et al., "Isomer-Pure Bis-PCBM-Assisted Crystal Engineering of Perovskite Solar Cells Showing Excellent Efficiency and Stability," Adv. Mater., vol. 29, no. 17, 2017.

[87] X. Liu et al., "Fluoroalkyl-substituted fullerene/perovskite heterojunction for efficient and ambient stable perovskite solar cells," Nano Energy, vol. 30, no. October, pp. 417-425, 2016.

[88] M. Qin et al., "Fused-Ring Electron Acceptor ITIC-Th: A Novel Stabilizer for Halide Perovskite Precursor Solution,” Adv. Energy Mater., vol. 8, no. 18, 2018.

[89] C. Park, H. Ko, D. H. Sin, K. C. Song, and K. Cho, "Organometal Halide Perovskite Solar Cells with Improved Thermal Stability via Grain Boundary Passivation Using a Molecular Additive," Adv. Funct. Mater., vol. 27, no. 42, pp. 1-8, 2017.

[90] G. Xu et al., "Hydrophilic Fullerene Derivative Doping in Active Layer and Electron Transport Layer for Enhancing Oxygen Stability of Perovskite Solar Cells," Sol. RRL, vol. 4, no. 2, pp. 1-9, 2020.

[91] M. Li et al., "Perovskite Grains Embraced in a Soft Fullerene Network Make Highly Efficient Flexible Solar Cells with Superior Mechanical Stability," Adv. Mater., vol. 31, no. 25, p. 1901519, Jun. 2019.

[92] M. Yavari et al., "Carbon Nanoparticles in High-Performance Perovskite Solar Cells," Adv. Energy Mater., vol. 8, no. 12, pp. 1-8, 2018.

[93] P. Chen et al., "Luminescent europium-doped titania for efficiency and UVstability enhancement of planar perovskite solar cells," Nano Energy, vol. 69, no. December 2019, p. 104392, 2020.

[94] Y. Gao et al., " $\mathrm{CsPbBr} 3$ perovskite nanoparticles as additive for environmentally stable perovskite solar cells with $20.46 \%$ efficiency," Nano Energy, vol. 59, no. March, pp. 517-526, 2019.

[95] W. T. Wang et al., "Nanoparticle-induced fast nucleation of pinhole-free $\mathrm{PbI} 2$ film for ambient-processed highly-efficient perovskite solar cell," Nano Energy, vol. 49, no. March, pp. 109-116, 2018.

[96] F. Rehman, K. Mahmood, A. Khalid, M. S. Zafar, and M. Hameed, "Solutionprocessed barium hydroxide modified boron-doped $\mathrm{ZnO}$ bilayer electron transporting materials: Toward stable perovskite solar cells with high efficiency of over 20.5\%," J. Colloid Interface Sci., vol. 535, pp. 353-362, 2019.

[97] T. H. Chang et al., "Planar Heterojunction Perovskite Solar Cells Incorporating Metal-Organic Framework Nanocrystals," Adv. Mater., vol. 27, no. 44, pp. 7229-7235, 2015. 
[98] H. L. Hsu et al., "Carbon Nanodot Additives Realize High-Performance AirStable p-i-n Perovskite Solar Cells Providing Efficiencies of up to 20.2\%," Adv. Energy Mater., vol. 8, no. 34, pp. 1-9, 2018.

[99] Y. Dou et al., "Toward Highly Reproducible, Efficient, and Stable Perovskite Solar Cells via Interface Engineering with CoO Nanoplates," ACS Appl. Mater. Interfaces, vol. 11, no. 35, pp. 32159-32168, 2019.

[100] H. Zai et al., "Congeneric Incorporation of $\mathrm{CsPbBr} 3$ Nanocrystals in a Hybrid Perovskite Heterojunction for Photovoltaic Efficiency Enhancement," ACS Energy Lett., vol. 3, no. 1, pp. 30-38, 2018.

[101] W. Li et al., "In situ induced core/shell stabilized hybrid perovskites via gallium(III) acetylacetonate intermediate towards highly efficient and stable solar cells," Energy Environ. Sci., vol. 11, no. 2, pp. 286-293, 2018.

[102] Z. Wang, Q. Lin, F. P. Chmiel, N. Sakai, L. M. Herz, and H. J. Snaith, "Efficient ambient-air-stable solar cells with 2D-3D heterostructured butylammoniumcaesium-formamidinium lead halide perovskites," Nat. Energy, vol. 2, no. 9, pp. 1-10, 2017.

[103] Y. Chen et al., "Impacts of alkaline on the defects property and crystallization kinetics in perovskite solar cells," Nat. Commun., vol. 10, no. 1, 2019.

[104] Y. Zhao et al., "Perovskite seeding growth of formamidinium-lead-iodide-based perovskites for efficient and stable solar cells," Nat. Commun., vol. 9, no. 1, pp. 1-10, 2018.

[105] Q. Li et al., "Efficient Perovskite Solar Cells Fabricated Through CsClEnhanced PbI 2 Precursor via Sequential Deposition," Adv. Mater., vol. 30, no. 40, pp. 19, 2018

[106] W. Li et al., "Enhanced UV-light stability of planar heterojunction perovskite solar cells with caesium bromide interface modification," Energy Environ. Sci., vol. 9, no. 2, pp. 490-498, 2016.

[107] Y. Zhou et al., "Composition-Tuned Wide Bandgap Perovskites: From Grain Engineering to Stability and Performance Improvement," Adv. Funct. Mater., vol. 28, no. 35, pp. 1-8, 2018.

[108] M. Zhang et al., "Synergistic effect of potassium and iodine from potassium triiodide complex additive on gas-quenched perovskite solar cells," Nano Energy, vol. 63, no. June, p. 103853, 2019.

[109] D. Prochowicz et al., "One-step mechanochemical incorporation of an insoluble cesium additive for high performance planar heterojunction solar cells," Nano Energy, vol. 49, no. May, pp. 523-528, 2018.

[110] P. Qin, J. Zhang, G. Yang, X. Yu, and G. Li, "Potassium-intercalated rubrene as a dual-functional passivation agent for high efficiency perovskite solar cells," $J$. Mater. Chem. A, vol. 7, no. 4, pp. 1824-1834, 2019.

[111] C. Chen et al., "CaI2: A more effective passivator of perovskite films than $\mathrm{PbI} 2$ for high efficiency and long-term stability of perovskite solar cells," J. Mater. Chem. A, vol. 6, no. 17, pp. 7903-7912, 2018. 
[112] Y. Lin et al., "Enhanced Thermal Stability in Perovskite Solar Cells by Assembling 2D/3D Stacking Structures," J. Phys. Chem. Lett., vol. 9, no. 3, pp. 654-658, 2018.

[113] J. Jin et al., "Enhanced Performance of Perovskite Solar Cells with Zinc Chloride Additives," ACS Appl. Mater. Interfaces, vol. 9, no. 49, pp. 42875-42882, 2017.

[114] J. T. W. Wang et al., "Efficient perovskite solar cells by metal ion doping," Energy Environ. Sci., vol. 9, no. 9, pp. 2892-2901, 2016.

[115] M. Saliba et al., "Cesium-containing triple cation perovskite solar cells: Improved stability, reproducibility and high efficiency," Energy Environ. Sci., vol. 9, no. 6, pp. 1989-1997, 2016.

[116] T. Bu et al., "A novel quadruple-cation absorber for universal hysteresis elimination for high efficiency and stable perovskite solar cells," Energy Environ. Sci., vol. 10, no. 12, pp. 2509-2515, 2017.

[117] Y. Yu et al., "Synergistic Effects of Lead Thiocyanate Additive and Solvent Annealing on the Performance of Wide-Bandgap Perovskite Solar Cells," ACS Energy Lett., vol. 2, no. 5, pp. 1177-1182, 2017.

[118] Z. K. Wang et al., "High Efficiency Pb-In Binary Metal Perovskite Solar Cells," Adv. Mater., pp. 6695-6703, 2016.

[119] J. H. Heo et al., "Planar CH3NH3PbI3 perovskite solar cells with constant 17.2\% average power conversion efficiency irrespective of the scan rate," Adv. Mater., vol. 27, no. 22, pp. 3424-3430, 2015.

[120] D. Bi et al., "High-performance perovskite solar cells with enhanced environmental stability based on amphiphile-modified $\mathrm{CH} 3 \mathrm{NH} 3 \mathrm{PbI} 3$," $A d v$. Mater., vol. 28, no. 15, pp. 2910-2915, 2016.

[121] R. Wang et al., "Constructive molecular configurations for surface-defect passivation of perovskite photovoltaics," Science (80-. )., vol. 366, no. 6472, pp. 1509-1513, 2019.

[122] W. Ke et al., "Employing Lead Thiocyanate Additive to Reduce the Hysteresis and Boost the Fill Factor of Planar Perovskite Solar Cells," Adv. Mater., vol. 28, no. 26, pp. 5214-5221, 2016.

[123] Y. C. Kim et al., "Beneficial Effects of PbI2 Incorporated in Organo-Lead Halide Perovskite Solar Cells," Adv. Energy Mater., vol. 6, no. 4, pp. 1-8, 2016.

[124] T. J. Jacobsson et al., "Unreacted PbI2 as a Double-Edged Sword for Enhancing the Performance of Perovskite Solar Cells," J. Am. Chem. Soc., vol. 138, no. 32, pp. 10331-10343, 2016.

[125] M. Abdi-Jalebi et al., "Maximizing and stabilizing luminescence from halide perovskites with potassium passivation," Nature, vol. 555, no. 7697, pp. 497501, 2018.

[126] Z. Tang et al., "Modulations of various alkali metal cations on organometal halide perovskites and their influence on photovoltaic performance," Nano Energy, vol. 45, no. December 2017, pp. 184-192, 2018. 
[127] J. Cao, S. X. Tao, P. A. Bobbert, C. P. Wong, and N. Zhao, "Interstitial Occupancy by Extrinsic Alkali Cations in Perovskites and Its Impact on Ion Migration," Adv. Mater., vol. 30, no. 26, pp. 1-9, 2018.

[128] Y. Cho et al., "Mixed 3D-2D Passivation Treatment for Mixed-Cation Lead Mixed-Halide Perovskite Solar Cells for Higher Efficiency and Better Stability," Adv. Energy Mater., vol. 8, no. 20, Jul. 2018.

[129] D. Y. Son et al., "Universal Approach toward Hysteresis-Free Perovskite Solar Cell via Defect Engineering," J. Am. Chem. Soc., vol. 140, no. 4, pp. 1358-1364, 2018.

[130] N. Li et al., "Cation and anion immobilization through chemical bonding enhancement with fluorides for stable halide perovskite solar cells," Nat. Energy, vol. 4, no. 5, pp. 408-415, 2019.

[131] L. Wang et al., "A Eu 3+ -Eu 2+ ion redox shuttle imparts operational durability to Pb-I perovskite solar cells," Science (80-. )., vol. 363, no. 6424, pp. 265-270, 2019.

[132] L. Liu et al., "R es e a rc h | r e po r ts," vol. 354, no. 6309, 2016.

[133] F. Yang et al., "Magnesium-Doped MAPbI3 Perovskite Layers for Enhanced

Photovoltaic Performance in Humid Air Atmosphere," ACS Appl. Mater. Interfaces, vol. 10, no. 29, pp. 24543-24548, 2018.

[134] X. Gong et al., "Highly Efficient Perovskite Solar Cells via Nickel Passivation," Adv. Funct. Mater., vol. 28, no. 50, pp. 1-8, 2018.

[135] X. Li et al., "Improved performance and stability of perovskite solar cells by crystal crosslinking with alkylphosphonic acid $\omega$-ammonium chlorides," Nat. Chem., vol. 7, no. 9, pp. 703-711, 2015.

[136] C. Li et al., "Monoammonium Porphyrin for Blade-Coating Stable Large-Area Perovskite Solar Cells with $>18 \%$ Efficiency," J. Am. Chem. Soc., vol. 141, no. 15, pp. 6345-6351, 2019.

[137] J. Cao et al., "Efficient Grain Boundary Suture by Low-Cost Tetra-ammonium Zinc Phthalocyanine for Stable Perovskite Solar Cells with Expanded Photoresponse," J. Am. Chem. Soc., vol. 140, no. 37, pp. 11577-11580, 2018.

[138] Y. He, W. Wang, and L. Qi, "HPbI3 as a Bifunctional Additive for Morphology Control and Grain Boundary Passivation toward Efficient Planar Perovskite Solar Cells," ACS Appl. Mater. Interfaces, vol. 10, no. 45, pp. 38985-38993, 2018.

[139] J. Xue et al., "Crystalline Liquid-like Behavior: Surface-Induced Secondary Grain Growth of Photovoltaic Perovskite Thin Film," 2019.

[140] S. C. Yun et al., "Amino acid salt-driven planar hybrid perovskite solar cells with enhanced humidity stability," Nano Energy, vol. 59, no. December 2018, pp. 481-491, 2019.

[141] X. Hou, S. Huang, W. Ou-Yang, L. Pan, Z. Sun, and X. Chen, “Constructing Efficient and Stable Perovskite Solar Cells via Interconnecting Perovskite Grains," ACS Appl. Mater. Interfaces, vol. 9, no. 40, pp. 35200-35208, 2017. 
[142] F. Zhang et al., "Suppressing defects through the synergistic effect of a Lewis base and a Lewis acid for highly efficient and stable perovskite solar cells," Energy Environ. Sci., 2018.

[143] Z. Li et al., "Acid Additives Enhancing the Conductivity of Spiro-OMeTAD Toward High-Efficiency and Hysteresis-Less Planar Perovskite Solar Cells," Adv. Energy Mater., vol. 7, no. 4, pp. 1-8, 2017.

[144] D. Yang et al., "High efficiency planar-type perovskite solar cells with negligible hysteresis using EDTA-complexed SnO2," Nat. Commun., 2018.

[145] L. Guan, N. Jiao, and Y. Guo, "Trap-State Passivation by Nonvolatile Small Molecules with Carboxylic Acid Groups for Efficient Planar Perovskite Solar Cells," J. Phys. Chem. C, vol. 123, no. 23, pp. 14223-14228, 2019.

[146] X. Hou, S. Huang, W. Ou-Yang, L. Pan, Z. Sun, and X. Chen, "Constructing Efficient and Stable Perovskite Solar Cells via Interconnecting Perovskite Grains," ACS Appl. Mater. Interfaces, vol. 9, no. 40, pp. 35200-35208, 2017.

[147] C. Zhang, S. Zhang, X. Miao, Y. Hu, L. Staaden, and G. Jia, "Rigid Amino Acid as Linker to Enhance the Crystallinity of CH3NH3PbI3 Particles," Part. Part. Syst. Charact., vol. 34, no. 4, pp. 1-6, 2017.

[148] F. Xie et al., "Vertical recrystallization for highly efficient and stable formamidinium-based inverted-structure perovskite solar cells," Energy Environ. Sci., vol. 10, no. 9, pp. 1942-1949, 2017.

[149] M. M. Tavakoli et al., "Synergistic Crystal and Interface Engineering for Efficient and Stable Perovskite Photovoltaics," Adv. Energy Mater., vol. 9, no. 1, pp. 1-8, 2019.

[150] S. Bai et al., "Planar perovskite solar cells with long-term stability using ionic liquid additives," Nature, vol. 571, no. 7764, pp. 245-250, 2019.

[151] K. T. Cho et al., "Selective growth of layered perovskites for stable and efficient photovoltaics," Energy Environ. Sci., vol. 11, no. 4, pp. 952-959, 2018.

[152] L. N. Quan et al., "Ligand-Stabilized Reduced-Dimensionality Perovskites," J. Am. Chem. Soc., vol. 138, no. 8, pp. 2649-2655, 2016.

[153] T. H. Han et al., "Perovskite-polymer composite cross-linker approach for highly-stable and efficient perovskite solar cells," Nat. Commun., vol. 10, no. 1, p. 520, 2019.

[154] J. W. Lee et al., "A Bifunctional Lewis Base Additive for Microscopic Homogeneity in Perovskite Solar Cells," Chem, vol. 3, no. 2, pp. 290-302, 2017.

[155] Z. Wu et al., "Improved Efficiency and Stability of Perovskite Solar Cells Induced by $\mathrm{C} \square \mathrm{O}$ Functionalized Hydrophobic Ammonium -Based Additives," Adv. Mater., vol. 30, no. 3, pp. 1-7, 2018.

[156] Y. Wu et al., "Thermally Stable MAPbI3 Perovskite Solar Cells with Efficiency of $19.19 \%$ and Area over $1 \mathrm{~cm} 2$ achieved by Additive Engineering," Adv. Mater., vol. 29, no. 28, pp. 1-8, 2017.

[157] M. M. Tavakoli et al., "Controllable Perovskite Crystallization via Antisolvent Technique Using Chloride Additives for Highly Efficient Planar Perovskite Solar Cells," Adv. Energy Mater., vol. 9, no. 17, 2019. 
[158] C. Wu et al., "FAPbI3 Flexible Solar Cells with a Record Efficiency of 19.38\% Fabricated in Air via Ligand and Additive Synergetic Process," Adv. Funct. Mater., vol. 1902974, pp. 1-7, 2019.

[159] F. Cai et al., "Ionic Additive Engineering Toward High-Efficiency Perovskite Solar Cells with Reduced Grain Boundaries and Trap Density," Adv. Funct. Mater., vol. 28, no. 34, pp. 1-9, 2018.

[160] C. Liang et al., "Simultaneously boost diffusion length and stability of perovskite for high performance solar cells," Nano Energy, vol. 59, no. March, pp. 721-729, 2019.

[161] X. Liu et al., "Pyrrole: An additive for improving the efficiency and stability of perovskite solar cells," J. Mater. Chem. A, vol. 7, no. 19, pp. 11764-11770, 2019.

[162] J. Chen, S. G. Kim, X. Ren, H. S. Jung, and N. G. Park, "Effect of bidentate and tridentate additives on the photovoltaic performance and stability of perovskite solar cells," J. Mater. Chem. A, vol. 7, no. 9, pp. 4977-4987, 2019.

[163] M. Wang, B. Li, P. Siffalovic, L. C. Chen, G. Cao, and J. Tian, "Monolayer-like hybrid halide perovskite films prepared by additive engineering without antisolvents for solar cells," J. Mater. Chem. A, vol. 6, no. 31, pp. 15386-15394, 2018.

[164] R. Fu, Y. Zhao, W. Zhou, Q. Li, Y. Zhao, and Q. Zhao, "Ultrahigh open-circuit voltage for high performance mixed-cation perovskite solar cells using acetate anions," J. Mater. Chem. A, vol. 6, no. 29, pp. 14387-14391, 2018.

[165] M. Sun, F. Zhang, H. Liu, X. Li, Y. Xiao, and S. Wang, "Tuning the crystalgrowth of perovskite thin-films by adding 2-pyridylthiourea," vol. 1, no. c, pp. 2-3, 2017.

[166] H. Zhao, S. Wang, M. Sun, F. Zhang, X. Li, and Y. Xiao, "Enhanced stability and optoelectronic properties of MAPbI 3 films by a cationic surface-active agent for perovskite solar cells," J. Mater. Chem. A, vol. 6, no. 23, pp. 10825-10834, 2018. [167] C. Gao et al., "Additive engineering to improve the efficiency and stability of inverted planar perovskite solar cells," J. Mater. Chem. C, vol. 6, no. 30, pp. 8234-8241, 2018.

[168] S. Bae, J. W. Jo, P. Lee, and M. J. Ko, "Controlling the Morphology of OrganicInorganic Hybrid Perovskites through Dual Additive-Mediated Crystallization for Solar Cell Applications," ACS Appl. Mater. Interfaces, vol. 11, no. 19, pp. 17452-17458, 2019.

[169] Y. Ma et al., "Enhancing the Performance of Inverted Perovskite Solar Cells via Grain Boundary Passivation with Carbon Quantum Dots," ACS Appl. Mater. Interfaces, vol. 11, no. 3, pp. 3044-3052, 2019.

[170] S. G. Kim, J. Chen, J. Y. Seo, D. H. Kang, and N. G. Park, "Rear-Surface Passivation by Melaminium Iodide Additive for Stable and Hysteresis-less Perovskite Solar Cells," ACS Appl. Mater. Interfaces, vol. 10, no. 30, pp. 25372 25383, 2018. 
[171] S. Jin et al., "Additive engineering induced perovskite crystal growth for high performance perovskite solar cells," Org. Electron. physics, Mater. Appl., vol. 63, no. September, pp. 207-215, 2018.

[172] H. Li et al., "3,4-Dihydroxybenzhydrazide as an additive to improve the morphology of perovskite films for efficient and stable perovskite solar cells," Org. Electron. physics, Mater. Appl., vol. 66, no. September 2018, pp. 47-52, 2019.

[173] Y. Wu et al., "Efficient inverted perovskite solar cells with preferential orientation and suppressed defects of methylammonium lead iodide by introduction of phenothiazine as additive," J. Alloys Compd., vol. 823, p. 153717, 2020.

[174] R. Zhang et al., "A potassium thiocyanate additive for hysteresis elimination in highly efficient perovskite solar cells," Inorg. Chem. Front., vol. 6, no. 2, pp. 434-442, 2019.

[175] J. Liu et al., "Additive engineering for high-performance roomtemperatureprocessed perovskite absorbers with micron-size grains and microsecond-range carrier lifetimes," Energy Environ. Sci., vol. 10, no. 11, pp. 2365-2371, 2017.

[176] M. Kim et al., "Methylammonium Chloride Induces Intermediate Phase Stabilization for Efficient Perovskite Solar Cells," Joule, pp. 1-14, 2019.

[177] J. C. Yu et al., "Highly Efficient and Stable Inverted Perovskite Solar Cell Obtained via Treatment by Semiconducting Chemical Additive," Adv. Mater., vol. 31, no. 6, pp. 1-10, 2019.

[178] Z. Liu et al., "Chemical Reduction of Intrinsic Defects in Thicker Heterojunction Planar Perovskite Solar Cells," Adv. Mater., vol. 29, no. 23, pp. 1-8, 2017.

[179] M. Abdi-Jalebi et al., "Impact of monovalent cation halide additives on the structural and optoelectronic properties of $\mathrm{CH} 3 \mathrm{NH} 3 \mathrm{PbI} 3$ perovskite," $A d v$. Energy Mater., vol. 6, no. 10, 2016.

[180] S. Yang et al., "Stabilizing halide perovskite surfaces for solar cell operation with wide-bandgap lead oxysalts," Science (80-. )., vol. 365, no. 6452, pp. 473478, 2019.

[181] Y.-H. Lin et al., "A piperidinium salt stabilizes efficient metal-halide perovskite solar cells," Science (80-. )., vol. 369, no. 6499, pp. 96-102, Jul. 2020.

[182] P. Docampo et al., "Solution deposition-conversion for planar heterojunction mixed halide perovskite solar cells," Adv. Energy Mater., vol. 4, no. 14, pp. 2-7, 2014.

[183] N. Li et al., "Mixed Cation FA x PEA 1-x PbI 3 with Enhanced Phase and Ambient Stability toward High-Performance Perovskite Solar Cells," Adv. Energy Mater., vol. 7, no. 1, pp. 1-9, 2017.

[184] C. F. J. Lau et al., "Fabrication of Efficient and Stable CsPbI 3 Perovskite Solar Cells through Cation Exchange Process," Adv. Energy Mater., vol. 1901685, p. 1901685, 2019. 
[185] J. W. Lee et al., "Tuning Molecular Interactions for Highly Reproducible and Efficient Formamidinium Perovskite Solar Cells via Adduct Approach," J. Am. Chem. Soc., vol. 140, no. 20, pp. 6317-6324, 2018.

[186] C. Fei, B. Li, R. Zhang, H. Fu, J. Tian, and G. Cao, "Highly Efficient and Stable Perovskite Solar Cells Based on Monolithically Grained CH3NH3PbI3 Film," Adv. Energy Mater., vol. 7, no. 9, pp. 1-10, 2017.

[187] T. Wang, M. Xie, S. Abbasi, Z. Cheng, H. Liu, and W. Shen, "High efficiency perovskite solar cells with tailorable surface wettability by surfactant," J. Power Sources, vol. 448, no. September 2019, p. 227584, 2020.

[188] J. V. Patil, S. S. Mali, and C. K. Hong, "A thiourea additive-based quadruple cation lead halide perovskite with an ultra-large grain size for efficient perovskite solar cells," Nanoscale, vol. 11, no. 45, pp. 21824-21833, 2019.

[189] L. Gao et al., "Excellent Stability of Perovskite Solar Cells by Passivation Engineering," Sol. RRL, vol. 2, no. 8, p. 1800088, Aug. 2018.

[190] H. C. Liao et al., "Enhanced Efficiency of Hot-Cast Large-Area Planar Perovskite Solar Cells/Modules Having Controlled Chloride Incorporation," Adv. Energy Mater., vol. 7, no. 8, pp. 1-9, 2017.

[191] H. Lai et al., "Two-dimensional ruddlesden-popper perovskite with nanorod-like morphology for solar cells with efficiency exceeding 15\%," J. Am. Chem. Soc., vol. 140, no. 37, pp. 11639-11646, 2018.

[192] Y. Rong et al., "Synergy of ammonium chloride and moisture on perovskite crystallization for efficient printable mesoscopic solar cells," Nat. Commun., vol. 8, 2017.

[193] W. Fu et al., "Two-Dimensional Perovskite Solar Cells with 14.1\% Power Conversion Efficiency and 0.68\% External Radiative Efficiency," ACS Energy Lett., vol. 3, no. 9, pp. 2086-2093, 2018.

[194] X. Zheng et al., "Defect passivation in hybrid perovskite solar cells using quaternary ammonium halide anions and cations," Nat. Energy, vol. 2, no. 7, pp. 1-10, 2017.

[195] T. Niu et al., "High performance ambient-air-stable FAPbI 3 perovskite solar cells with molecule-passivated Ruddlesden-Popper/3D heterostructured film," Energy Environ. Sci., vol. 11, no. 12, pp. 3358-3366, 2018.

[196] D. S. Lee et al., "Passivation of Grain Boundaries by Phenethylammonium in Formamidinium-Methylammonium Lead Halide Perovskite Solar Cells," ACS Energy Lett., vol. 3, no. 3, pp. 647-654, 2018.

[197] D. Bi et al., "High-performance perovskite solar cells with enhanced environmental stability based on amphiphile-modified CH3NH3PbI3," Adv. Mater., vol. 28, no. 15, pp. 2910-2915, 2016.

[198] M. Salado, S. Kazim, M. K. Nazeeruddin, and S. Ahmad, "Appraisement of Crystal Expansion in $\mathrm{CH} 3 \mathrm{NH} 3 \mathrm{PbI} 3$ on Doping: Improved Photovoltaic Properties," ChemSusChem, no. April, 2019.

[199] Y. Zhang et al., "Auto-passivation of crystal defects in hybrid imidazolium/methylammonium lead iodide films by fumigation with 
methylamine affords high efficiency perovskite solar cells," Nano Energy, vol. 58, no. December 2018, pp. 105-111, 2019.

[200] D. Bi et al., "High-performance perovskite solar cells with enhanced environmental stability based on amphiphile-modified $\mathrm{CH} 3 \mathrm{NH} 3 \mathrm{PbI} 3$," $A d v$. Mater., vol. 28, no. 15, pp. 2910-2915, Apr. 2016.

[201] M. Salado et al., "Extending the Lifetime of Perovskite Solar Cells using a Perfluorinated Dopant," ChemSusChem, vol. 9, no. 18, pp. 2708-2714, 2016.

[202] M. Salado et al., "Towards Extending Solar Cell Lifetimes: Addition of a Fluorous Cation to Triple Cation-Based Perovskite Films," ChemSusChem, vol. 10, no. 19, pp. 3846-3853, 2017.

[203] Y. Zhang et al., "A Strategy to Produce High Efficiency, High Stability Perovskite Solar Cells Using Functionalized Ionic Liquid-Dopants," Adv. Mater., vol. 29, no. 36, pp. 1-8, 2017.

[204] X. Zhou, Y. Wang, C. Li, and T. Wu, "Doping amino-functionalized ionic liquid in perovskite crystal for enhancing performances of hole-conductor free solar cells with carbon electrode," Chem. Eng. J., 2019.

[205] R. Xia et al., "Retarding Thermal Degradation in Hybrid Perovskites by Ionic Liquid Additives," Adv. Funct. Mater., vol. 29, no. 22, 2019.

[206] S. Fu et al., "Efficient Passivation with Lead Pyridine-2-Carboxylic for HighPerformance and Stable Perovskite Solar Cells," Adv. Energy Mater., vol. 9, no. 35, pp. 1-10, 2019.

[207] J. Y. Seo et al., "Ionic Liquid Control Crystal Growth to Enhance Planar Perovskite Solar Cells Efficiency," Adv. Energy Mater., vol. 6, no. 20, p. 1600767, Oct. 2016.

[208] W. S. Yang et al., "Iodide management in formamidinium-lead-halide-based perovskite layers for efficient solar cells," Science (80-. )., vol. 356, no. 6345, pp. 1376-1379, 2017.

[209] D. Bi et al., "Multifunctional molecular modulators for perovskite solar cells with over $20 \%$ efficiency and high operational stability," Nat. Commun., vol. 9 , no. $1,2018$.

[210] X. Feng et al., "Perfection of Perovskite Grain Boundary Passivation by EuPorphyrin Complex for Overall-Stable Perovskite Solar Cells," Adv. Sci., vol. 6, no. 5, 2019.

[211] S. Wang et al., "Water-Soluble Triazolium Ionic-Liquid-Induced Surface SelfAssembly to Enhance the Stability and Efficiency of Perovskite Solar Cells," Adv. Funct. Mater., vol. 29, no. 15, pp. 1-11, 2019.

[212] Y. Wang et al., "Stabilizing heterostructures of soft perovskite semiconductors," Science (80-. )., vol. 365, no. 6454, pp. 687-691, 2019.

[213] S. S. Mali, J. V. Patil, H. Kim, H. Kim, and C. K. Hong, "A Dual_Retarded Reaction Processed Mixed_Cation Perovskite Layer for High_Efficiency Solar Cells," Adv. Funct. Mater., vol. 29, no. 15, p. 1807420, Apr. 2019. 
[214] W. Zhao, Z. Yao, F. Yu, D. Yang, and S. F. Liu, "Alkali Metal Doping for Improved CH 3 NH 3 PbI 3 Perovskite Solar Cells," Adv. Sci., vol. 5, no. 2, pp. 1-7, 2018.

[215] Y. Chen et al., "Thermally stable methylammonium-free inverted perovskite solar cells with $\mathrm{Zn} 2+$ doped $\mathrm{CuGaO} 2$ as efficient mesoporous hole-transporting layer," Nano Energy, vol. 61, no. January, pp. 148-157, 2019.

[216] S. Bi et al., "Halogen bonding reduces intrinsic traps and enhances charge mobilities in halide perovskite solar cells," J. Mater. Chem. A, vol. 7, no. 12, pp. 6840-6848, 2019.

[217] J. F. Liao, W. Q. Wu, J. X. Zhong, Y. Jiang, L. Wang, and D. Bin Kuang, "Enhanced efficacy of defect passivation and charge extraction for efficient perovskite photovoltaics with a small open circuit voltage loss," J. Mater. Chem. A, vol. 7, no. 15, pp. 9025-9033, 2019.

[218] H. Zhu, F. Zhang, Y. Xiao, S. Wang, and X. Li, "Suppressing defects through thiadiazole derivatives that modulate $\mathrm{CH} 3 \mathrm{NH} 3 \mathrm{PbI} 3$ crystal growth for highly stable perovskite solar cells under dark conditions," J. Mater. Chem. A, vol. 6, no. 12, pp. 4971-4980, 2018.

[219] S. Wang et al., "Unveiling the Role of tBP-LiTFSI Complexes in Perovskite Solar Cells," J. Am. Chem. Soc., vol. 140, no. 48, pp. 16720-16730, 2018.

[220] M. Zhang et al., "High-Performance Fused Ring Electron Acceptor-Perovskite Hybrid," J. Am. Chem. Soc., vol. 140, no. 44, pp. 14938-14944, 2018.

[221] X. Zheng et al., "Quantum Dots Supply Bulk- and Surface-Passivation Agents for Efficient and Stable Perovskite Solar Cells," Joule, pp. 1-14, 2019.

[222] W. Xiang et al., "Europium-Doped CsPbI 2 Br for Stable and Highly Efficient Inorganic Perovskite Solar Cells," Joule, vol. 3, no. 1, pp. 205-214, 2019.

[223] R. Wang et al., "Caffeine Improves the Performance and Thermal Stability of Perovskite Solar Cells," Joule, vol. 3, no. 6, pp. 1464-1477, 2019.

[224] P. W. Liang et al., "Additive enhanced crystallization of solution-processed perovskite for highly efficient planar-heterojunction solar cells," Adv. Mater., vol. 26, no. 22, pp. 3748-3754, 2014.

[225] T. Niu et al., "Stable High-Performance Perovskite Solar Cells via Grain Boundary Passivation," Adv. Mater., vol. 30, no. 16, pp. 1-11, 2018.

[226] S. Yang et al., "Tailoring Passivation Molecular Structures for Extremely Small Open-Circuit Voltage Loss in Perovskite Solar Cells," J. Am. Chem. Soc., vol. 141, no. 14, pp. 5781-5787, 2019.

[227] P. Guo et al., "Surface \& grain boundary co-passivation by fluorocarbon based bifunctional molecules for perovskite solar cells with efficiency over $21 \%$," $J$. Mater. Chem. A, vol. 7, no. 6, pp. 2497-2506, 2019.

[228] L. Liu et al., "Grain-Boundary 'Patches' by In Situ Conversion to Enhance Perovskite Solar Cells Stability," Adv. Mater., vol. 30, no. 29, pp. 1-8, 2018.

[229] Y. Guo et al., "Enhanced performance of perovskite solar cells: Via anti-solvent nonfullerene Lewis base IT-4F induced trap-passivation," J. Mater. Chem. A, vol. 6, no. 14, pp. 5919-5925, 2018. 
[230] T. Y. Wen et al., "Surface Electronic Modification of Perovskite Thin Film with Water-Resistant Electron Delocalized Molecules for Stable and Efficient Photovoltaics," Adv. Energy Mater., vol. 8, no. 13, pp. 1-7, 2018.

[231] W. Chen et al., "A general strategy to prepare high-quality inorganic chargetransporting layers for efficient and stable all-layer-inorganic perovskite solar cells," J. Mater. Chem. A, vol. 7, no. 31, pp. 18603-18611, 2019.

[232] M. Sun, F. Zhang, H. Liu, X. Li, Y. Xiao, and S. Wang, "Tuning the crystal growth of perovskite thin-films by adding the 2-pyridylthiourea additive for highly efficient and stable solar cells prepared in ambient air," J. Mater. Chem. A, vol. 5, no. 26, pp. 13448-13456, 2017.

[233] H. Zhu, F. Zhang, Y. Xiao, S. Wang, and X. Li, "Suppressing defects through thiadiazole derivatives that modulate $\mathrm{CH} 3 \mathrm{NH} 3 \mathrm{PbI} 3$ crystal growth for highly stable perovskite solar cells under dark conditions," J. Mater. Chem. A, vol. 6, no. 12, pp. 4971-4980, 2018.

[234] T. Wu et al., "Efficient Defect Passivation for Perovskite Solar Cells by Controlling the Electron Density Distribution of Donor- $\pi$-Acceptor Molecules," Adv. Energy Mater., vol. 9, no. 17, pp. 1-8, 2019.

[235] X. Ji et al., "A mixed hole transport material employing a highly planar conjugated molecule for efficient and stable perovskite solar cells," J. Mater. Chem. A, vol. 8, no. 10, pp. 5163-5170, 2020.

[236] M. Zhang et al., "High-Performance Fused Ring Electron Acceptor-Perovskite Hybrid," J. Am. Chem. Soc., vol. 140, no. 44, pp. 14938-14944, 2018.

[237] J. Zou et al., "An efficient guanidinium isothiocyanate additive for improving the photovoltaic performances and thermal stability of perovskite solar cells," Electrochim. Acta, vol. 291, pp. 297-303, 2018.

[238] Y. Liu et al., "Ultrahydrophobic 3D/2D fluoroarene bilayer-based waterresistant perovskite solar cells with efficiencies exceeding 22\%," Sci. Adv., vol. 5, no. 6, p. 2543, 2019.

[239] J. Yang et al., "Crystallization tailoring of cesium/formamidinium double-cation perovskite for efficient and highly stable solar cells," J. Energy Chem., vol. 48, pp. 217-225, Sep. 2020.

[240] J.-W. Lee, D.-H. Kim, H.-S. Kim, S.-W. Seo, S. M. Cho, and N.-G. Park, "Formamidinium and Cesium Hybridization for Photo- and Moisture-Stable Perovskite Solar Cell," Adv. Energy Mater., vol. 5, no. 20, p. 1501310, Oct. 2015.

[241] H. X. Dang et al., "Multi-cation Synergy Suppresses Phase Segregation in Mixed-Halide Perovskites," Joule, vol. 3, no. 7, pp. 1746-1764, Jul. 2019.

[242] E. Bae, W. Choi, J. Park, H. S. Shin, S. Bin Kim, and J. S. Lee, "Effects of surface anchoring groups (Carboxylate vs Phosphonate) in rutheniumcomplexsensitized $\mathrm{TiO} 2$ on visible light reactivity in aqueous suspensions," $J$. Phys. Chem. B, vol. 108, no. 37, pp. 14093-14101, Sep. 2004.

[243] G. Guerrero, J. G. Alauzun, M. Granier, D. Laurencin, and P. H. Mutin, "Phosphonate coupling molecules for the control of surface/interface properties and the synthesis of nanomaterials," Dalt. Trans., vol. 42, no. 35, pp. 1256912585, Sep. 2013. 
[244] D. G. Brown, P. A. Schauer, J. Borau-Garcia, B. R. Fancy, and C. P. Berlinguette, "Stabilization of Ruthenium Sensitizers to $\mathrm{TiO}_{2}$ Surfaces through Cooperative Anchoring Groups," J. Am. Chem. Soc., vol. 135, no. 5, pp. 1692-1695, Feb. 2013.

[245] L. Zhang and J. M. Cole, "Anchoring Groups for Dye-Sensitized Solar Cells," ACS Appl. Mater. Interfaces, vol. 7, no. 6, pp. 3427-3455, Feb. 2015.

[246] L. A. Martini et al., "Modular assembly of high-potential zinc porphyrin photosensitizers attached to TiO2 with a series of anchoring groups," J. Phys. Chem. C, vol. 117, no. 28, pp. 14526-14533, Jul. 2013.

[247] R. Luschtinetz, S. Gemming, and G. Seifert, "Anchoring functional molecules on Tio2 surfaces: A comparison between the carboxylic and the phosphonic acid group," Eur. Phys. J. Plus, vol. 126, no. 10, pp. 1-13, Oct. 2011.

[248] D. Wei et al., "Ion-Migration Inhibition by the Cation- $\pi$ Interaction in Perovskite Materials for Efficient and Stable Perovskite Solar Cells," Adv. Mater., vol. 30, no. 31, Aug. 2018.

[249] X. Zheng et al., "Managing grains and interfaces via ligand anchoring enables 22.3\%-efficiency inverted perovskite solar cells," Nat. Energy, vol. 5, no. 2, pp. 131-140, Feb. 2020.

[250] J. W. Blanchard, T. L. Groy, J. L. Yarger, and G. P. Holland, "Investigating hydrogen-bonded phosphonic acids with proton ultrafast MAS NMR and DFT calculations," J. Phys. Chem. C, vol. 116, no. 35, pp. 18824-18830, Sep. 2012.

[251] Y. Chen, J. Yang, S. Wang, Y. Wu, N. Yuan, and W. H. Zhang, "Interfacial Contact Passivation for Efficient and Stable Cesium-Formamidinium DoubleCation Lead Halide Perovskite Solar Cells," iScience, vol. 23, no. 1, p. 100762, Jan. 2020.

[252] Z. Zhang et al., "A New Passivation Route Leading to Over 8\% Efficient PbSe Quantum-Dot Solar Cells via Direct Ion Exchange with Perovskite Nanocrystals," Adv. Mater., vol. 29, no. 41, p. 1703214, Nov. 2017.

[253] J. Han et al., "Hybrid PbS Quantum-Dot-in-Perovskite for High-Efficiency Perovskite Solar Cell," Small, vol. 14, no. 31, p. 1801016, Aug. 2018.

[254] P. L. Qin et al., "Stable and Efficient Organo-Metal Halide Hybrid Perovskite Solar Cells via $\pi$-Conjugated Lewis Base Polymer Induced Trap Passivation and Charge Extraction," Adv. Mater., vol. 30, no. 12, Mar. 2018.

[255] P. Ardalan et al., "Effects of self-assembled monolayers on solid-state CdS quantum dot sensitized solar cells," ACS Nano, vol. 5, no. 2, pp. 1495-1504, Feb. 2011.

[256] J. W. Lee, S. G. Kim, J. M. Yang, Y. Yang, and N. G. Park, "Verification and mitigation of ion migration in perovskite solar cells," APL Mater., vol. 7, no. 4, p. 41111, Apr. 2019.

[257] T. Li, Y. Pan, Z. Wang, Y. Xia, Y. Chen, and W. Huang, “Additive engineering for highly efficient organic-inorganic halide perovskite solar cells: Recent advances and perspectives," Journal of Materials Chemistry A, vol. 5, no. 25. Royal Society of Chemistry, pp. 12602-12652, 27-Jun-2017. 
[258] Y. Yang, F. Gao, S. Gao, and S.-H. Wei, "Origin of the stability of twodimensional perovskites: a first-principles study," 2018.

[259] Q. Fu et al., "Recent Progress on the Long-Term Stability of Perovskite Solar Cells," Adv. Sci., vol. 5, no. 5, 2018.

[260] B. Conings, L. Baeten, C. De Dobbelaere, J. D'Haen, J. Manca, and H. G. Boyen, "Perovskite-based hybrid solar cells exceeding $10 \%$ efficiency with high reproducibility using a thin film sandwich approach," Adv. Mater., vol. 26, no. 13, pp. 2041-2046, Apr. 2014.

[261] G. E. Eperon, V. M. Burlakov, P. Docampo, A. Goriely, and H. J. Snaith, "Morphological Control for High Performance, Solution-Processed Planar Heterojunction Perovskite Solar Cells," Adv. Funct. Mater., vol. 24, no. 1, pp. 151-157, Jan. 2014.

[262] H. Xie $\square$ and M. Lira-Cantu $\square$, "PAPER - OPEN ACCESS Multi component engineering to enable long-term operational stability of perovskite solar cells Multi-component engineering to enable long-term operational stability of perovskite solar cells," J. Phys. Energy, vol. 2, p. 24008, 2020.

[263] Y. Reyna, M. Salado, S. Kazim, A. Pérez-Tomas, S. Ahmad, and M. Lira-Cantu, "Performance and stability of mixed FAPbI3(0.85)MAPbBr3(0.15) halide perovskite solar cells under outdoor conditions and the effect of low light irradiation," Nano Energy, vol. 30, pp. 570-579, Dec. 2016.

[264] I. Gonzalez-Valls, Y. Yu, B. Ballesteros, J. Oro, and M. Lira-Cantu, "Synthesis conditions, light intensity and temperature effect on the performance of $\mathrm{ZnO}$ nanorods-based dye sensitized solar cells," J. Power Sources, vol. 196, no. 15, pp. 6609-6621, Aug. 2011.

[265] M. V. Khenkin et al., "Reconsidering figures of merit for performance and stability of perovskite photovoltaics," Energy Environ. Sci., vol. 11, no. 4, pp. 739-743, Apr. 2018.

[266] G. Grancini et al., "One-Year stable perovskite solar cells by 2D/3D interface engineering," Nat. Commun., vol. 8, no. 1, pp. 1-8, Jun. 2017.

[267] H. Tsai et al., "High-efficiency two-dimensional ruddlesden-popper perovskite solar cells," Nature, vol. 536, no. 7616, pp. 312-317, Jul. 2016.

[268] S. S. Shin et al., "Colloidally prepared La-doped BaSnO3 electrodes for efficient, photostable perovskite solar cells," Science (80-. )., vol. 356, no. 6334, pp. 167171, Apr. 2017.

[269] W. Chen et al., "Efficient and stable large-area perovskite solar cells with inorganic charge extraction layers," Science (80-. )., vol. 350, no. 6263, pp. 944948, Nov. 2015.

[270] R. Shang et al., "Disodium Benzodipyrrole sulfonate as neutral hole-transporting materials for perovskite solar cells," J. Am. Chem. Soc., vol. 140, no. 15, pp. 5018-5022, Apr. 2018.

[271] Y. Hou et al., "A generic interface to reduce the efficiency-stability-cost gap of perovskite solar cells," Science (80-. )., vol. 358, no. 6367, pp. 1192-1197, Dec. 2017. 
[272] K. A. Bush et al., "23.6\%-efficient monolithic perovskite/silicon tandem solar cells with improved stability," Nat. Energy, vol. 2, no. 4, p. 17009, Apr. 2017.

[273] S. H. Turren-Cruz, A. Hagfeldt, and M. Saliba, "Methylammonium-free, highperformance, and stable perovskite solar cells on a planar architecture," Science (80-. )., vol. 362, no. 6413, pp. 449-453, Oct. 2018.

[274] N. Arora et al., "Perovskite solar cells with CuSCN hole extraction layers yield stabilized efficiencies greater than 20\%," Science (80-. )., vol. 358, no. 6364, pp. 768-771, Nov. 2017.

[275] J. A. Christians et al., "Tailored interfaces of unencapsulated perovskite solar cells for \&gt;1,000 hour operational stability," Nat. Energy, vol. 3, no. 1, pp. 6874, Jan. 2018.

[276] X. Li et al., "Outdoor Performance and Stability under Elevated Temperatures and Long-Term Light Soaking of Triple-Layer Mesoporous Perovskite Photovoltaics," Energy Technol., vol. 3, no. 6, pp. 551-555, Jun. 2015.

[277] Q. Luo et al., "All-Carbon-Electrode-Based Endurable Flexible Perovskite Solar Cells," Adv. Funct. Mater., vol. 28, no. 11, p. 1706777, Mar. 2018.

[278] P. Holzhey et al., "A chain is as strong as its weakest link - Stability study of MAPbI3 under light and temperature," Mater. Today, vol. 29, pp. 10-19, Oct. 2019.

[279] A. Mingorance et al., "Interfacial Engineering of Metal Oxides for Highly Stable Halide Perovskite Solar Cells," Advanced Materials Interfaces, vol. 5, no. 22. Wiley-VCH Verlag, 23-Nov-2018.

[280] M. Lira-Cantú, "Perovskite solar cells: Stability lies at interfaces," Nature Energy, vol. 2, no. 7. Nature Publishing Group, p. 17115, 11-Jul-2017.

[281] A. Pérez-Tomas et al., "PbZrTiO 3 ferroelectric oxide as an electron extraction material for stable halide perovskite solar cells," Sustain. Energy Fuels, vol. 3, no. 2, pp. 382-389, Jan. 2019.

[282] B. Li, V. Ferguson, S. R. P. Silva, and W. Zhang, "Defect Engineering toward Highly Efficient and Stable Perovskite Solar Cells," Adv. Mater. Interfaces, vol. 5, no. 22, p. 1800326, Nov. 2018.

[283] D. Shi et al., "Low trap-state density and long carrier diffusion in organolead trihalide perovskite single crystals," Science (80-. )., vol. 347, no. 6221, pp. 519522, Jan. 2015.

[284] Y. Wu et al., "Thermally Stable MAPbI3 Perovskite Solar Cells with Efficiency of $19.19 \%$ and Area over $1 \mathrm{~cm} 2$ achieved by Additive Engineering," Adv. Mater., vol. 29 , no. $28,2017$.

[285] N. Li, X. Niu, Q. Chen, and H. Zhou, "Towards commercialization: The operational stability of perovskite solar cells," Chemical Society Reviews, vol. 49, no. 22. Royal Society of Chemistry, pp. 8235-8286, 21-Nov-2020.

[286] B. Chen, P. N. Rudd, S. Yang, Y. Yuan, and J. Huang, "Imperfections and their passivation in halide perovskite solar cells," Chemical Society Reviews, vol. 48, no. 14. Royal Society of Chemistry, pp. 3842-3867, 21-Jul-2019. 
[287] S. Tan et al., "Shallow Iodine Defects Accelerate the Degradation of $\alpha$-Phase Formamidinium Perovskite," Joule, vol. 4, no. 11, pp. 2426-2442, Nov. 2020.

[288] A. H. and M. L.-C. Haibing Xie, Zaiwei Wang, Zehua Chen, Mike Pols, Krzysztof Gałkowski, Miguel Anaya, Shuai Fu, Xiaoyu Jia, Pengyi Tang, Dominik Kubicki, Anand Agarwalla, Hui-Seon Kim, Daniel Prochowicz, Xavier Borrise, Carlos Pereyra, Mischa Bonn, Shaik Mohammed Zakeerudd, "No Title," vol. Submitted, 2020.

[289] S. Xu et al., "Boosting Photovoltaic Performance and Stability of SuperHalogenSubstituted Perovskite Solar Cells by Simultaneous Methylammonium Immobilization and Vacancy Compensation," ACS Appl. Mater. Interfaces, vol. 12, no. 7, pp. 8249-8259, Feb. 2020.

[290] X. Liu et al., "Shallow defects levels and extract detrapped charges to stabilize highly efficient and hysteresis-free perovskite photovoltaic devices," Nano Energy, vol. 71, p. 104556, May 2020.

[291] S. Bai et al., "Planar perovskite solar cells with long-term stability using ionic liquid additives," Nature, vol. 571, no. 7764, pp. 245-250, Jul. 2019.

[292] M. Elawad, H. Lee, Z. Yu, and L. Sun, "Ionic liquid doped organic hole transporting material for efficient and stable perovskite solar cells," Phys. B Condens. Matter, vol. 586, p. 412124, Jun. 2020.

[293] N. K. Noel et al., "Elucidating the Role of a Tetrafluoroborate_Based Ionic Liquid at the n_Type Oxide/Perovskite Interface," Adv. Energy Mater., vol. 10, no. 4, p. 1903231, Jan. 2020.

[294] G. Niu, X. Guo, and L. Wang, "Review of recent progress in chemical stability of perovskite solar cells," J. Mater. Chem. A, vol. 3, no. 17, pp. 8970-8980, 2015.

[295] T. Leijtens, G. E. Eperon, S. Pathak, A. Abate, M. M. Lee, and H. J. Snaith, "Overcoming ultraviolet light instability of sensitized $\mathrm{TiO} 2$ with mesosuperstructured organometal tri-halide perovskite solar cells," Nat. Commun., vol. 4, pp. 1-8, 2013.

\section{Eye-catching graphic abstract}

Additive engineering for the passivation of defects to enhance efficiency (deep defects) and stability (shallow defects) in perovskite solar cells. 


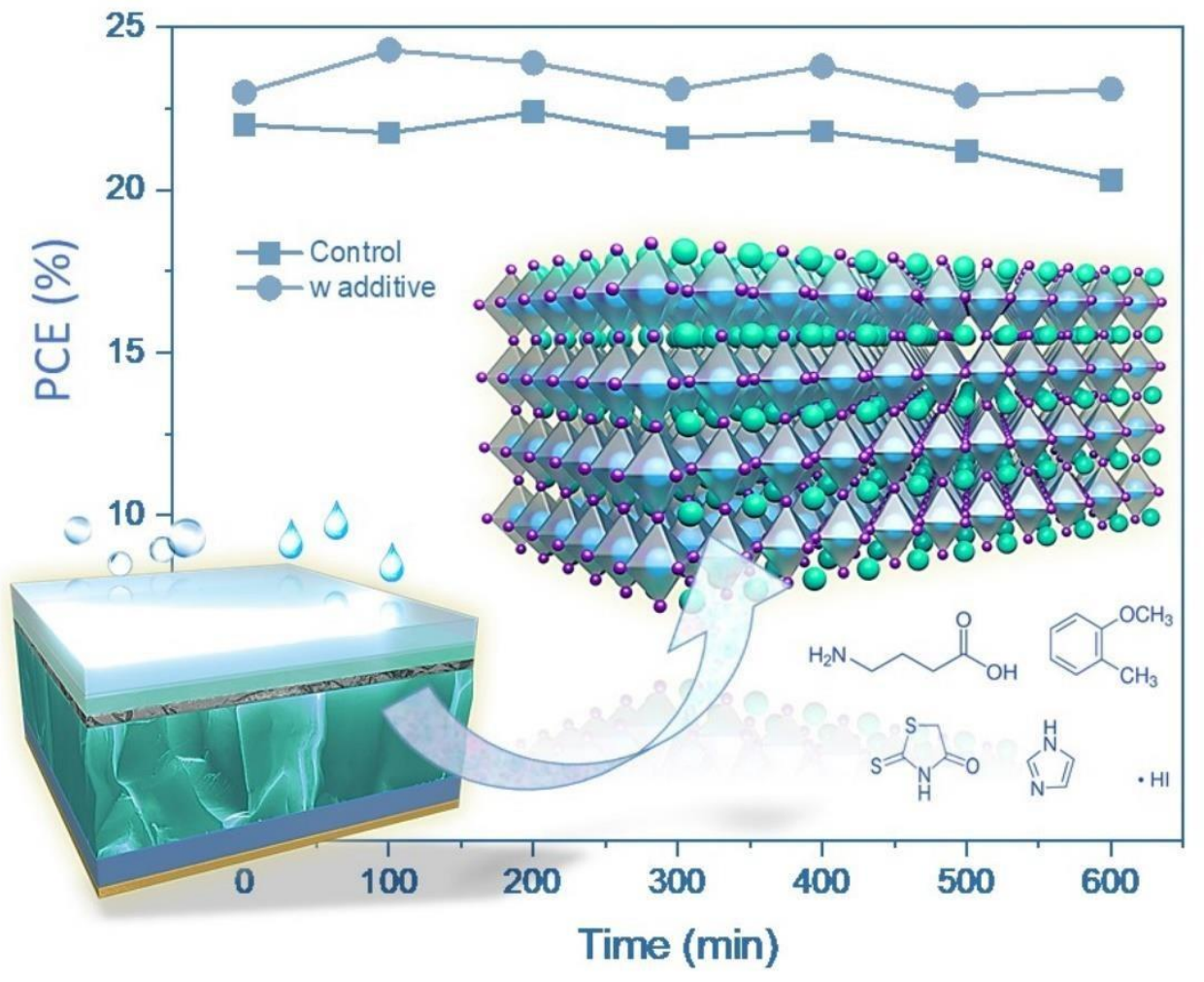


